\title{
Fabrication Report for the AFC-2A and AFC-2B Capsule Irradiations in the ATR
}

\author{
Timothy A. Hyde
}

October 2007

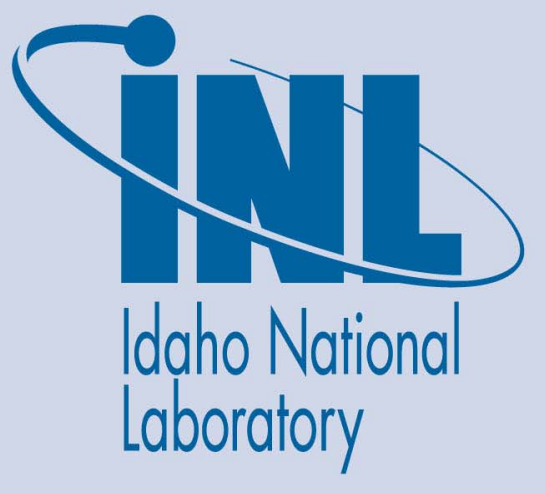

The INL is a U.S. Department of Energy National Laboratory operated by Battelle Energy Alliance 
INL/EXT-07-13021

\title{
Fabrication Report for the AFC-2A and AFC-2B Capsule Irradiations in the ATR
}

\author{
Timothy A. Hyde
}

October 2007

\begin{abstract}
Idaho National Laboratory
Idaho Falls, Idaho 83415
\end{abstract}

Prepared for the

U.S. Department of Energy

Office of Nuclear Energy

Under DOE Idaho Operations Office

Contract DE-AC07-05ID14517 


\section{DISCLAIMER}

This information was prepared as an account of work sponsored by an agency of the U.S. Government. Neither the U.S. Government nor any agency thereof, nor any of their employees, makes any warranty, expressed or implied, or assumes any legal liability or responsibility for the accuracy, completeness, or usefulness, of any information, apparatus, product, or process disclosed, or represents that its use would not infringe privately owned rights. References herein to any specific commercial product, process, or service by trade name, trade mark, manufacturer, or otherwise, does not necessarily constitute or imply its endorsement, recommendation, or favoring by the U.S. Government or any agency thereof. The views and opinions of authors expressed herein do not necessarily state or reflect those of the U.S. Government or any agency thereof. 



\section{Fabrication Report for the AFC-2A and AFC-2B Capsule Irradiations in the ATR}

INL/EXT-07-13021

October 2007

\section{Approved by:}

Timothy A. Hyde

Date

Principle Investigator

Steven Hayes

GNEP Fuels Irradiation Experiments Technical Lead 


\section{ABSTRACT, SUMMARY, FOREWORD, AND ACKNOWLEDGEMENTS}

This document provides a general narrative description of the AFC-2A and 2B fuel fabrication processes for the AFC-2A and AFC-2B fuel irradiation experiments fabricated at the Idaho National Laboratory's Materials and Fuels Complex for irradiation in the Advanced Test Reactor. 


\section{CONTENTS}

ABSTRACT, SUMMARY, FOREWORD, AND ACKNOWLEDGEMENTS ....................................... iv

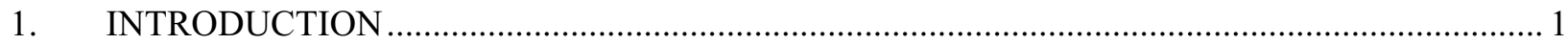

$1.1 \quad$ AFC-2A and AFC-2B Experiment Overview ........................................................... 1

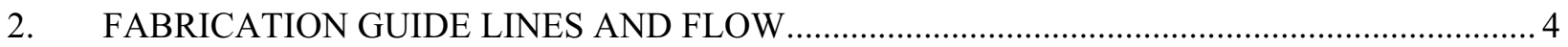

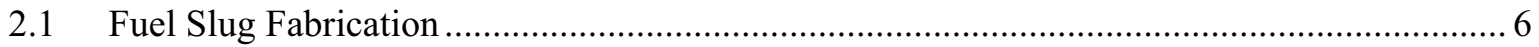

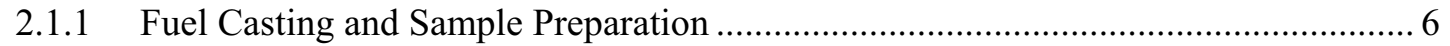

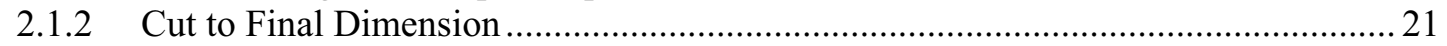

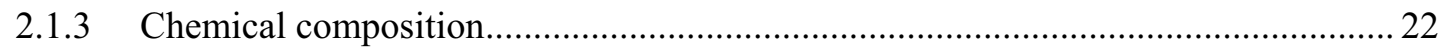

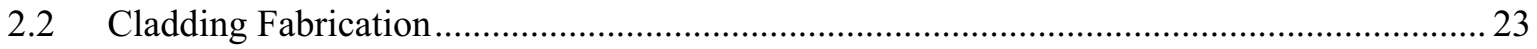

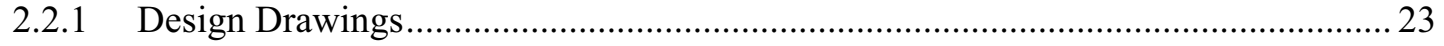

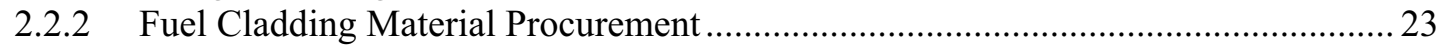

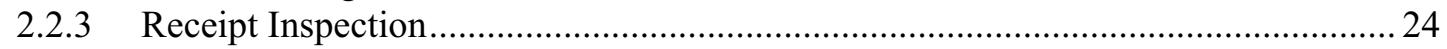

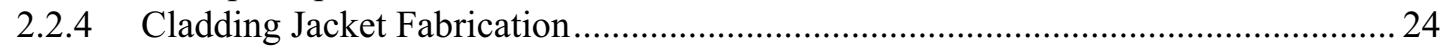

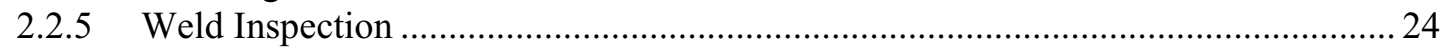

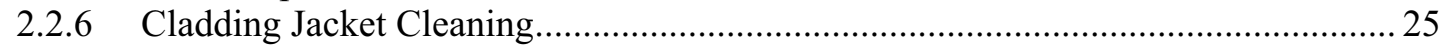

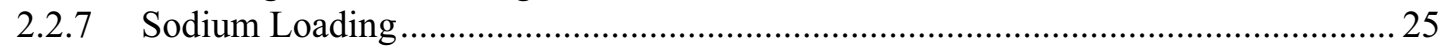

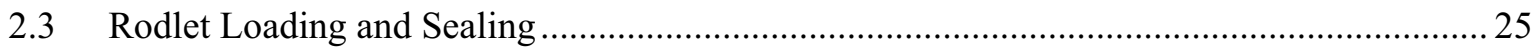

2.3.1 Rodlet Weld inspection and Leak Certification ..................................................... 25

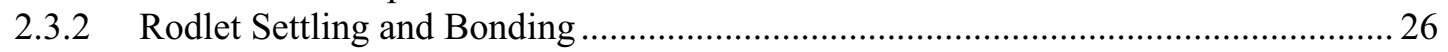

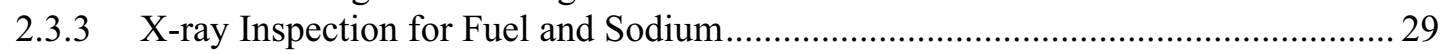

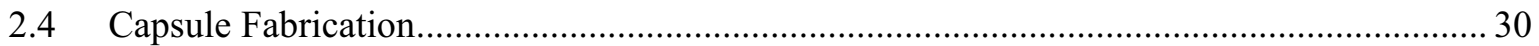

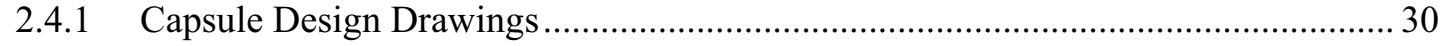

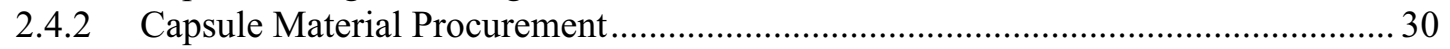

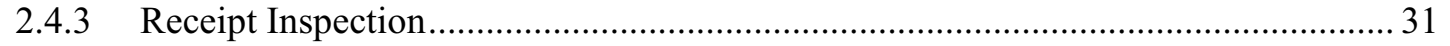

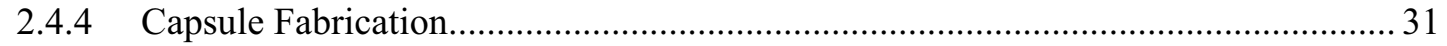

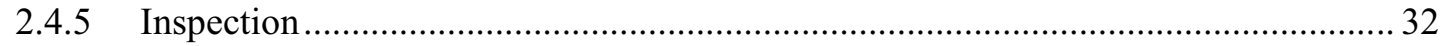

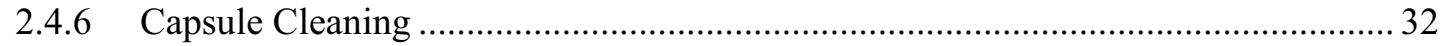

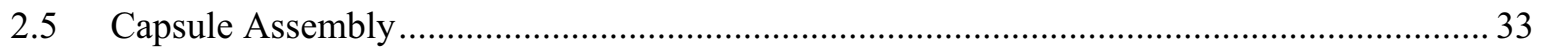

2.5.1 Rodlet Loading into the Capsule and End Plug Welding...................................... 33

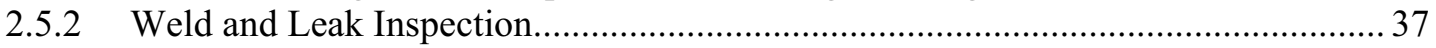

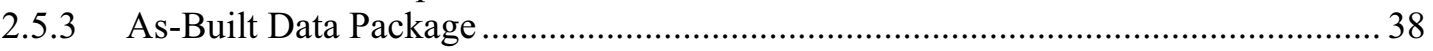

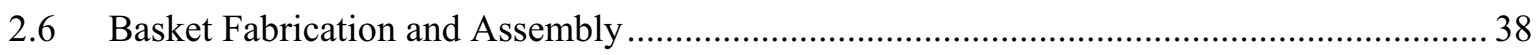

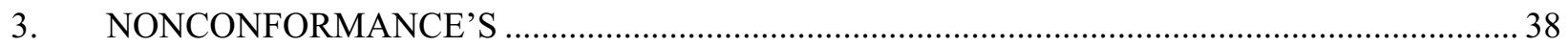

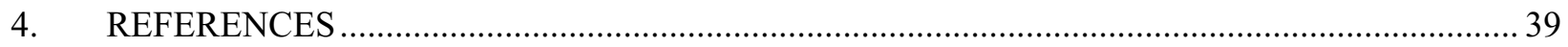

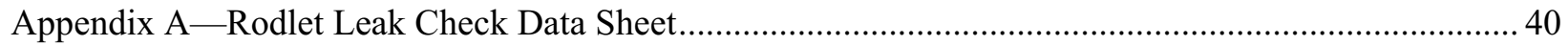

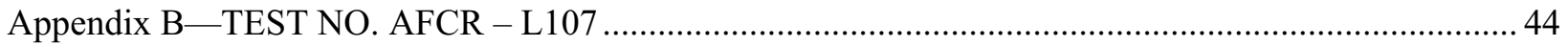

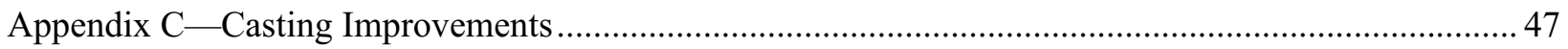




\section{FIGURES}

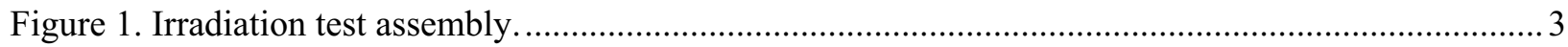

Figure 2. AFC-2A and 2B fuel, rodlet, and capsule fabrication. ............................................................ 5

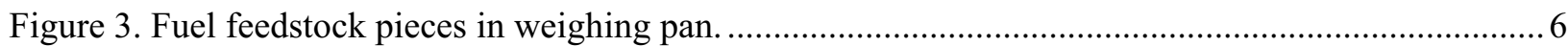

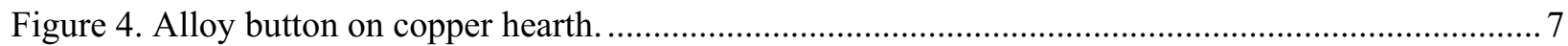

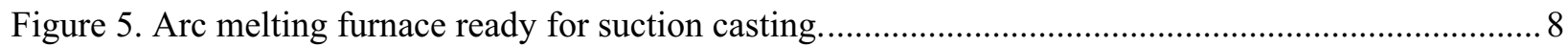

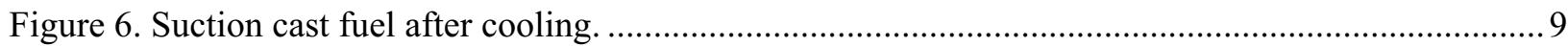

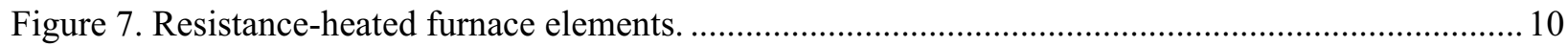

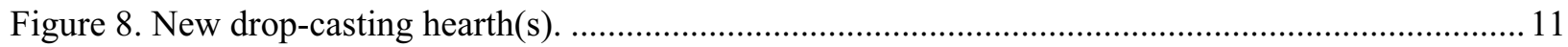

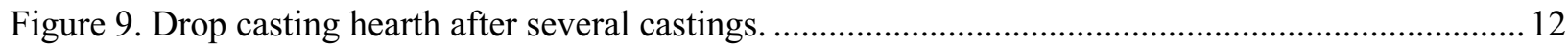

Figure 10. Inverted hearth(s) showing fuel inside quartz mold. ......................................................... 13

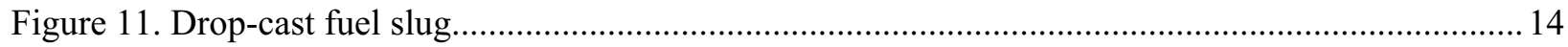

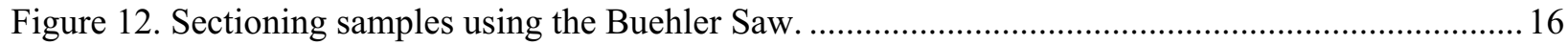

Figure 13. AFC2-A1 fuel slugs and characterization samples............................................................ 17

Figure 14. AFC2-A2 fuel slugs and characterization samples............................................................... 18

Figure 15. AFC2-A3 fuel slugs and characterization samples............................................................. 18

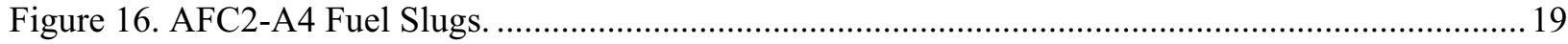

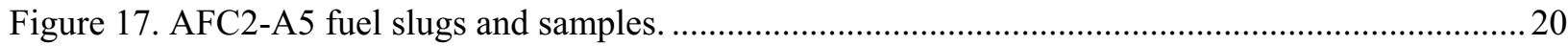

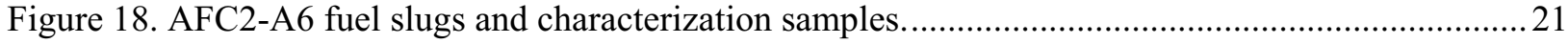

Figure 19. Chemical composition of cast fuel compared to target compositions. ..................................2 23

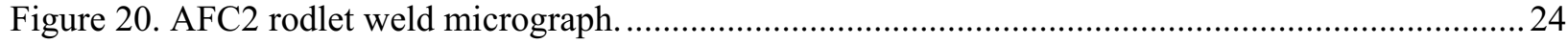

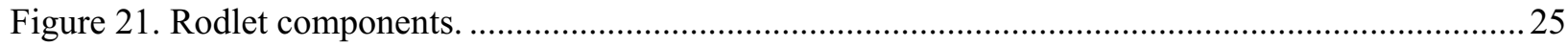

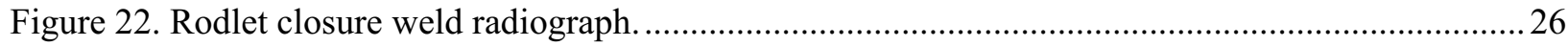

Figure 23. Loading rodlets into the settling and bonding furnace for heating.......................................2

Figure 24. Settling and bonding furnace with four rodlets in place .......................................................28

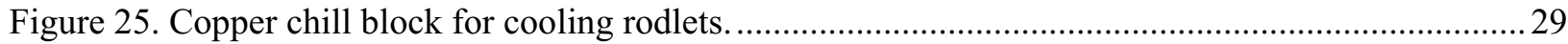

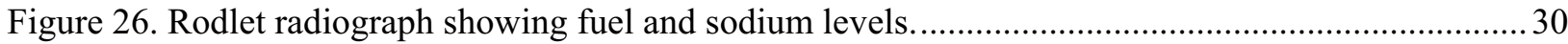

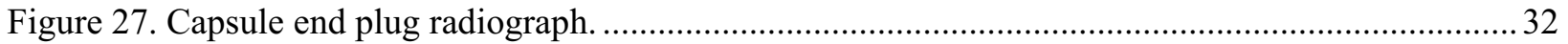

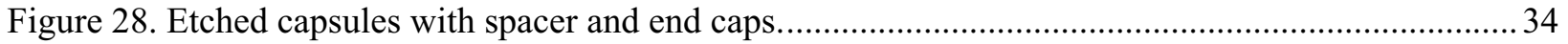

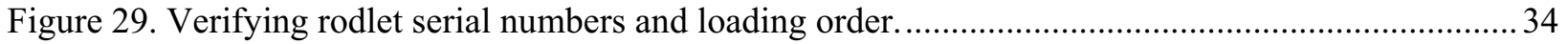

Figure 30. Rodlets and spacers laid out for loading into capsule. (The rod to the far left is a push

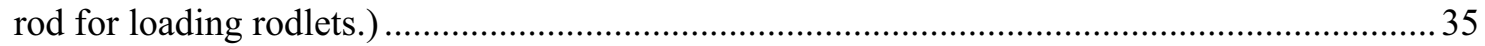

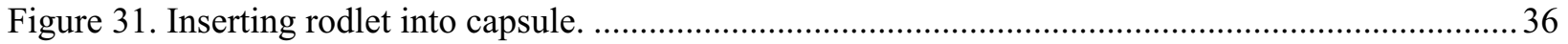

Figure 32. Orbital welding system for capsule closure inside a He glove bag with a test tube shown in place. 
Figure 33. Inserting a loaded capsule into the orbital welding enclosure.

Figure 34. Capsule radiograph verifying rodlet position. ..................................................................... 38

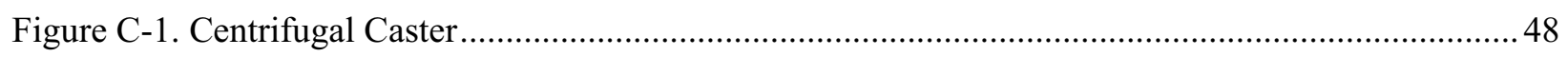

Figure C-2. Single Large Diameter Casting in Quartz Mold............................................................... 49

Figure C-3. Multiple AFC2 Representative Diameter Casting of Titanium......................................... 49

Figure C-4. Stand-Alone Vacuum Casting System......................................................................... 50

Figure C-5. Section view of the two-chamber casting concept. .......................................................... 51

\section{TABLES}

Table 1. Nominal fuel rodlet compositions and letter codes.............................................................. 1

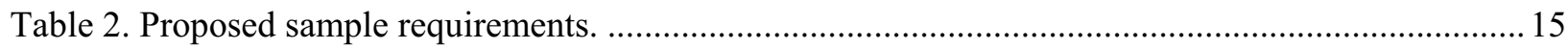

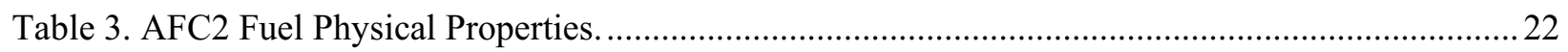

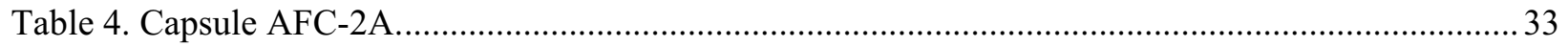

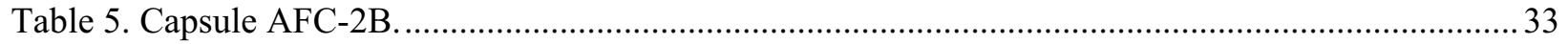




\section{Fabrication Report for the AFC-2A and AFC-2B Capsule Irradiations in the ATR}

\section{INTRODUCTION}

\subsection{AFC-2A and AFC-2B Experiment Overview}

The proposed Advanced Fuel Cycle (AFC)-2A and AFC-2B irradiation experiments are a continuation of the metallic fuel test series in progress in the Advanced Test Reactor (ATR) at the Idaho National Laboratory (INL). These experiments will consist of metallic fuel alloys of uranium $(\mathrm{U})$, plutonium $(\mathrm{Pu})$, neptunium $(\mathrm{Np})$, americium $(\mathrm{Am})$ and zirconium $(\mathrm{Zr})$, some with minor additions of rare earth elements, which are meant to simulate expected fission product carryFigure 2.over from pyro-metallurgical reprocessing. The alloys will be irradiated in the ATR to burnup levels of $\geq 10$ and $\geq 25$ atom $\%$ burnup. The AFC-2A and B experiments will be irradiated in two of the East Flux Trap positions of the ATR using the same hardware design as for the AFC-1B, D and H tests $(1,2$, and 3$)$.

The AFC-2A and B irradiation experiments are expected to provide important irradiation performance data on metallic transmutation fuel forms, including irradiation growth and swelling, helium production, helium and fission gas release fractions, fission product and fuel constituent migration, fuel phase equilibria, and fuel-cladding chemical interaction. Of particular interest in these tests will be the effect that small additions of rare earth elements, expected to be carried over as a result of pyro-metallurgical reprocessing, might have on irradiation performance.

Experiments AFC-2A and B will have design and test conditions analogous to the AFC-1F and $\mathrm{H}$ metallic fuel tests. AFC-2A and B will have the addition of rare earths to some of the fuel compositions. The fuel test matrix in AFC-2A and B will be identical; only the target discharge burnups will differ for the two tests. Table 1 shows the target compositions for the fuel. Fuel chemical and isotopic compositions vary over a wide range in this experiment. The factors that limit chemical and isotopic composition are the in-reactor fission heat generation rate, the fuel solidus temperature, and the gas production by Am-241. As such, the U-235 enrichments have been determined for each alloy.

Table 1. Nominal fuel rodlet compositions and letter codes.

\begin{tabular}{|l|l|l|}
\hline Designator & Metallic Fuel Alloy $\dagger$ & $\begin{array}{l}\text { Uranium-235 } \\
\text { Enrichments }\end{array}$ \\
\hline AFC2-A1 & 60U-20Pu-3Am-2Np-15Zr & $93 \%$ U-235 \\
\hline AFC2-A2 & 59U-20Pu-3Am-2Np-1.0RE*-15Zr & $55 \%$ U-235 \\
\hline AFC2-A3 & $58.5 \mathrm{U}-20 \mathrm{Pu}-3 \mathrm{Am}-2 \mathrm{~Np}-1.5 \mathrm{RE}^{*}-15 \mathrm{Zr}$ & $45 \% \mathrm{U}-235$ \\
\hline AFC2-A4 & $40.5 \mathrm{U}-30 \mathrm{Pu}-5 \mathrm{Am}-3 \mathrm{~Np}-1.5 \mathrm{RE}^{*}-20 \mathrm{Zr}$ & $55 \% \mathrm{U}-235$ \\
\hline AFC2-A5 & $41 \mathrm{U}-30 \mathrm{Pu}-5 \mathrm{Am}-3 \mathrm{~Np}-1.0 \mathrm{RE}^{*}-20 \mathrm{Zr}$ & $65 \% \mathrm{U}-235$ \\
\hline AFC2-A6 & $42 \mathrm{U}-30 \mathrm{Pu}-5 \mathrm{Am}-3 \mathrm{~Np}-20 \mathrm{Zr}$ & $93 \% \mathrm{U}-235$ \\
\hline
\end{tabular}

$\dagger$ Alloy composition expressed in weight percent.

$* \mathrm{RE}=$ rare earth alloy $(6 \% \mathrm{La}, 16 \% \mathrm{Pr}, 25 \% \mathrm{Ce}, 53 \% \mathrm{Nd})$.

The primary component for each experiment, which contains the fuel specimen, is termed a "rodlet." Rodlets are simply miniature fuel rods six inches in length. Externally, each of the rodlets in both 
experiments will be identical. The "Irradiation of Metallic Fuels with Rare Earth Additions for Actinide Transmutation in the ATR; Experiment Description for AFC-2A and AFC-2B"

(INL/EXT-06-11707, Rev. 2) provides further details on experiment configuration and performance. Technical and functional requirements for this experiment are defined in the "Specification for the AFC-2A and AFC-2B Fuel Specimen and Fuel Capsule Irradiation Experiment in the ATR" (Technical and Functional Requirements [TFR]-452). This document provides details on fuel isotopic limits and details of the metallic fuel rodlet construction. The full experiment is also described in "Advanced Fuel Cycle Initiative, AFC-2A and AFC-2B Experiments" (INL/EXT-07-12388).

Figure 1 shows the graphic description of the complete test assembly. The terminology used in this example will be followed in this and all AFC-2 description documents. 


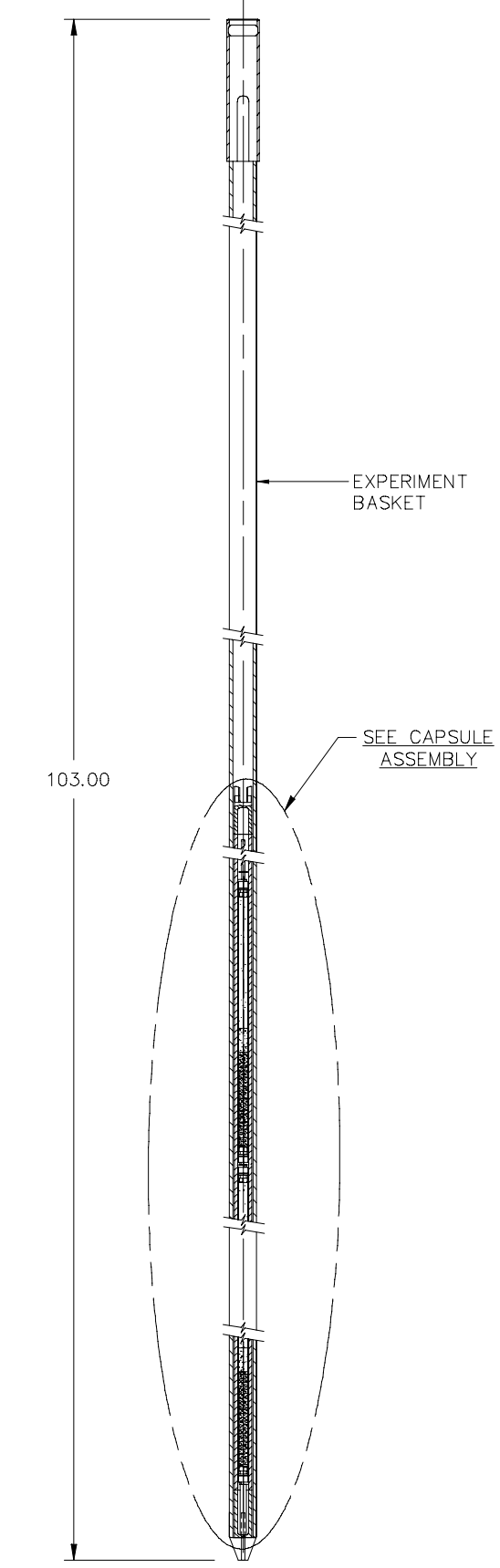

IRRADIATION TEST ASSEMBLY

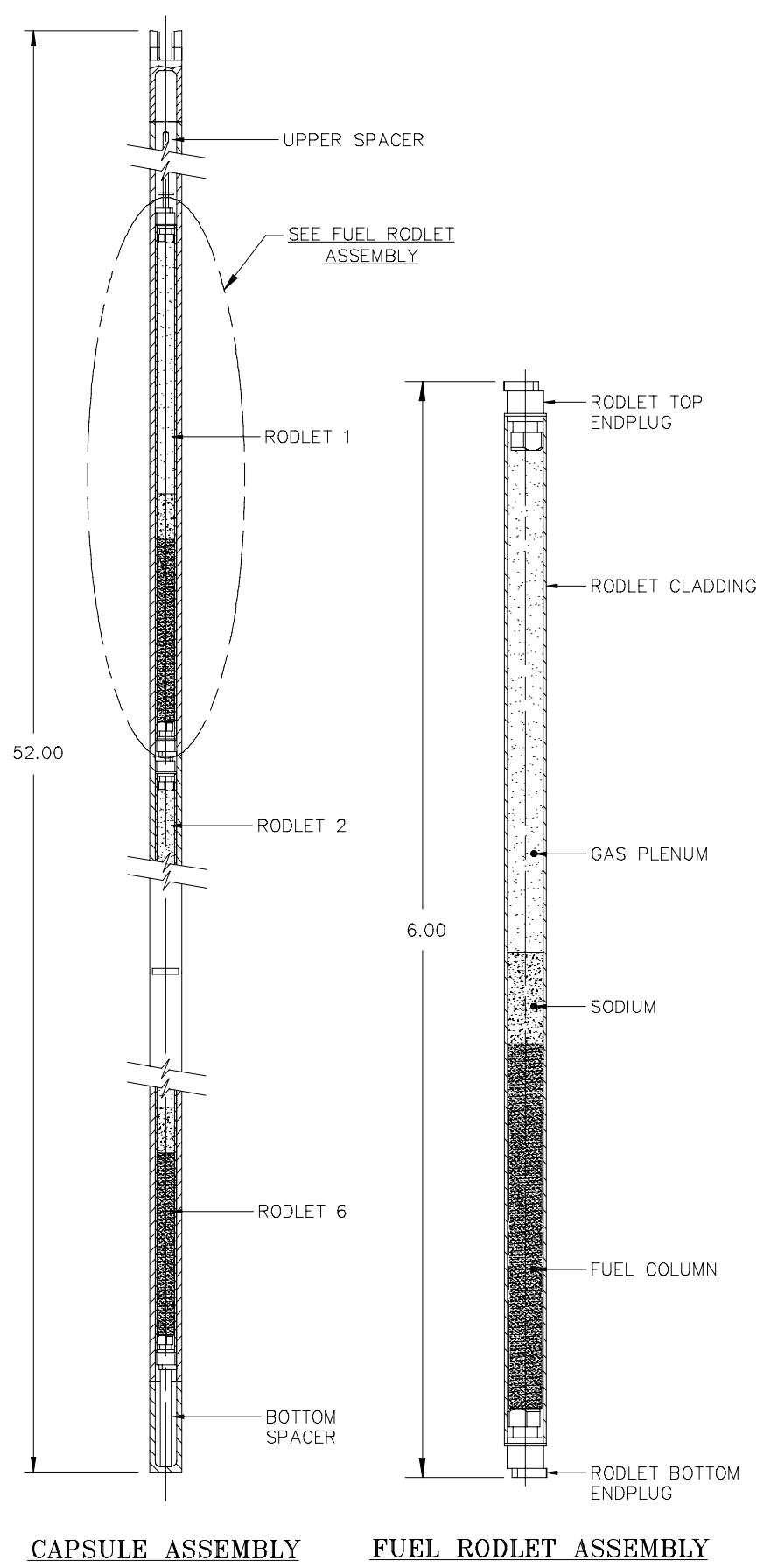

CAPSULE ASSEMBLY FUEL RODLET ASSEMBLY

Figure 1. Irradiation test assembly. 


\section{FABRICATION GUIDE LINES AND FLOW}

The fabrication flow diagram for the AFC-2A and 2B experiments is shown in Figure 2. This figure was used to guide fabrication and will be used in this report to guide the description of activities. 
AFC-2A and 2B Fuel, Rodlet and Capsule Fabrication Flow Diagram iman

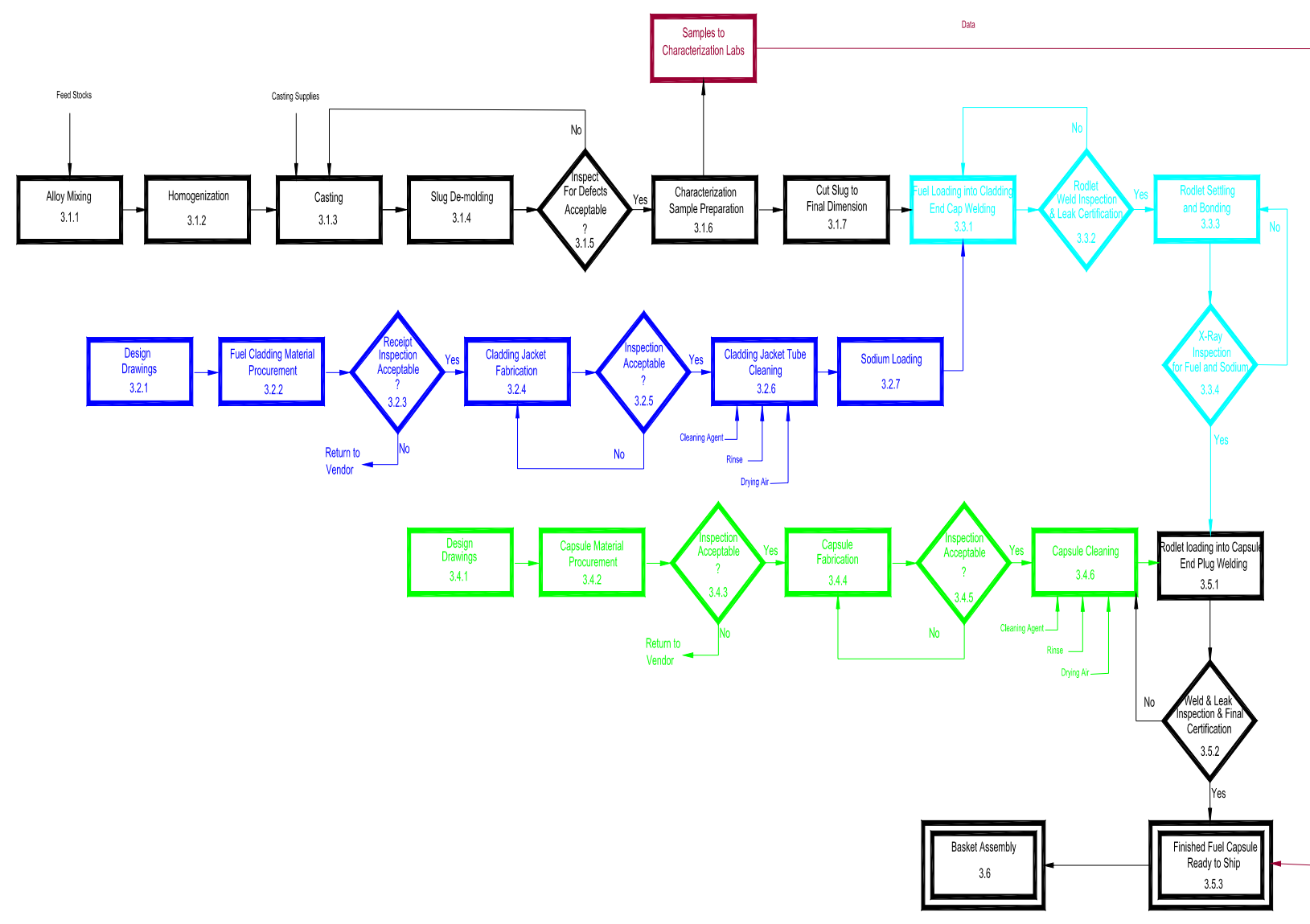

Figure 2. AFC-2A and 2B fuel, rodlet, and capsule fabrication. 


\subsection{Fuel Slug Fabrication}

This section will describe the fabrication of the metal fuel slugs that will be tested.

\subsubsection{Fuel Casting and Sample Preparation}

The process of taking raw feedstock and turning it into experimental fuel involves alloy mixing, homogenizing, and casting. This section also describes the actual fuel that was cast and samples that were cut from the original casting.

\subsubsection{Alloy Mixing}

Alloy mixing will consist of mixing the raw materials as required to make the appropriate alloy specified in the Fuel Specification and is simply the process of weighing each needed constituent (see Figure 3) and getting it ready to melt together into a new alloy. Mixing control and direction is established by using a Casting Lab (CL) metal fuel fabrication process work sheet and program personnel's technical knowledge or by using procedure FMF-OI-607 and its corresponding metal process worksheet.

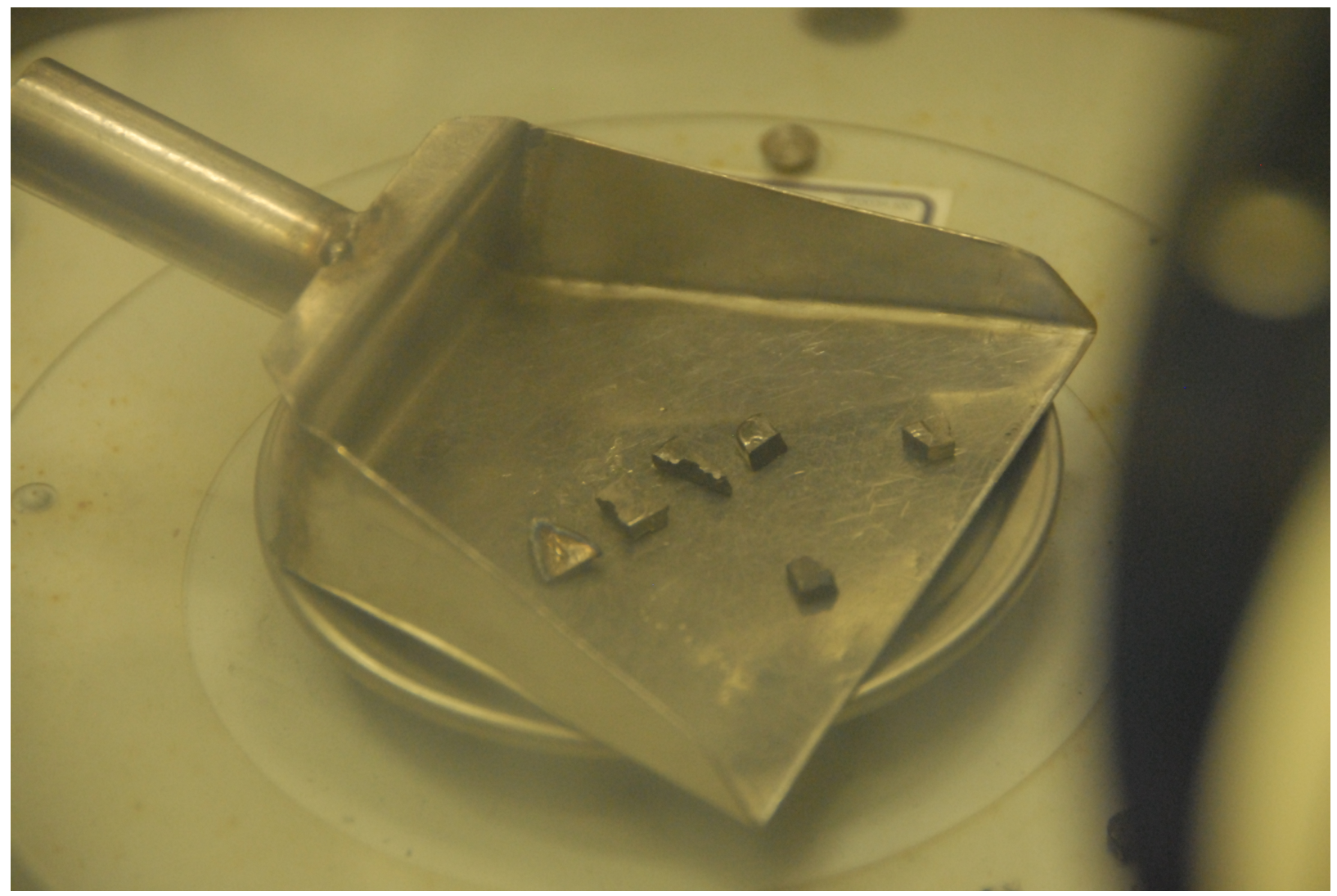

Figure 3. Fuel feedstock pieces in weighing pan.

\subsubsection{Homogenization}

Homogenization is the process of melting the alloy components together using an arc melting furnace. Each alloy was homogenized three times before being ready to cast. Figure 4 shows a homogenized button. 


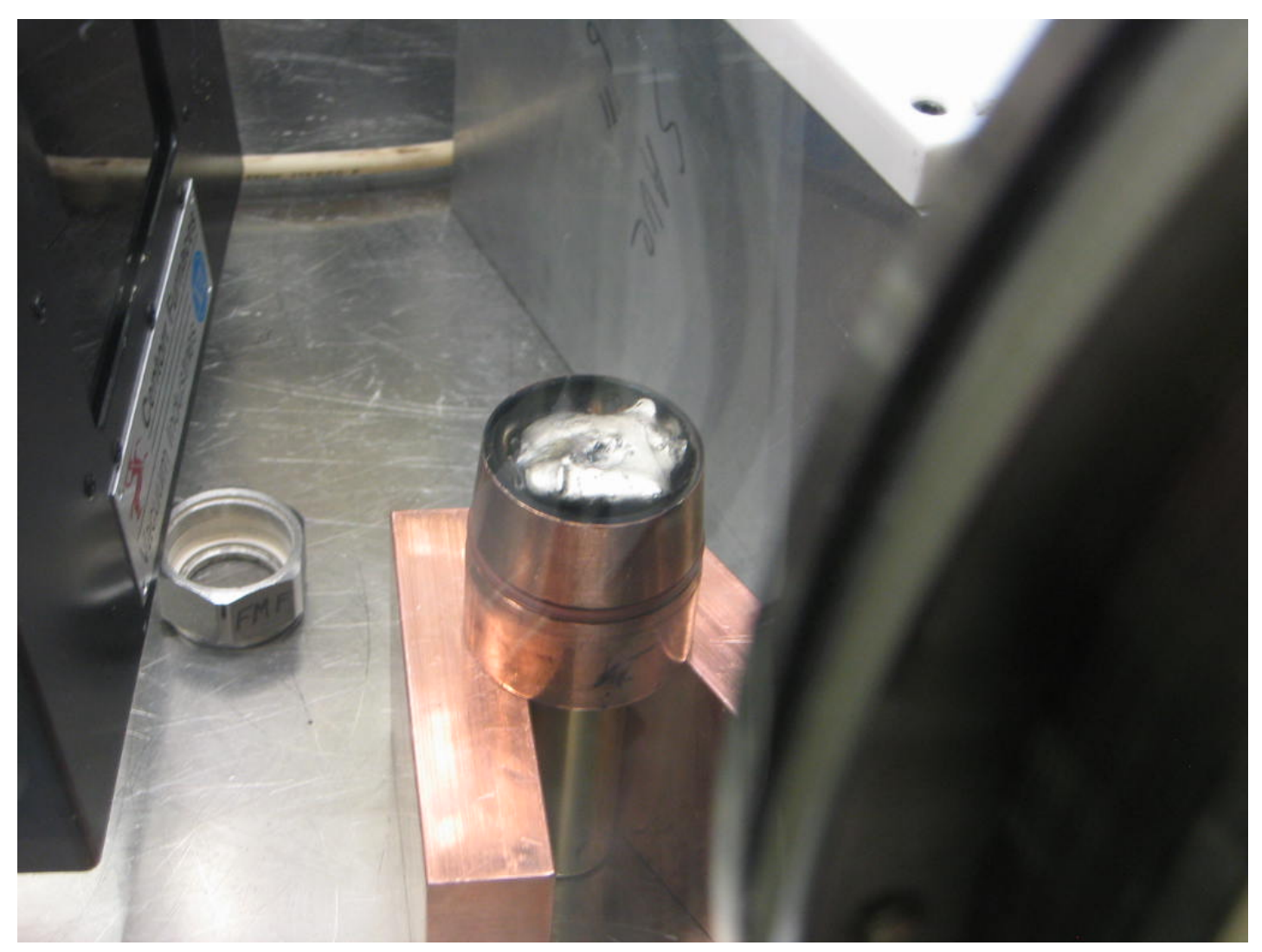

Figure 4. Alloy button on copper hearth.

\subsubsection{Casting}

Three of the six alloys needed for the complete experiment were cast in the CL using a suction casting technique developed for use in the CL. This technique utilizes the arc melting furnace to melt the alloy, followed by placement of the open end of a quart tube into the molten alloy. When the tube (mold) is in the molten alloy, a second operator draws a vacuum on the other end of the tube and the alloy is drawn (cast) inside the quartz tube, where it then solidifies into a solid slug. Figures 5 and 6 show the suction casting process. Casting was done using a 0.175 in. I.D. quartz tube that yields a fuel slug of 0.168 " diameter. The quartz tube used for this casting consists of old EBR-II casting tubes. Zirconium Oxide $\left(\mathrm{ZrO}_{2}\right)$ "mold wash" can be used to coat the molds if needed. The "mold wash" acts as a mold release and prevents the slug from sticking to the quartz. This was done at the discretion of the operator/technician doing the casting. 


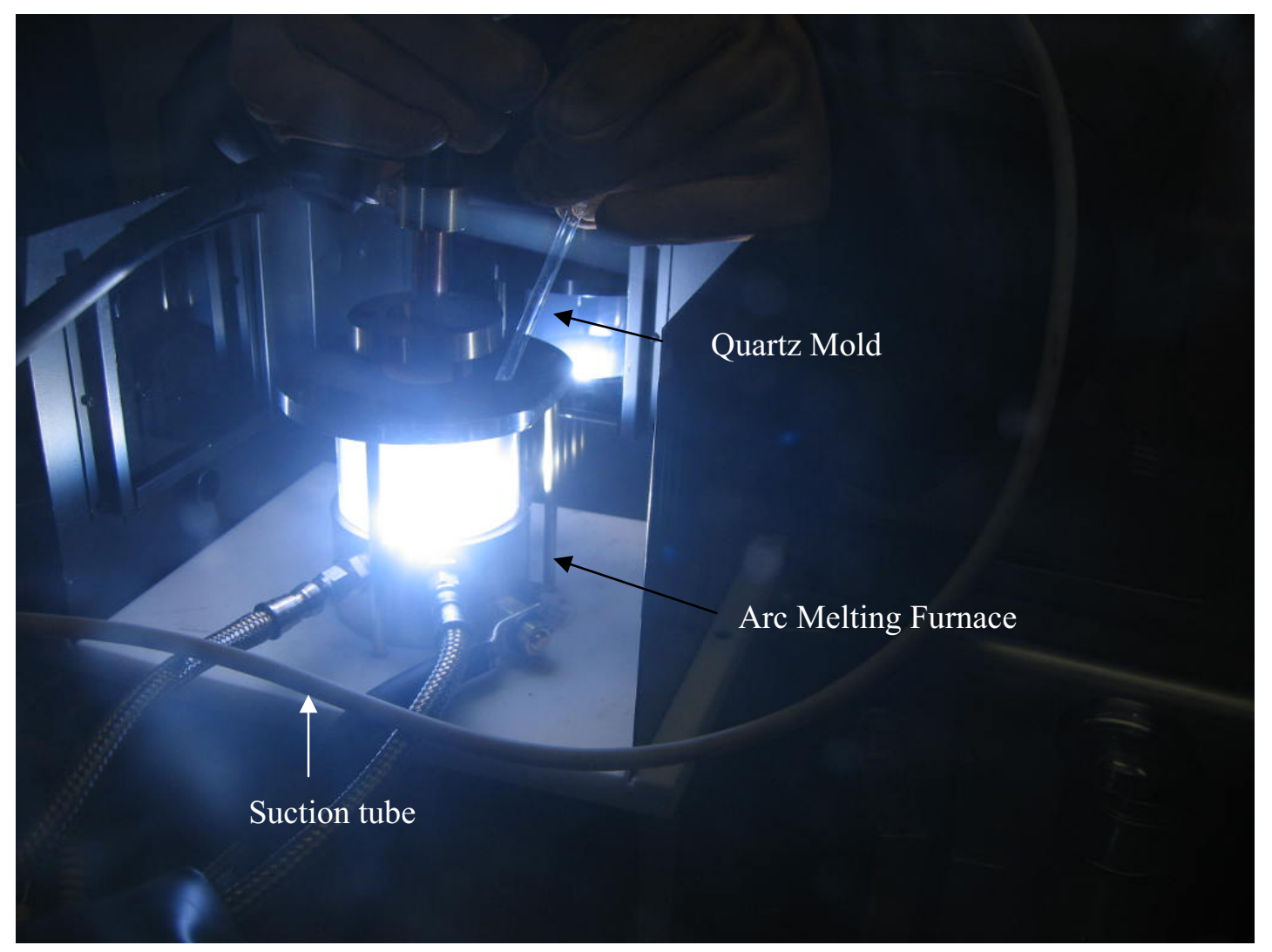

Figure 5. Arc melting furnace ready for suction casting. 


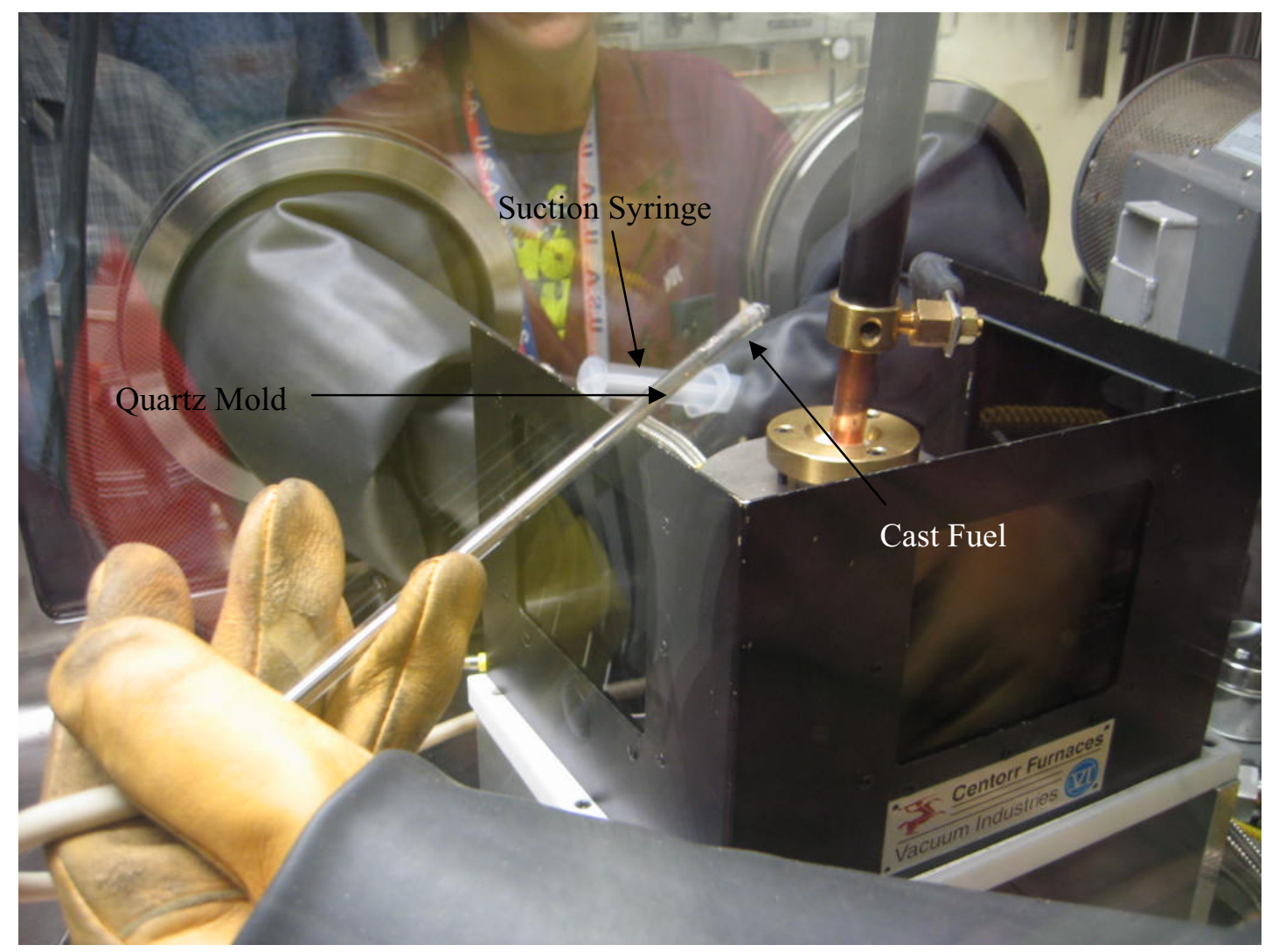

Figure 6. Suction cast fuel after cooling.

Other casting techniques can be used at the discretion of the Fabrication Work Package Manager and were investigated because of suction casting limitations.

\subsubsection{Research Casting Development}

The suction casting technique has been used on many experimental fuel fabrication campaigns, but it is very inconsistent and is very dependent on the experience of the technician doing the casting. As a result, it is difficult to repeat castings and each remelt negatively affects the flow characteristics of the melt. As a result, a new casting technique was developed by Gavin Knighton in FASB. This investigation was constrained to use the arc melting furnace power supply and, if possible, to use the existing safety envelope developed for the arc melting furnace.

The first radiologically cold engineering evaluations were performed using a resistance-heating technique (see Figure 7) and coated carbon crucibles. This technique has potential, but carbon contamination seems to dramatically affect alloy behavior, especially after repeated melts. As a result, the resistance-heating technique was not completely developed for glove box implementation. 


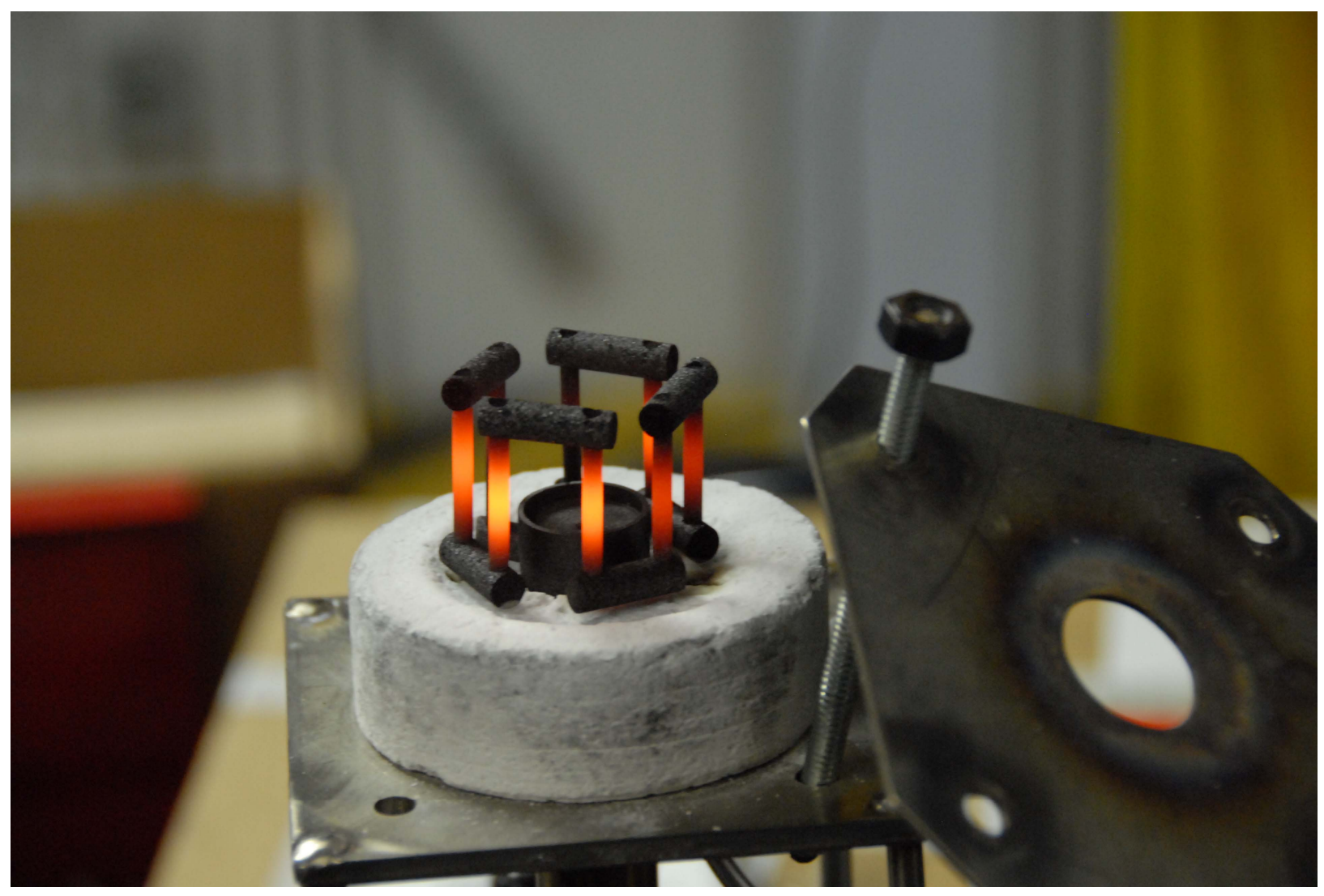

Figure 7. Resistance-heated furnace elements.

A new drop-casting technique, which is actually a refinement of a previously used gravity casting process, was also worked on. This process uses the arc melting furnace, but, instead of relying on suction to draw up molten material, it uses a small copper hearth for electrical conduction with a hole in the middle and a ceramic hearth for thermal insulation. This setup allows enough heat to remain in the melt until the material becomes completely molten (and with some super heat) and flows into the quartz mold that is located in the hole in the center of the copper hearth. A new drop-casting hearth is shown in Figure 8. 


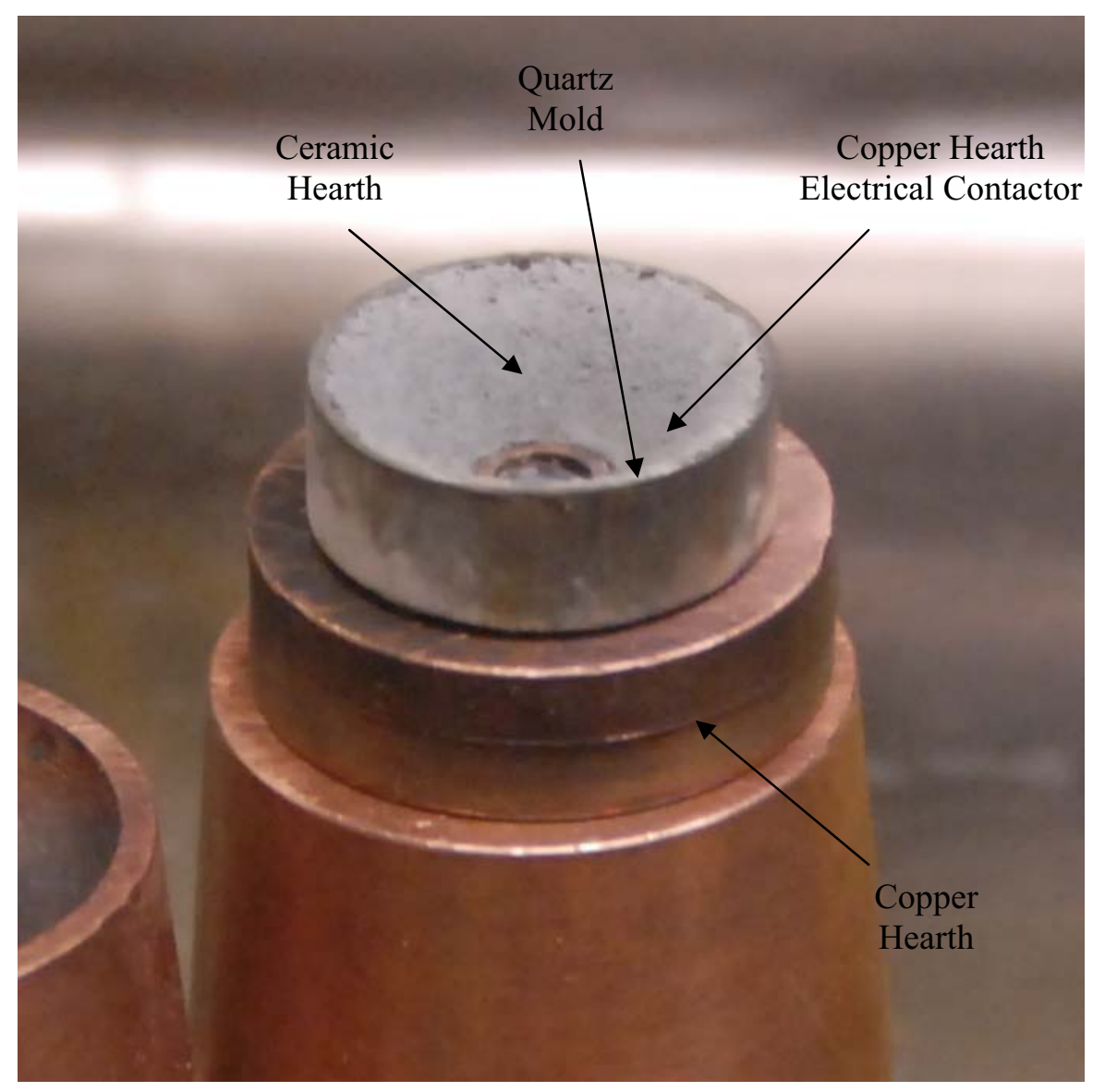

Figure 8. New drop-casting hearth(s).

Repeated castings with this technique and the same ceramic hearth, produces a copper-looking coating on the hearth (see Figure 9). At this time, we have not received chemical analysis back that will indicate if there is any difference in the copper contamination levels in fuel produced from suction casting or drop casting. Figure 10 shows a cast fuel slug inside the quartz mold. 


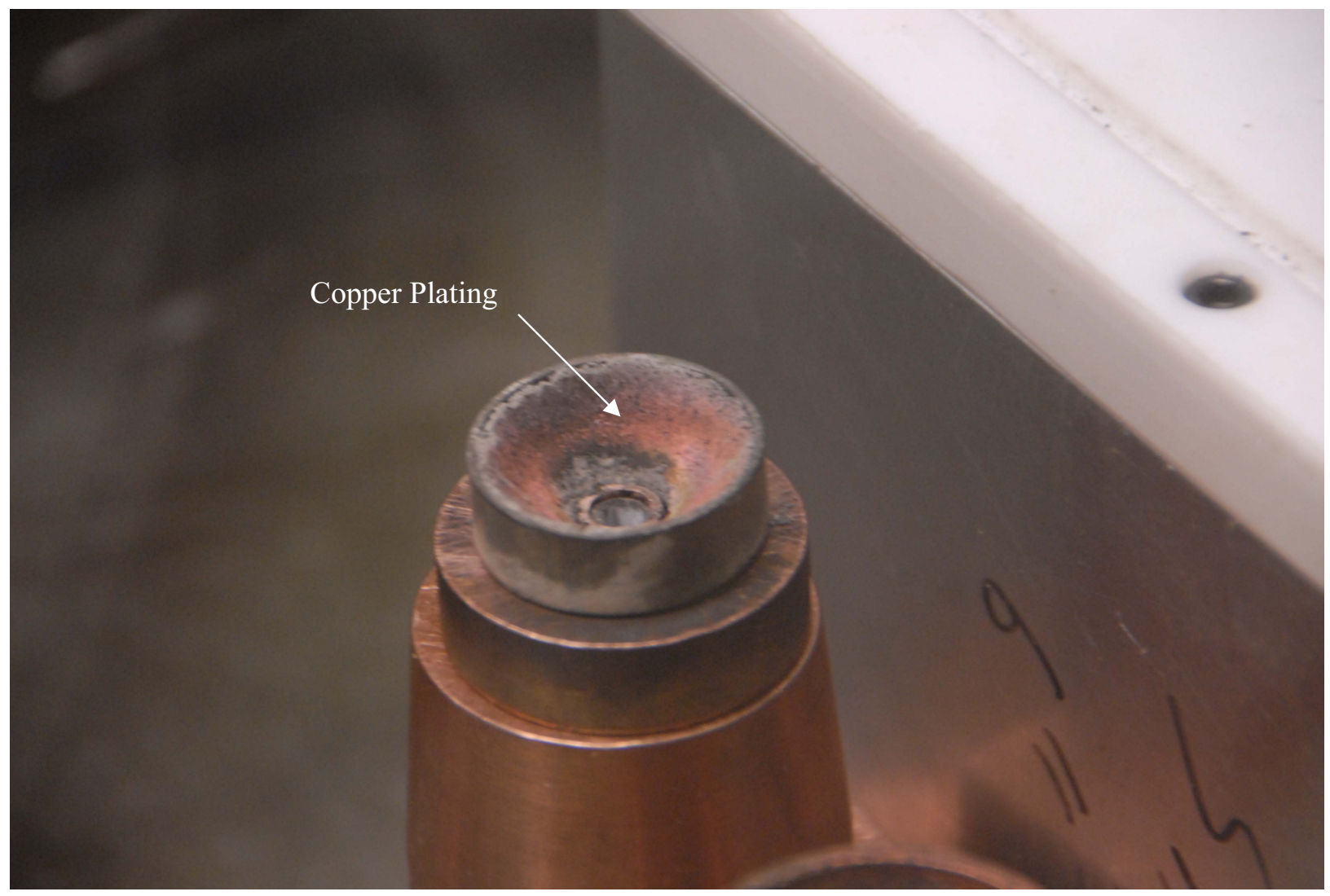

Figure 9. Drop casting hearth after several castings. 


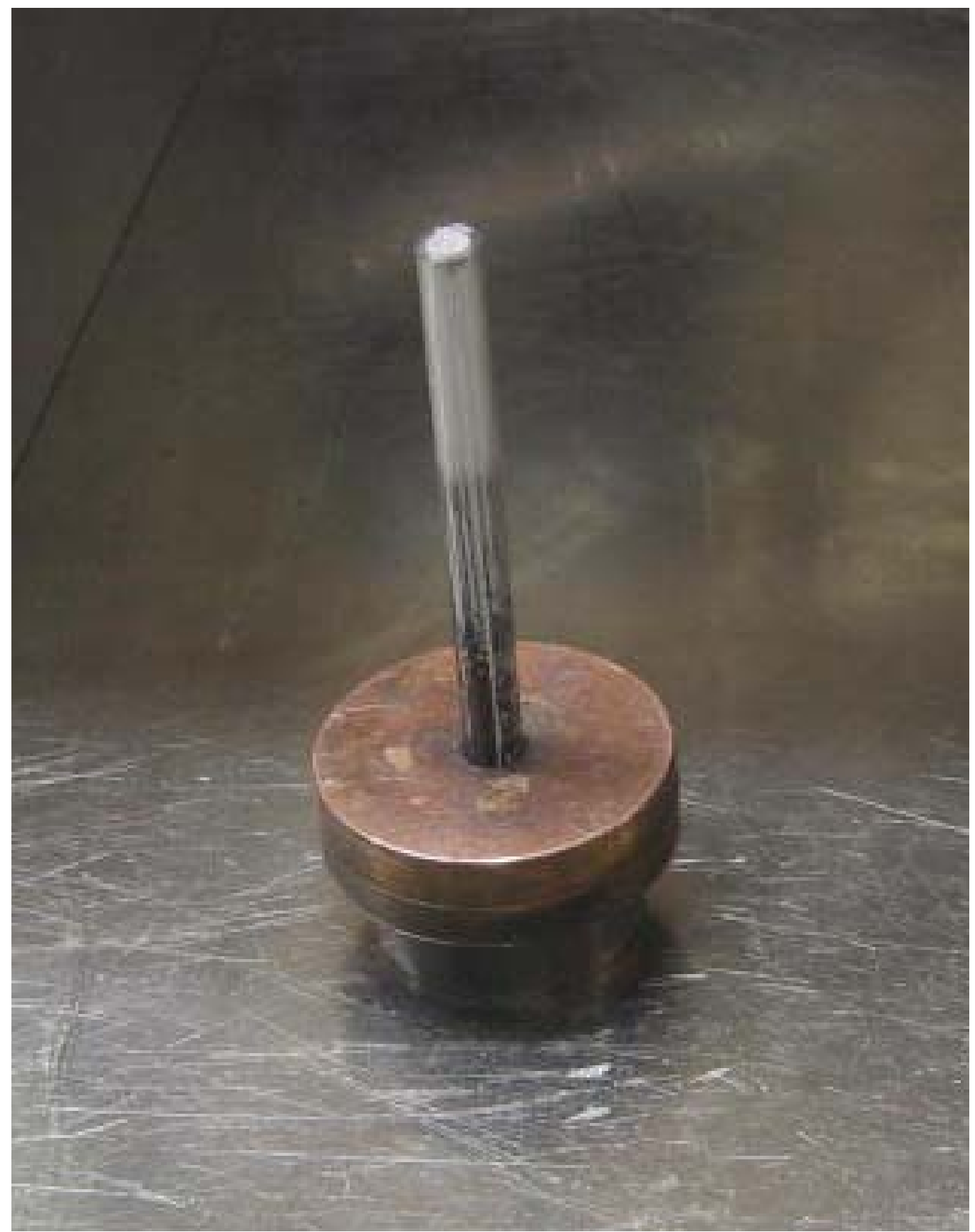

Figure 10. Inverted hearth(s) showing fuel inside quartz mold.

The white inside the quartz mold is the zirconia mold wash that can be used to coat the inside of the mold. This technique was implemented in the AFCI glove box to cast the last of the AFC2 experimental fuel. Figure 11 shows a successful 2-in. fuel casting. 


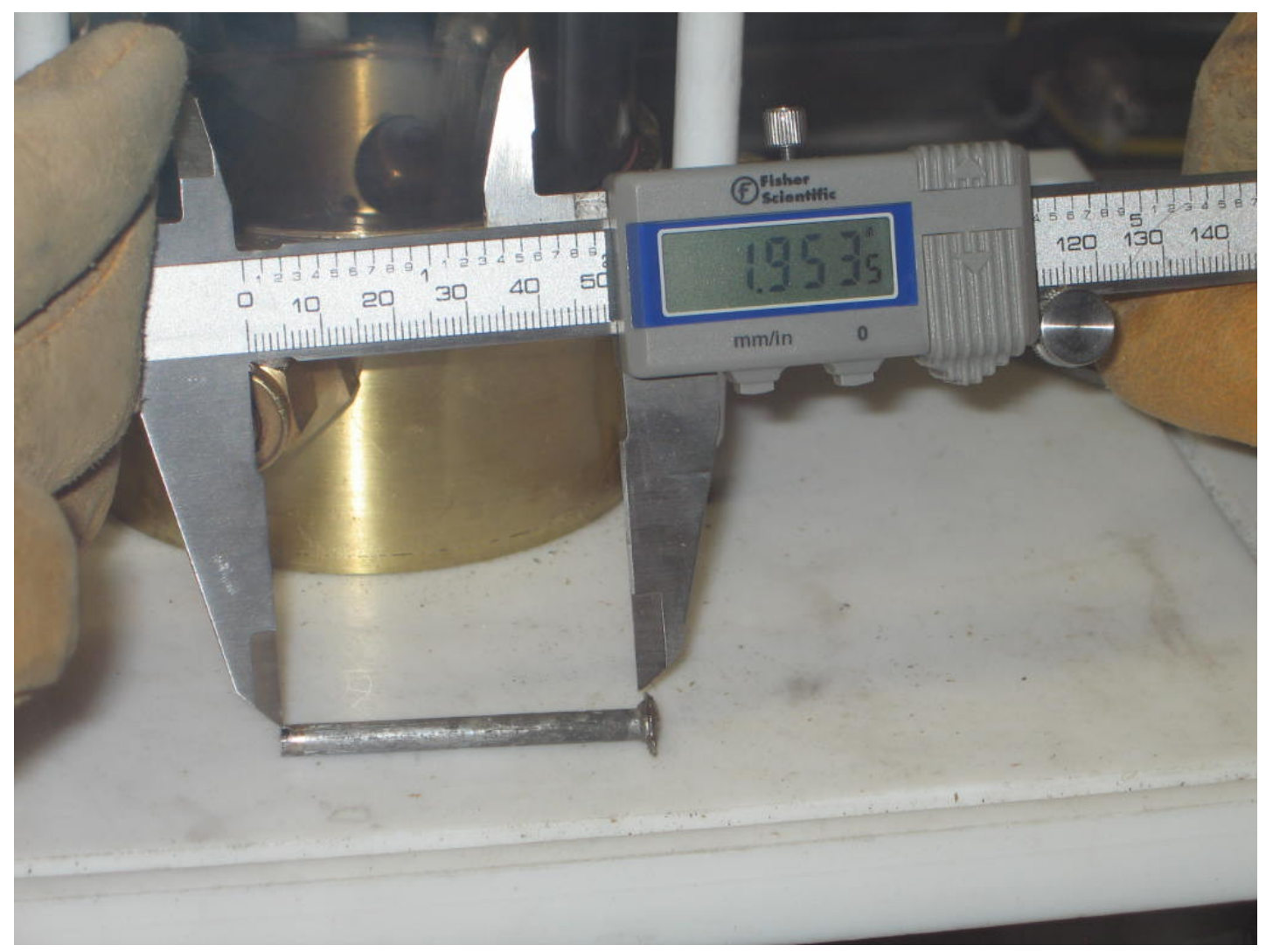

Figure 11. Drop-cast fuel slug.

Appendix $\mathrm{C}$ contains information on future research scale casting techniques that were pursued. These techniques were not considered for AFC-2A and 2B, because implementing their use in an existing glove box is outside the existing scope of work. However, investigating them for future use was deemed worthwhile.

\subsubsection{Characterization Sample Preparation}

For each alloy produced, the following samples were prepared for analysis by Fuels Characterization personnel and Analytical Laboratory (AL) personnel. These samples will be used for meeting the technical and functional requirements of the fuel specification as well as for scientific studies and to generate data needed for other report milestones. (Table 2 outlines the requirements for the samples, but is not intended to be a fixed requirement for sample numbers.) The Fuels Characterization and Fuel Fabrication Work Managers determined how to do the cutting and sectioning of the slug(s) in order to obtain these samples. The Buehler Saw, used for sectioning, appears in Figure 12. 
Table 2. Proposed sample requirements.

\begin{tabular}{|c|c|c|c|c|c|}
\hline \multirow[b]{2}{*}{ Analysis } & \multirow[b]{2}{*}{ Technique } & \multicolumn{3}{|c|}{ Sample size } & \multirow[b]{2}{*}{$\begin{array}{c}\text { No. } \\
\text { Samples }\end{array}$} \\
\hline & & $\begin{array}{l}\text { Length } \\
(\mathrm{mm})\end{array}$ & $\begin{array}{c}\text { Diameter } \\
(\mathrm{mm})\end{array}$ & $\begin{array}{l}\text { Mass } \\
(\mathrm{mg})\end{array}$ & \\
\hline Elemental and isotopics & ICP-MS/ICP-AES & & & $\sim 500$ & $1-2 /$ cast $^{\#}$ \\
\hline Heat capacity & DSC & $1.0-1.2$ & $5.4^{*}$ & & $\geq 2$ \\
\hline Thermal expansion & TMA & $5.0-12.0$ & $4.0-10.0$ & & $\geq 1$ \\
\hline \multirow[t]{3}{*}{ Thermal diffusivity } & LFD & 1 & $11.0-12.5$ & & $\geq 1$ \\
\hline & LFD & 1.5 & $11.0-12.5$ & & $\geq 1$ \\
\hline & LFD & 2 & $11.0-12.5$ & & $\geq 1$ \\
\hline As-cast phase Identification & XRD & $1.0-1.2$ & $4.0-5.0$ & & 3 \\
\hline Microstructure & SEM & $1.0-2.0$ & $4.0-5.0$ & & $\geq 1$ \\
\hline FCCI & SEM & $2.0-5.0$ & $4.0-5.0$ & & $\geq 3$ \\
\hline Annealed sample & XRD, SEM, TA & $10.0-15.0$ & $4.0-5.0$ & & 1 \\
\hline
\end{tabular}

* Optimal diameter, however 4.0-5.0 diameter material will work. 


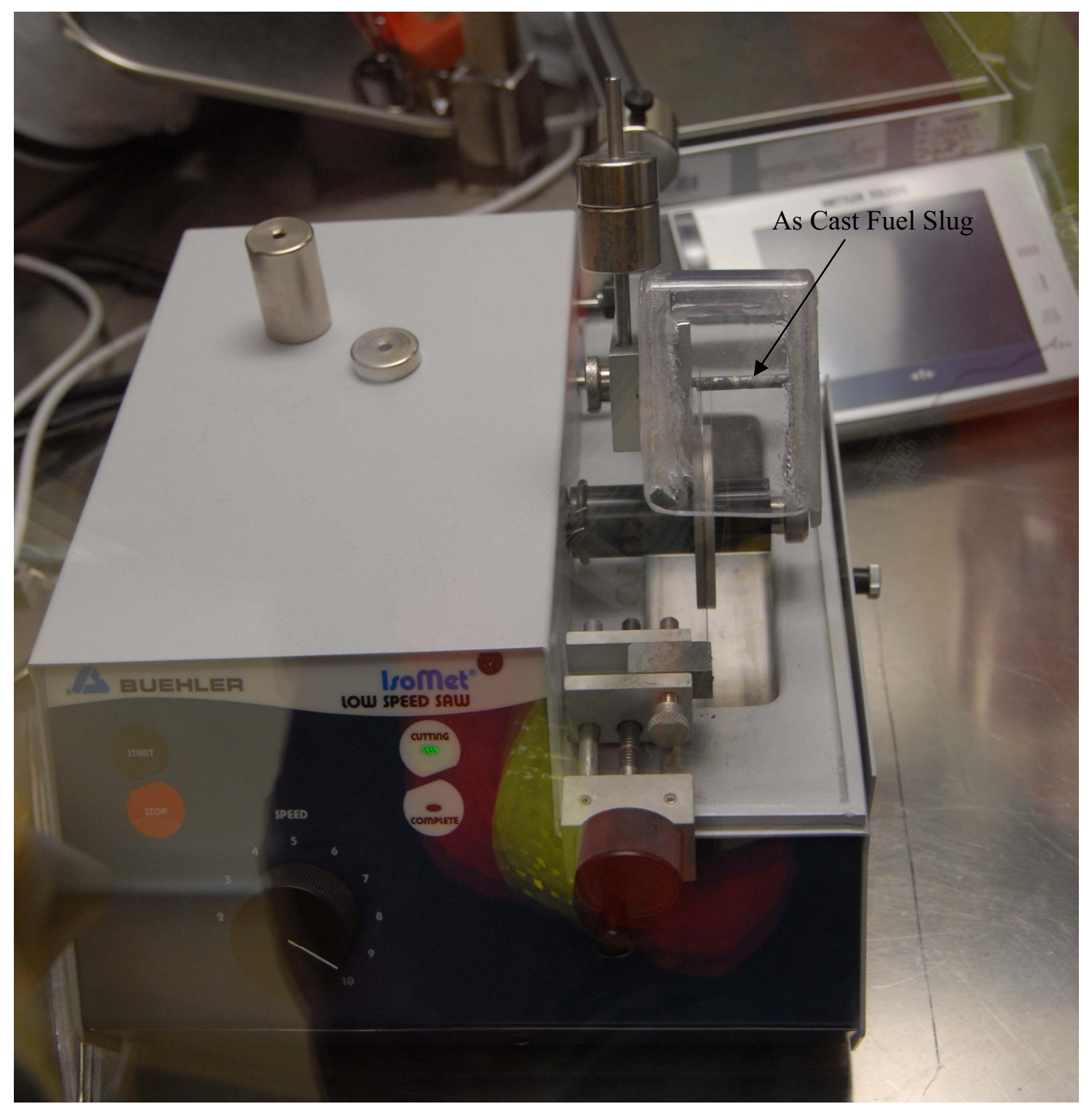

Figure 12. Sectioning samples using the Buehler Saw.

\subsubsection{Casting and Sectioning Functional Description}

AFC2-A1 alloy was completely cast in the CL and sectioned for characterization in the Waste Form Testing Glove Box. The CL glove box is an Argon atmosphere glove box operated at less that $50 \mathrm{ppm}$ oxygen. Waste form testing is a negative pressure, air glove box. In addition, the fuel is sectioned using water as a lubricant for the Buehler Saw.

A total of five slugs were cast in order to achieve all of the fuel and samples that will be needed. Four slugs, approximately 0.75 " each, will be used as fuel for rodlets. The remainder of the material was sectioned as 6 chemistry and isotopics samples, 2 SEM, 3 DSC, 3 XRD/DIF, and 1 TMA sample. An additional larger diameter LFD sample was cast and sectioned into 2 LFD sections for analysis. The 2 SEM samples were mounted and polished and were transferred to the Electron Microscopy Lab (EML) for scanning electron microscope (SEM) analysis. Figure 13 shows representative pictures of the fuel and samples. 


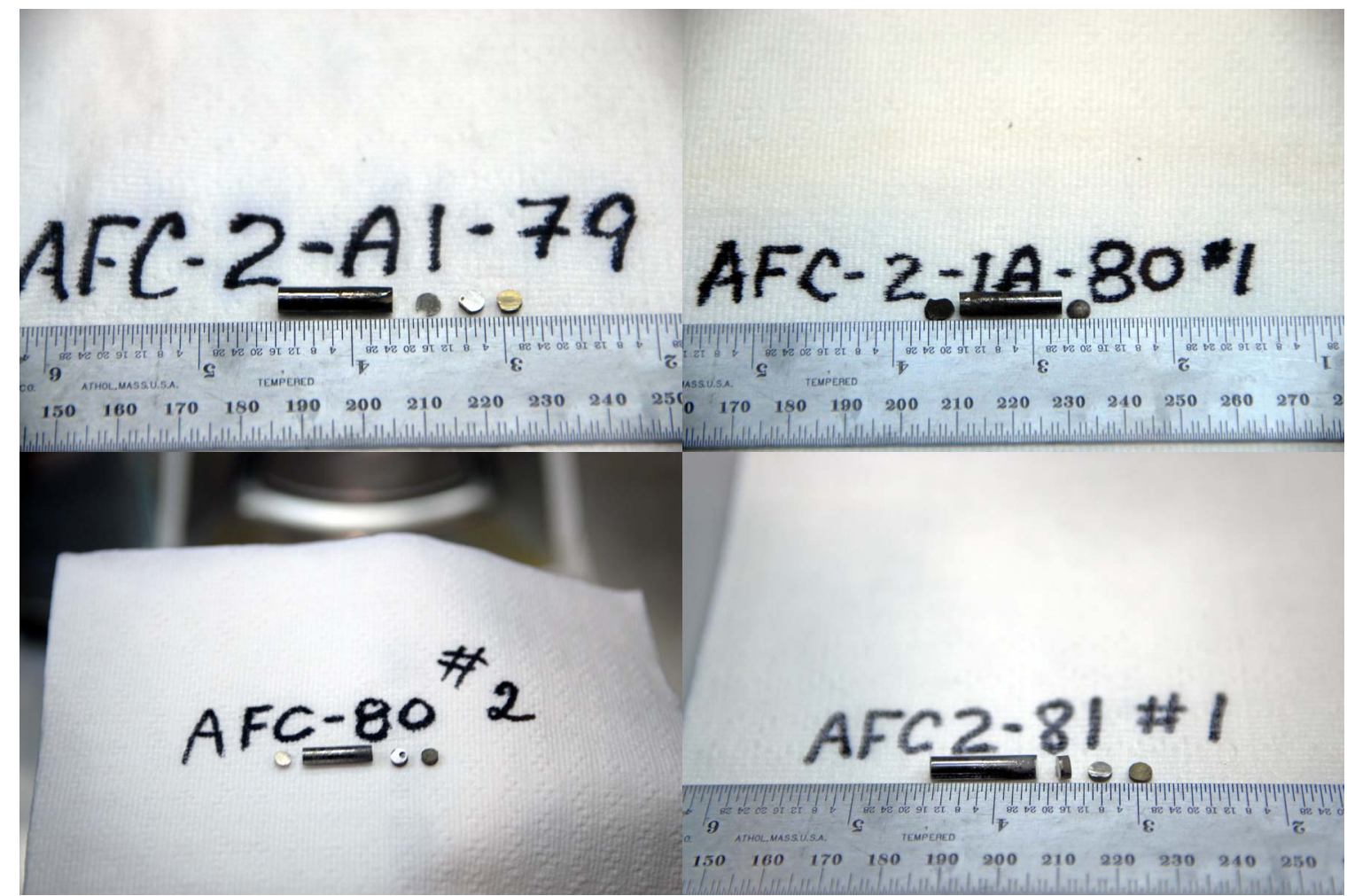

Figure 13. AFC2-A1 fuel slugs and characterization samples.

The rare earth alloy consisting of $6 \% \mathrm{La}, 16 \% \mathrm{Pr}, 25 \% \mathrm{Ce}, 53 \% \mathrm{Nd}$ was alloyed using an arc melting furnace in the INL Research Center (IRC). This alloy was also chemically analyzed and verified for use in the AFC2 fuel.

AFC2-A2 was cast and sectioned in the Fuel Manufacturing Facility inside the new Advanced Fuel-Cycle Initiative (AFCI) glove box. A total of four slugs were cast using the drop-casting technique. Two slugs were used as fuel; the remainder was sectioned into samples. A sample was sectioned from each of the fuel slugs for chemistry and isotopics, five 1-mm samples were sectioned for SEM, DSC, or XRD and two 2-mm samples were sectioned for diffusion couples. The remaining slug material was used for archiving, thermal-mechanical analysis (TMA), and anneal samples. The LFD sample still remains to be cast. Figure 14 shows representative pictures of the fuel slugs and 1-mm samples. 


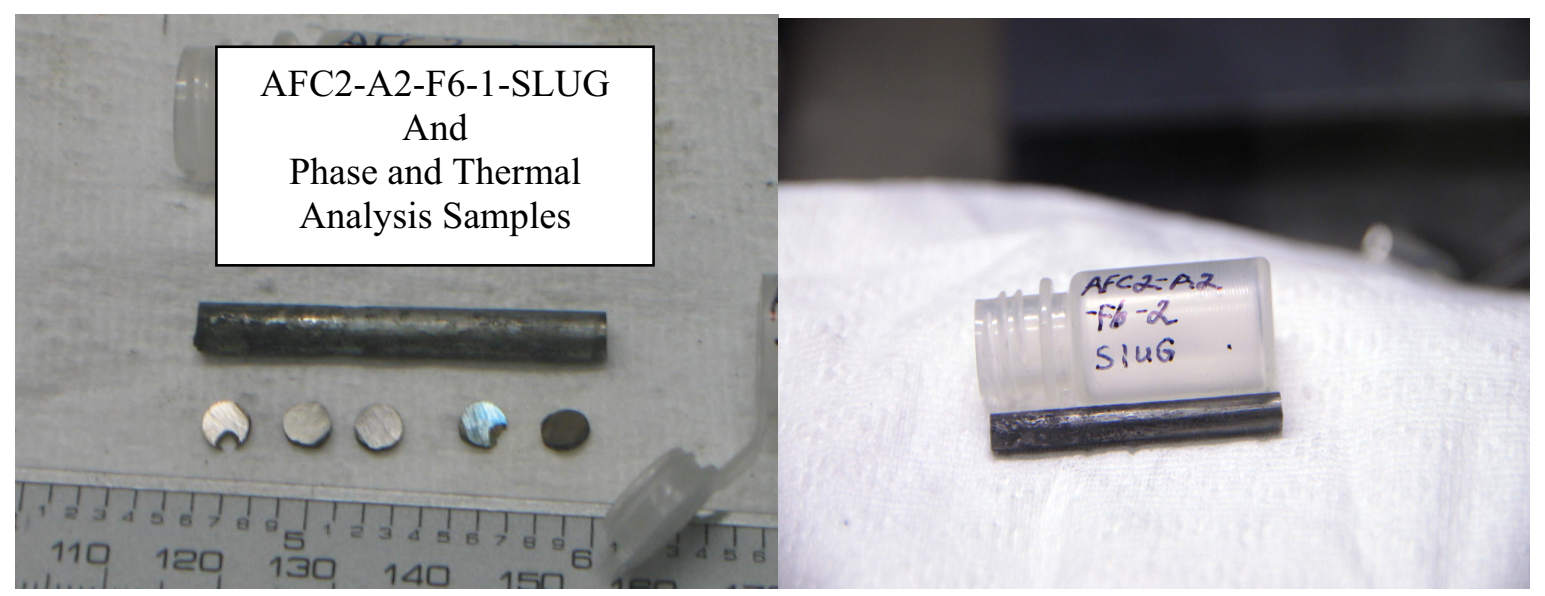

Figure 14. AFC2-A2 fuel slugs and characterization samples.

AFC2-A3 alloy was completely cast in the CL and sectioned for characterization in the Waste Form Testing Glove Box. A total of four slugs and a 12-mm-diameter laser flash sample were cast in order to achieve all of the fuel and samples that were needed. Three slugs were cut from these original castings to be used as fuel for rodlets (Figure 15). The remainder of the material was sectioned as 6 chemistry and isotopics samples, 2 SEM, 3 DSC, 3 XRD, 2 LFD and 1 TMA sample. The 2 SEM samples were mounted and polished and were transferred to EML for SEM analysis.

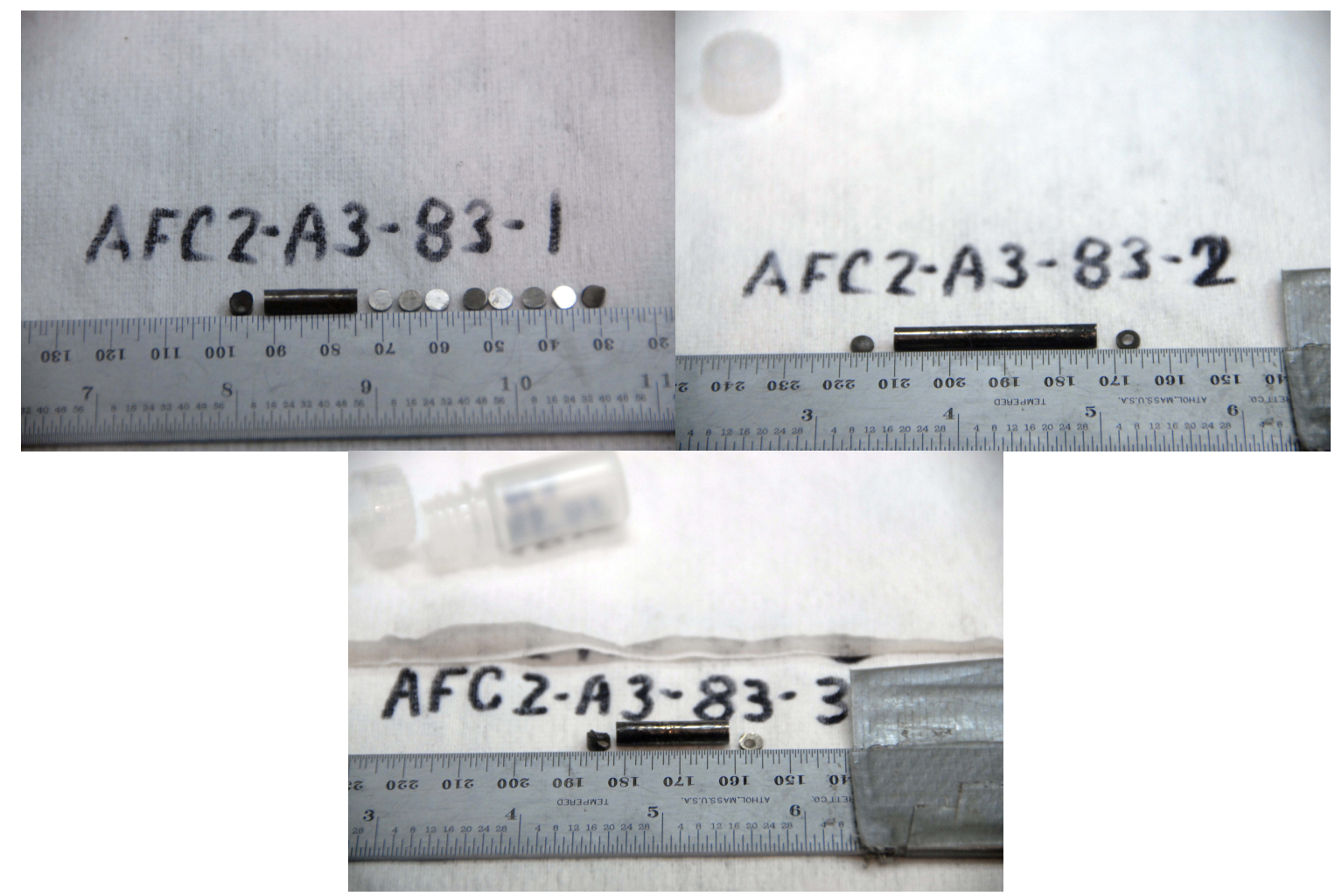

Figure 15. AFC2-A3 fuel slugs and characterization samples. 
AFC2-A4 was cast and sectioned in the AFCI glove box; a total of three slugs were cast using the drop-casting technique. Two slugs were used as fuel; the remainder was sectioned into samples. A sample was sectioned from each of the fuel slugs for chemistry and isotopics; in addition, a second sample was taken from one slug to verify homogeneity. Two 1-mm samples were sectioned for SEM, DSC, or XRD. The remaining slug material was used for archiving, TMA, and anneal samples. The LFD sample still remains to be cast. Figure 16 shows representative pictures of the fuel slugs.

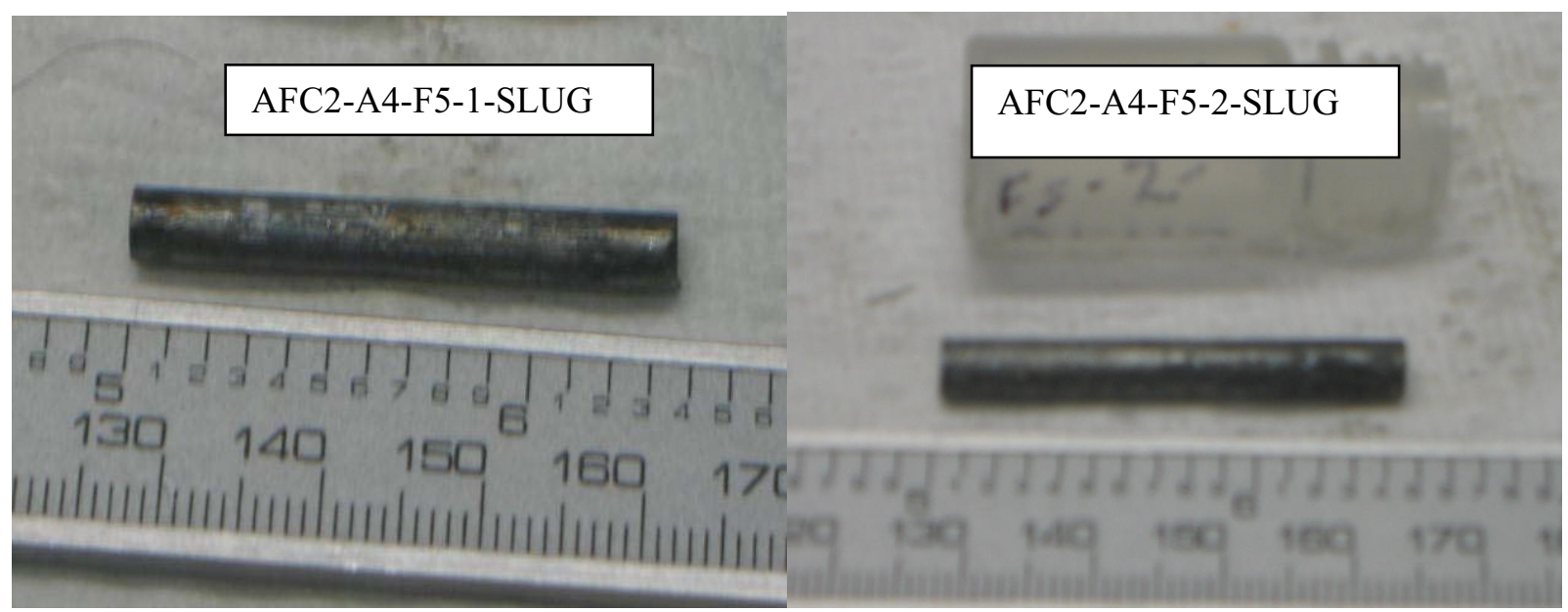

Figure 16. AFC2-A4 Fuel Slugs.

AFC2-A5 was cast and sectioned in the AFCI glove box; a total of five slugs were cast using the drop-casting technique. Four slugs were used as fuel; the remainder was sectioned into samples. A sample was sectioned from AFC2-A5-F4-3, AFC2-A5-F4-4, and AFC2-A5-F4-5 slugs for chemistry and isotopics. AFC2-A5-F4-2 is a small 7.21-mm slug; AFC2-A5-F4-3 was cast immediately after, so it is assumed to have the same chemistry. Five 1-mm samples were sectioned for SEM, DSC, or XRD. The remaining slug material was used for archiving, TMA, and anneal samples. The LFD sample still remains to be cast. Figure 17 shows representative pictures of the fuel slugs and samples. 

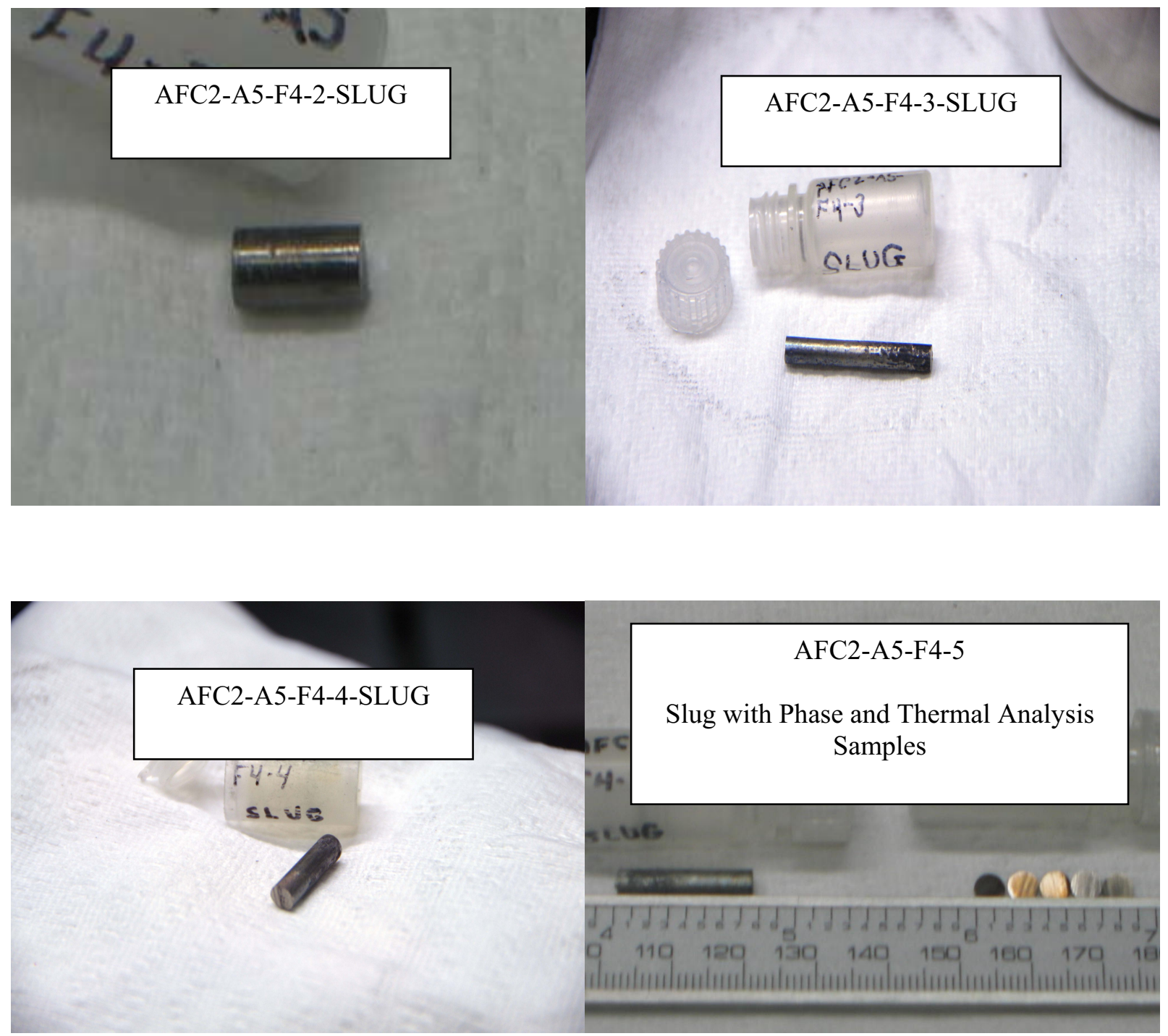

Figure 17. AFC2-A5 fuel slugs and samples.

AFC2-A6 alloy was completely cast in the CL and sectioned for characterization in the Waste Form Testing Glove Box. A total of six slugs and a 12-mm-diameter laser flash sample were cast in order to achieve all of the fuel and samples that are needed. Four slugs cut from these original castings are to be used as fuel. The remainder of the material was sectioned as 7 chemistry and isotopics samples, 2 SEM, 3 DSC, 4 XRD, 3 FCCI, 2 LFD and 1 TMA sample. The 2 SEM samples were mounted and polished and were transferred to EML for SEM analysis. Figure 18 shows fuel and characterization samples. 


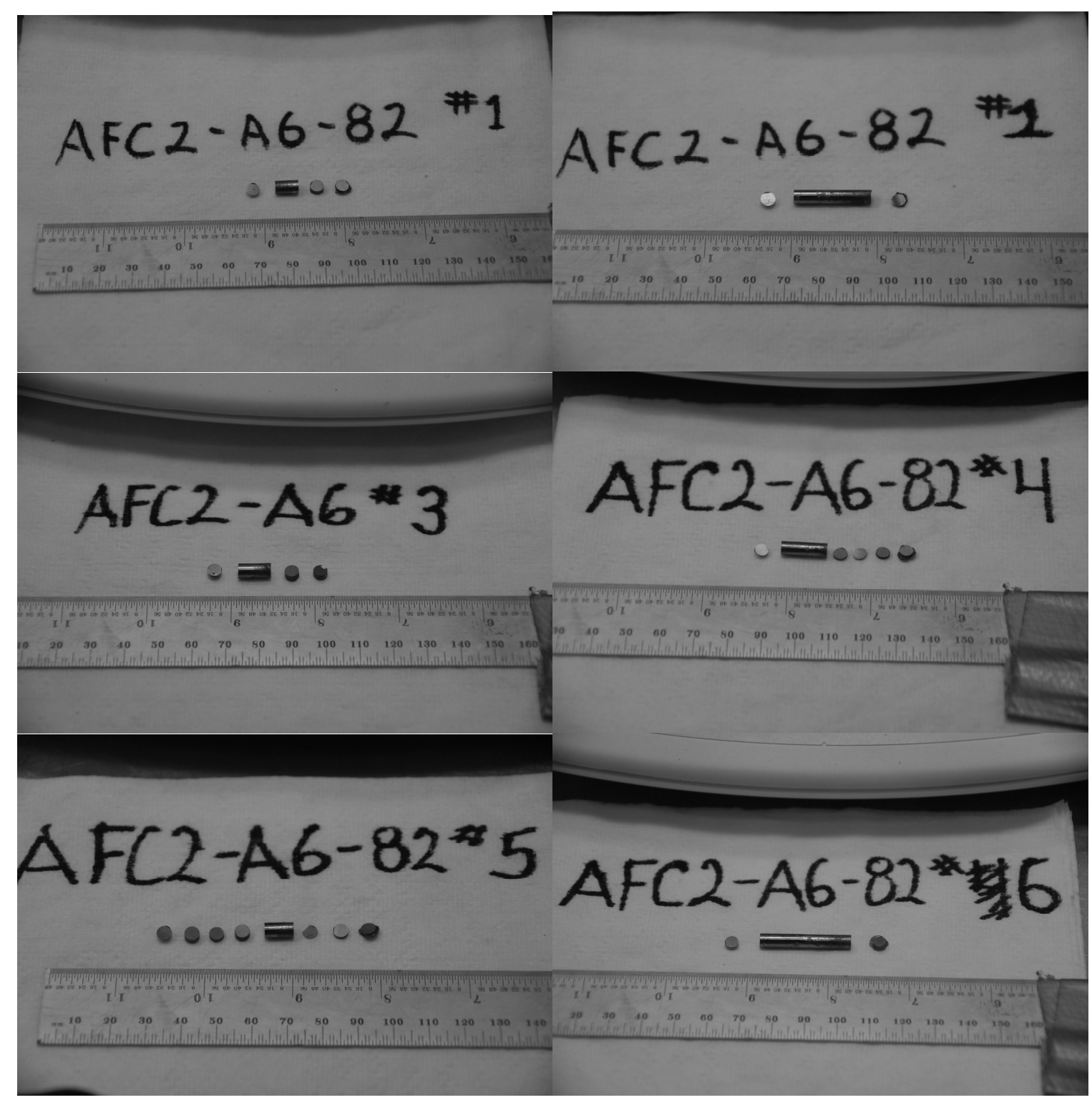

Figure 18. AFC2-A6 fuel slugs and characterization samples.

\subsubsection{Cut to Final Dimension}

Fuel slugs are generally cut to length in conjunction with sample sectioning. Table 3 shows the data on fuel physical properties and casting source for AFC2 fuel slugs. Density is determined by the Archimedes method, when possible and, otherwise, by dimensional analysis. 
Table 3. AFC2 Fuel Physical Properties.

\begin{tabular}{|c|c|c|c|c|}
\hline Slug Designation & $\begin{array}{c}\text { Rodlet } \\
\text { Designation }\end{array}$ & Mass (gr) & Length (mm) & Density (g/cc) \\
\hline AFC2-A1-79-ROD1 & AFC2A-R1 & 4.068 & 19.24 & $* 13.74$ \\
\hline AFC2-A1-80-1-ROD1 & AFC2A-R1 & 4.196 & 18.84 & $* 14.50$ \\
\hline AFC2-A1-80-2-ROD1 & AFC2B-R1 & 3.888 & 18.24 & *13.88 \\
\hline AFC2-A1-81-1-ROD1 & AFC2B-R1 & 4.225 & 19.36 & $* 14.07$ \\
\hline AFC2-A2-F6-1-SLUG & AFC2A-R2 & 8.006 & 37.69 & 14.16 \\
\hline AFC2-A2-F6-2-SLUG & AFC2B-R2 & 8.047 & 38.05 & 14.10 \\
\hline AFC2-A3-83-1-ROD1 & AFC2A-R3 & 3.664 & 17.36 & $* 13.54$ \\
\hline AFC2-A3-83-3-ROD1 & AFC2A-R3 & 4.498 & 20.72 & *13.93 \\
\hline AFC2-A3-83-2-ROD1 & AFC2-XX & 8.003 & 37.22 & $* 13.77$ \\
\hline AFC2-A4-F5-2-SLUG & AFC2A-R4 & 7.525 & 36.93 & 13.40 \\
\hline AFC2-A4-F5-1-SLUG & AFC2B-R4 & 6.814 & 35.02 & 12.97 \\
\hline AFC2-A5-F4-2-SLUG & AFC2A-R5 & 1.480 & 7.21 & 13.38 \\
\hline AFC2-A5-F4-3-SLUG & AFC2A-R5 & 5.910 & 30.58 & 12.71 \\
\hline AFC2-A5-F4-4-SLUG & AFC2B-R5 & 3.373 & 17.55 & 12.41 \\
\hline AFC2-A5-F4-5-SLUG & AFC2B-R5 & 3.747 & 19.08 & 12.92 \\
\hline AFC2-A6-82-2-ROD1 & AFC2A-R6 & 4.628 & 23.33 & *12.83 \\
\hline AFC2-A6-82-4-ROD1 & AFC2A-R6 & 2.891 & 14.36 & $* 12.88$ \\
\hline AFC2-A6-82-5-ROD1 & AFC2B-R6 & 1.731 & 8.58 & $* 12.93$ \\
\hline AFC2-A6-82-6-ROD1 & AFC2B-R6 & 5.854 & 29.24 & $* 12.89$ \\
\hline
\end{tabular}

* Archimedes

TFR-452 requires each alloy fuel column to be one or two slugs totaling $1.5 \mathrm{in}$. long $+0,-0.2$ $(38.1 \mathrm{~mm}-33.02 \mathrm{~mm})$ with a diameter of $0.168 \mathrm{in} .+0.001,-0.003(4.29 \mathrm{~mm}-4.19 \mathrm{~mm})$. However, all six alloys did not shrink after cooling as did a straight uranium/zirconium alloy. As a result, all fuel slugs were larger in diameter than was written in the fuel specification. The actual fuel was all 0.175 in $+0.001,-0.003$. This is documented in the as-built data package and is covered under Nonconformance Report (NCR) \#46125.

\subsubsection{Chemical composition}

In general, the fuel was all close to the target compositions. The fuel specification was written very tightly and, as a result, an NCR (NCR \#41623) was issued to address the compositions being out of compliance with the published specification. Figure 19 shows the chemical analysis results from the cast fuel and the target compositions. 


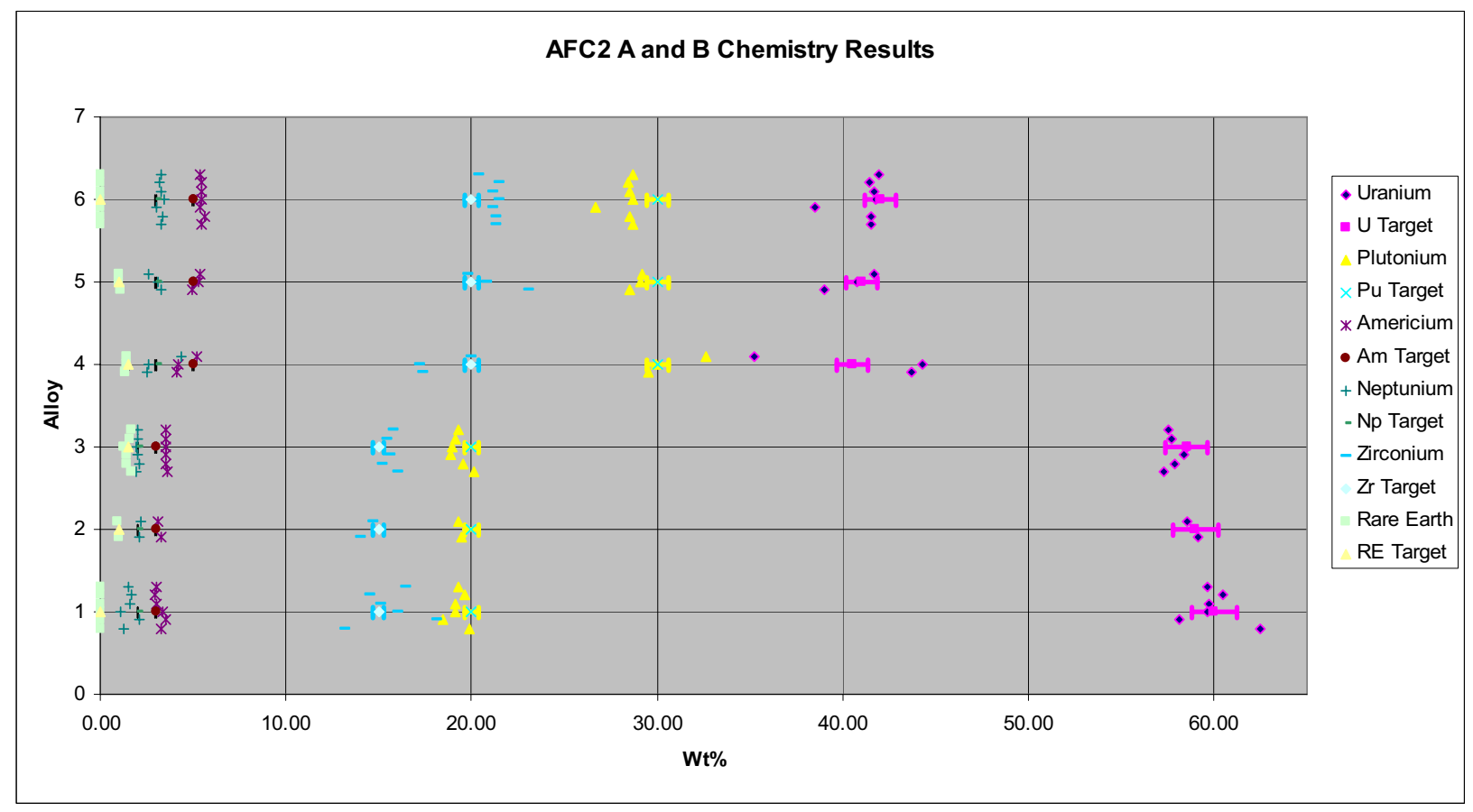

Figure 19. Chemical composition of cast fuel compared to target compositions.

\subsection{Cladding Fabrication}

This section describes the fabrication and control of the cladding tubes and end plugs.

\subsubsection{Design Drawings}

The design drawings for the rodlet components are as follows:

Metallic Fuel Rodlet Assembly, Drawing Number 747153

Tube, Drawing Number 747151

Top and Bottom End Plug, Drawing Number 747167

Metallic Fuel, Drawing Number 747154.

\subsubsection{Fuel Cladding Material Procurement}

Cladding used to encapsulate the fuel slugs for this test was excess Alloy HT-9 EBR-II cladding tubes. All cladding tubes are traceable to the manufacturer certification. Sections of length suitable for AFC-2 fuel specimens were cut from these original vendor stocks. Traceability of the cut sections to the original serialized cladding tube will be maintained by re-serializing each new cut section and by logging the correspondence between the original tubes and cut sections. The traceability log will be maintained in the Experiment As-Built Data Package. 


\subsubsection{Receipt Inspection}

Due to the fact that EBR-II tubes with traceable pedigree were used, no inspection was required.

\subsubsection{Cladding Jacket Fabrication}

Rodlet components were fabricated and inspected to be within the tolerances specified in the rodlet drawings laid out in Section 2.2.1. This was all accomplished in INL machine shops.

The end plug-to-tubing joint of the fuel rodlet is considered to be a butt joint with integral backing, which conforms to a Category $\mathrm{C}$ joint on a Class 3 vessel per "ASME Boiler and Pressure Vessel Code," Section III, ND-3351.3. The joint will be fabricated as a Type 2 joint as required by ND-4243 and will be fabricated to allow for $100 \%$ penetration. The welds for both ends of the AFC-2 rodlets were done in the AFCI glove box using an ARC Machines Orbital welder. Figure 20 shows a cross-section micrograph of the cladding end plug weld. This micrograph was used as part of the package to qualify the weld process in the AFCI glove box.

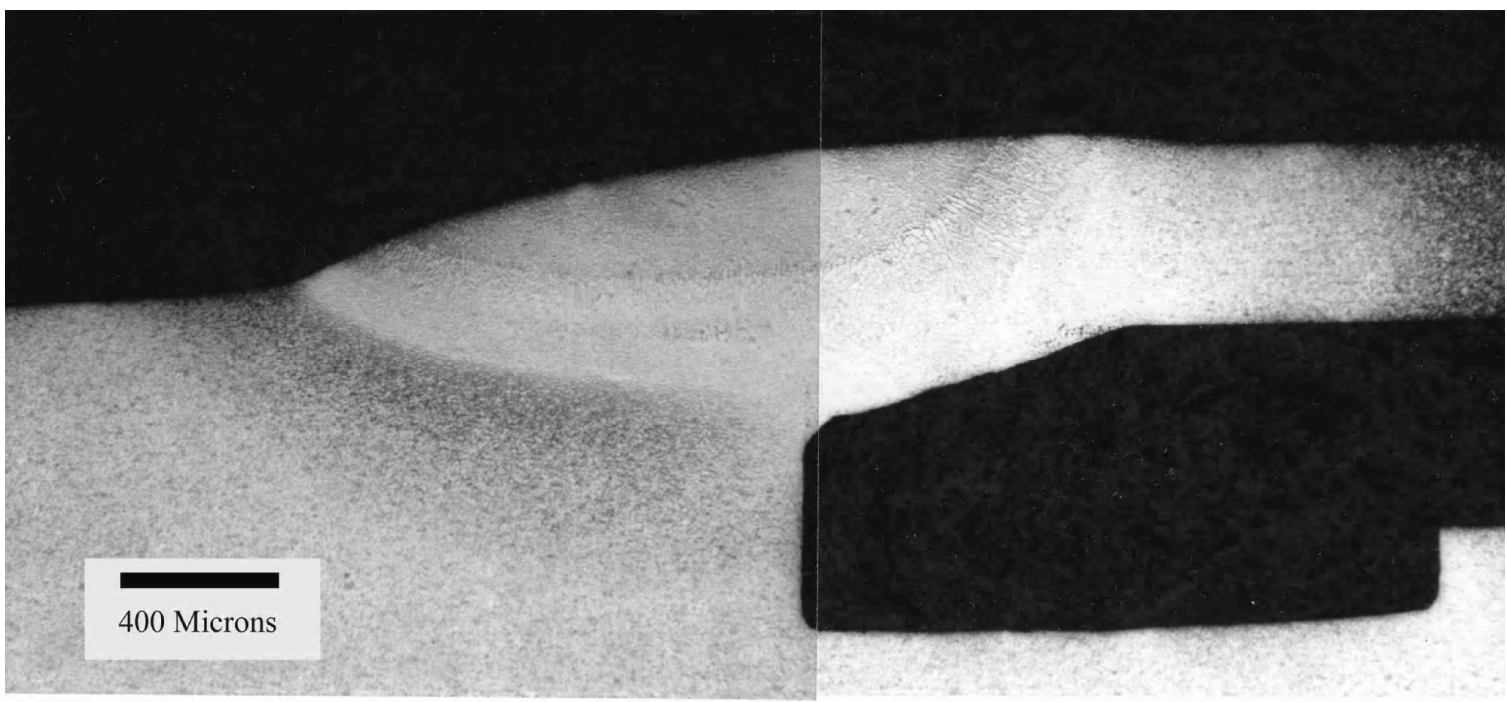

Figure 20. AFC2 rodlet weld micrograph.

\subsubsection{Weld Inspection}

Data relating to weld qualification for each weld type are available for inspection from the AFC welding engineer. Weld inspection data for each weld, including the weld qualification package and process control specimen inspection data, will be included in the AFC-2A and AFC-2B as-built data package.

The cladding tubes with the first end plug welded were weld inspected and leak checked to the requirements established in the fuels specification TFR-452 and the "AFC-2 Fuel Rodlet and Capsule Final Inspection Plan,” PLN-2443.

The leak check report for all rodlet bottom end plugs is included in Appendix A. 


\subsubsection{Cladding Jacket Cleaning}

Jacket cleaning will be done as needed to meet the requirements of the TFR fuels specification using the appropriate work request that, in effect, is a simple wipedown to make sure there is no contamination.

\subsubsection{Sodium Loading}

The sodium was loaded into the cladding jackets in the AFCI glove box as specified in the fuel specification. The essential requirement is that the mass of the loaded sodium be $0.40+/-0.01$ grams and be documented in a Process Worksheet.

\subsection{Rodlet Loading and Sealing}

Rodlets were loaded and welded in an atmosphere of $70 \%$ argon and 30\% helium. This was verified with a calibrated He analyzer that is integral to the Vac Atmosphere section of the AFCI glove box. Figure 21 illustrates rodlet components.

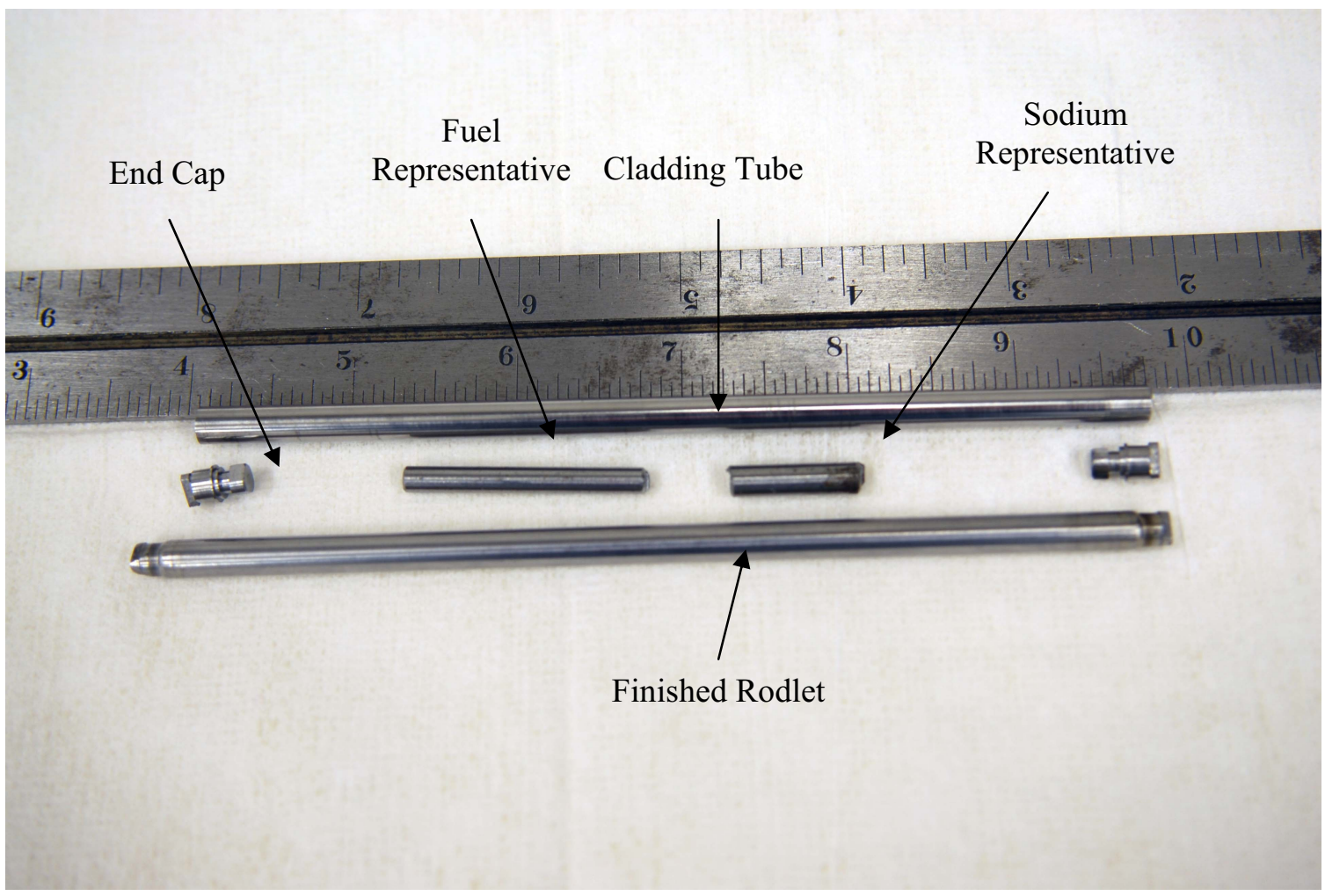

Figure 21. Rodlet components.

\subsubsection{Rodlet Weld inspection and Leak Certification}

Finished fuel rodlets will be subject to helium leak testing in accordance with PLN-2443. Appendix B shows an example of this report for A1, A3, and A6 rodlets.

Radiographic inspection was performed in accordance with PLN-2443. Radiographs for this inspection will be included in the as-built data package. Figure 22 shows an example of an x-ray weld inspection radiograph. 


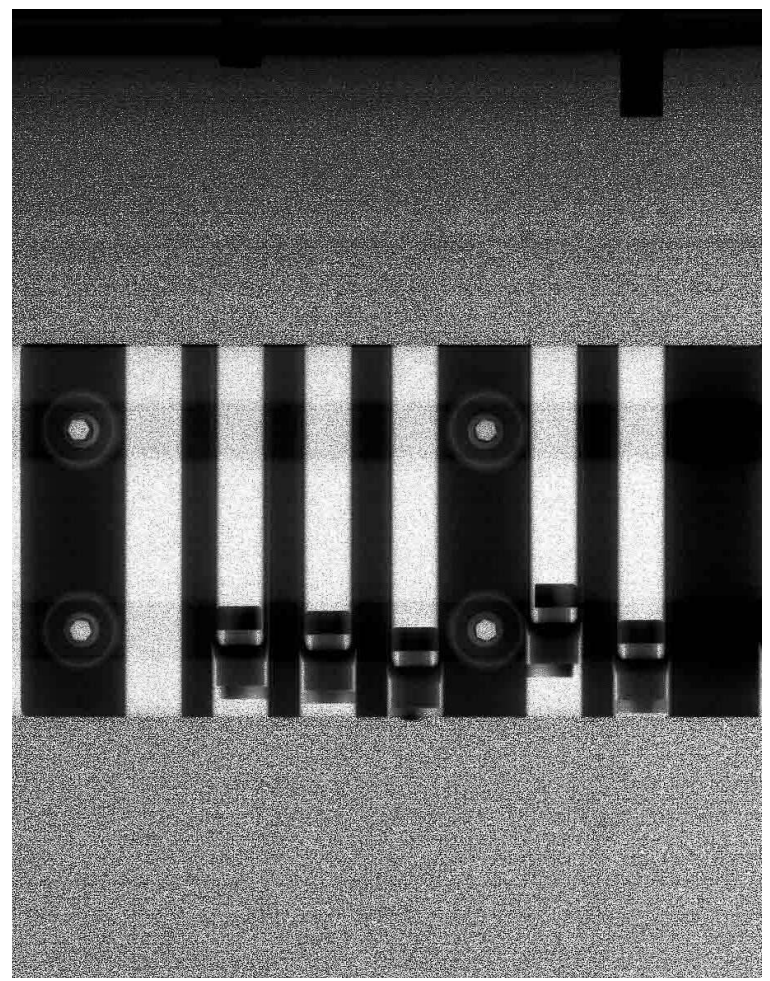

Figure 22. Rodlet closure weld radiograph.

\subsubsection{Rodlet Settling and Bonding}

Settling and bonding is the process of heating the sealed rodlet to a sufficiently high temperature to melt the metallic sodium, thus allowing it to flow completely around the fuel slug(s) and bond to the cladding. Figures 23-25 show the settling and bonding process. 


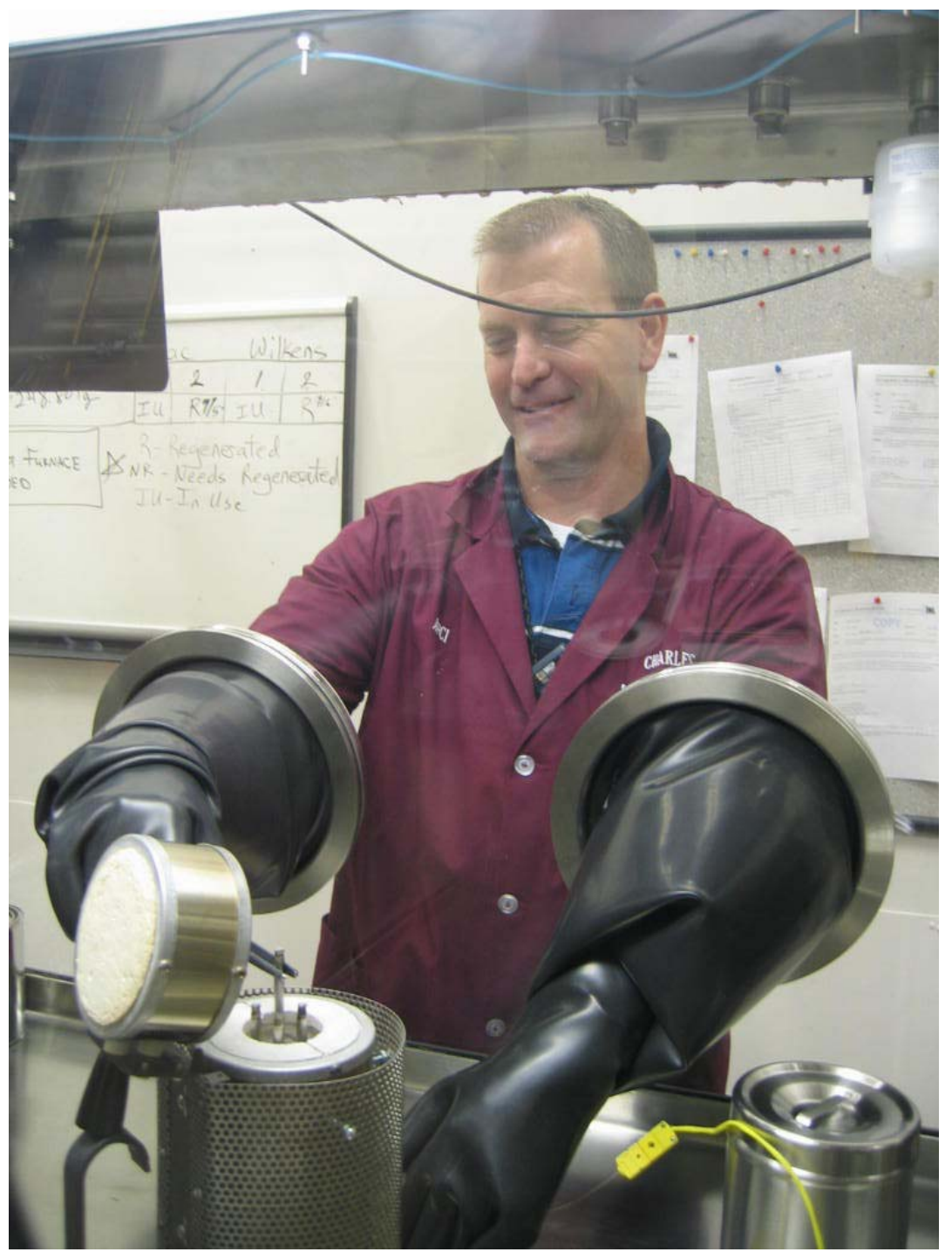

Figure 23. Loading rodlets into the settling and bonding furnace for heating. 


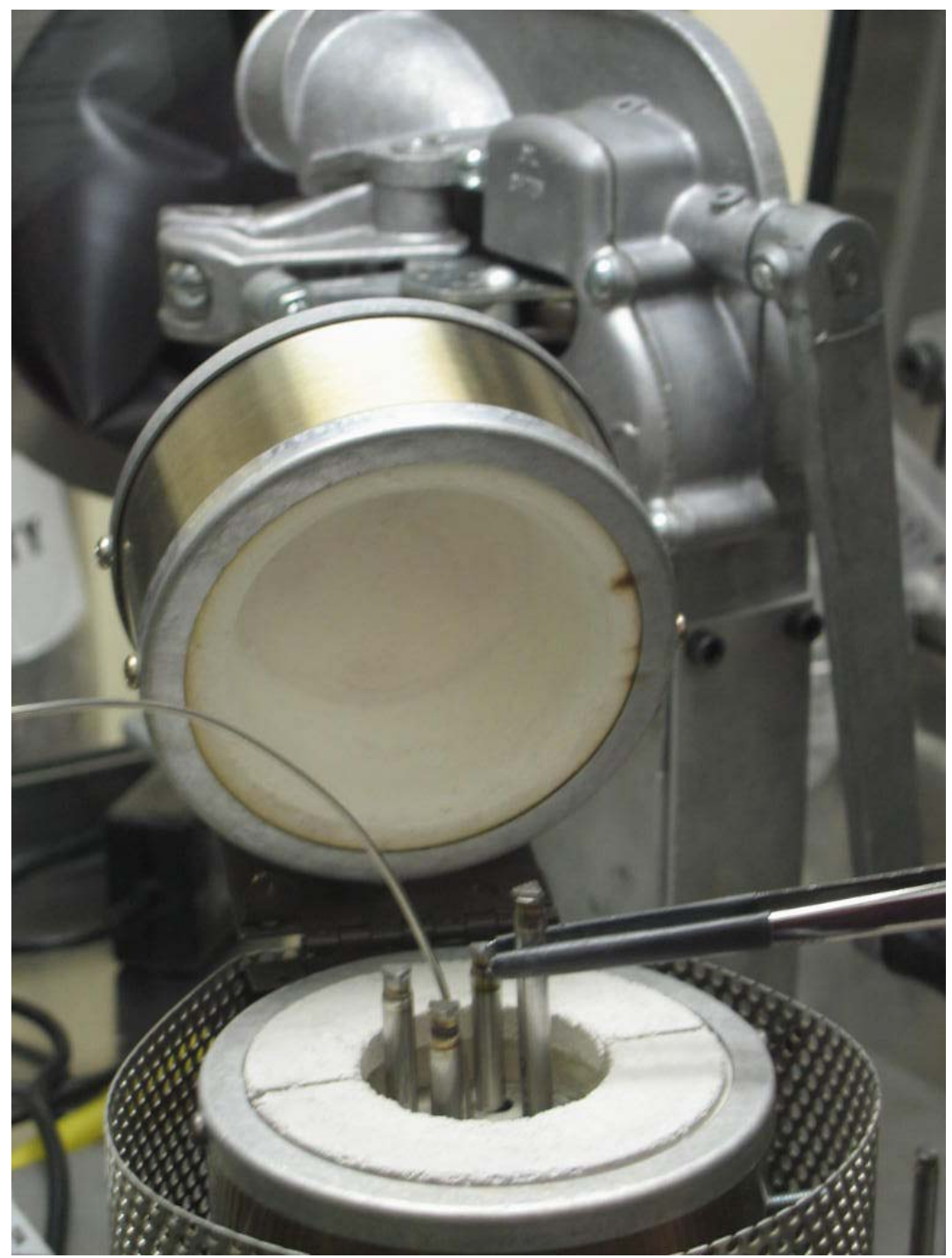

Figure 24. Settling and bonding furnace with four rodlets in place 


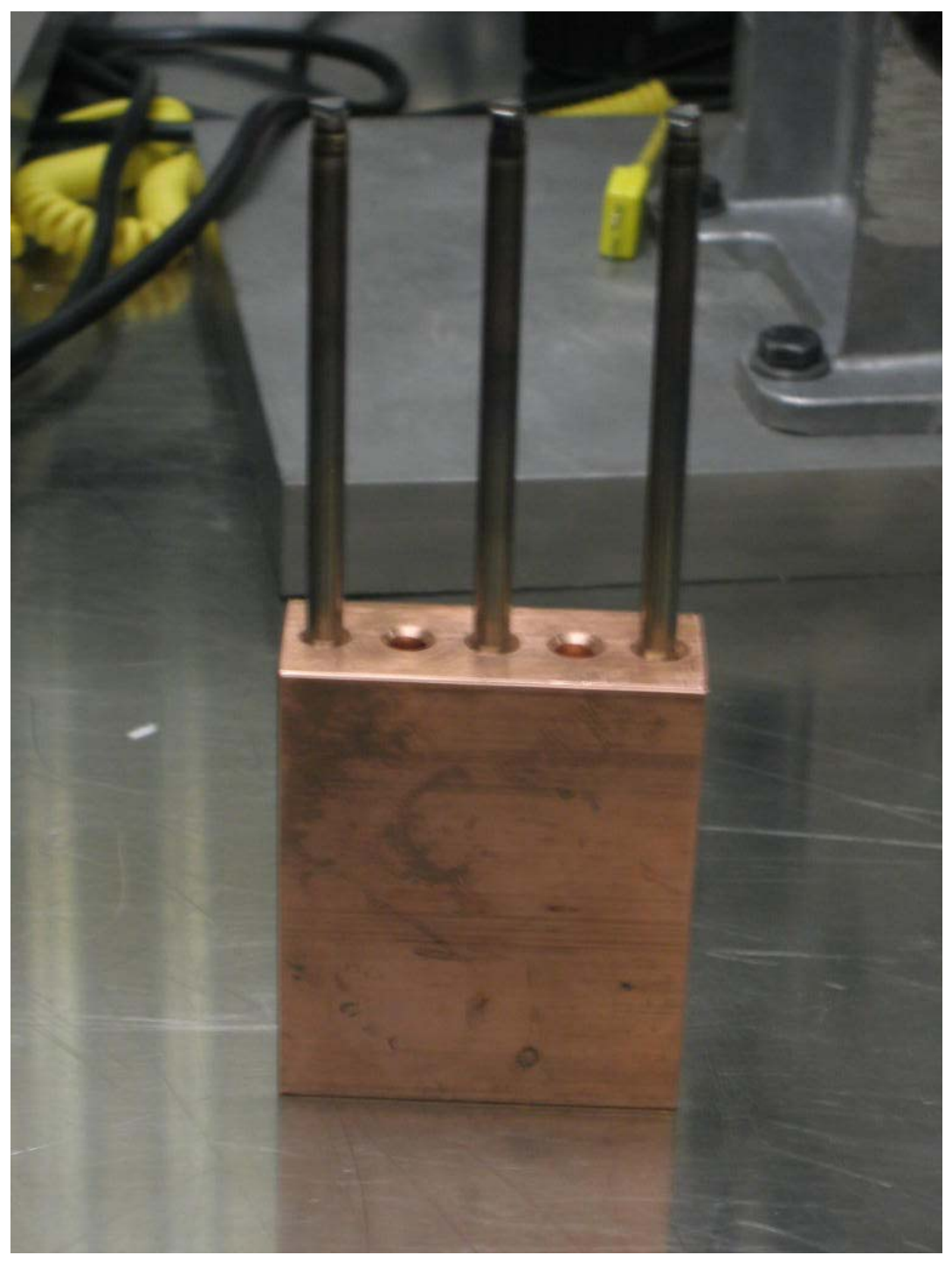

Figure 25. Copper chill block for cooling rodlets.

\subsubsection{X-ray Inspection for Fuel and Sodium}

Radiographic inspection will be performed in accordance with PLN-2443 to verify the integrity of the final product. The radiograph in Figure 26 shows an example of fuel and sodium positions and levels inside a sealed rodlet. 


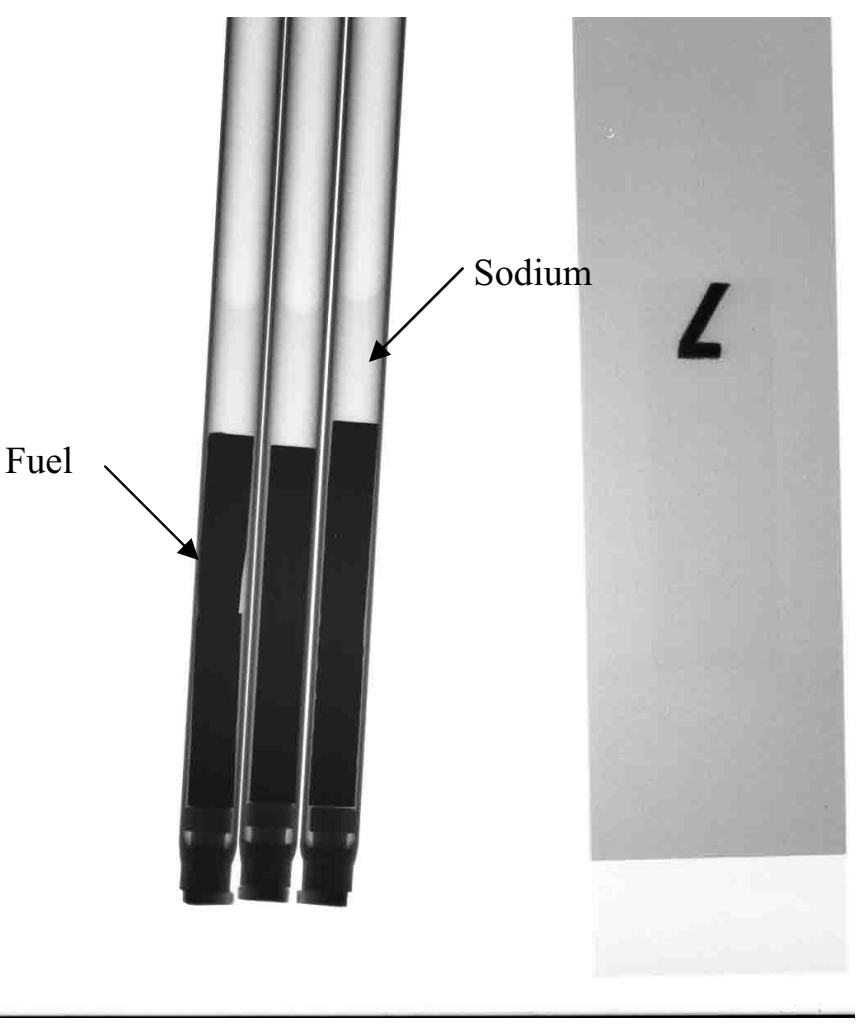

Figure 26. Rodlet radiograph showing fuel and sodium levels.

\subsection{Capsule Fabrication}

This section describes fabrication of the rodlet capsules.

\subsubsection{Capsule Design Drawings}

The design drawings for the rodlet components are as follows:

Capsule Assembly, Drawing Number 747159

Capsule Tube, Drawing Number 747168

Capsule Lower End Cap, Drawing Number 747157

Capsule Upper Spacer, Drawing Number 747160

Capsule Bottom Spacer, Drawing Number 747161

Capsule Upper End Cap, Drawing Number 747164

\subsubsection{Capsule Material Procurement}

Capsule material was purchased to QA Level 1 to meet the specifications outlined in the capsule drawings, Section 3.4.1. For the AFC-2A and 2B capsules, we will be using material purchased in the past for ATR experiments. 


\subsubsection{Receipt Inspection}

New material inspections were not required for the AFC-2A and $2 \mathrm{~B}$ capsules because tractability documents exist.

\subsubsection{Capsule Fabrication}

The containment vessel design will be identical in both experiments. The assembly is shown in Drawing 747159. The experiment capsule is constructed to meet the intent of "ASME Section III, Class 1, Pressure Vessel Code." Design criteria are specified in SPC-390, "Advanced Accelerator Applications ATW-1 Fuel Test Specimen Drop-In Capsule," and the capsule is considered to be Quality Assurance Level 1 fabrication.

Weld procedure specifications for the containment capsule top and bottom capsule closure welds are given in the "AAA Containment Capsule Cap Welding Procedure Specification," W7520-0477-ES. This specification falls within the range given in INL Welding Procedure Specification S4.2.

Two capsules will need to be fabricated, plus two equivalent shortened sections for welding controls, and two for actual rodlet loading. One of the two capsule tubes containing the fuel rodlets will be etched AFC-2A and the other AFC-2B. 


\subsubsection{Inspection}

After the first end plug is welded on, it will be radiographed and leak checked per PLN-2443. Figure 27 shows a radiograph of a capsule end plug weld.

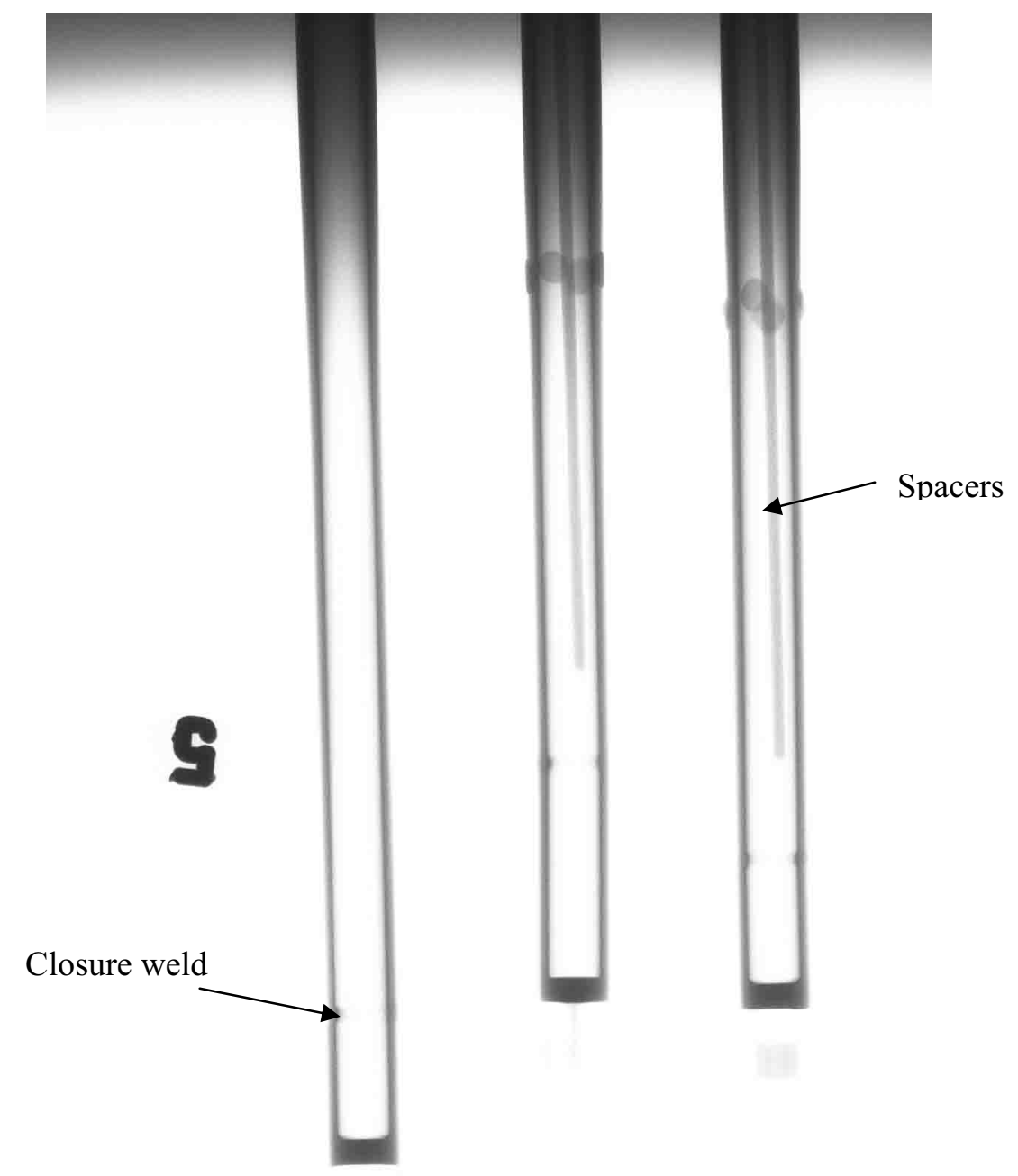

Figure 27. Capsule end plug radiograph.

Data relating to weld qualification for each weld type are available for inspection from the AFC welding engineer. Weld inspection data for each weld, including the weld qualification package and process control specimen inspection data, will be included in the AFC-2A and AFC-2B as-built data package(s).

If a loaded capsule fails to meet the welding and leak rate standards, it can be re-welded once.

\subsubsection{Capsule Cleaning}

Clean as needed to meet the requirements in the fuels specification using the appropriate work request. This is essentially a wipedown with an ethanol non-lint cloth. 


\subsection{Capsule Assembly}

This section describes the loading of the rodlets into the capsule, capsule end plug welding, and the associated inspections. This section also includes the description of the as-built data package required for ATR acceptance of the experiment.

\subsubsection{Rodlet Loading into the Capsule and End Plug Welding}

Experiment assembly will be conducted in accordance with the procedure "Assembling Rodlets into Capsules," FMF-OI-817. Loading of the experiment stack will be witnessed and verified as detailed in this procedure. The experiment containment capsule is filled with helium and welded inside a He-filled chamber in accordance with this procedure. Helium purity in the capsule is guaranteed through process knowledge, process qualification, and sampling of process control specimens. Gas process control specimens will be collected prior to and after welding of each capsule. The helium gas content of all process control specimens will be analyzed by mass spectrometry at the MFC Analytical Laboratory. The requirement is $99.5-100 \%$.

Welding of the capsule top closure will be in accordance with W7520-0477-ES. All welds made on process control specimens will be non-destructively inspected according to PLN-2443 and the documents referenced therein. Welds made on process control samples will be destructively inspected according to "Welding Program for Welding Fuel Elements and Containment Capsules," W7520-0474-ES.

Capsule AFC-2A will be loaded with the appropriate rodlets as follows in Table 4.

Table 4. Capsule AFC-2A.

\begin{tabular}{|l|l|l|}
\hline \multicolumn{1}{|c|}{ Rodlet Order } & \multicolumn{1}{c|}{ Rodlet Designation } & \multicolumn{1}{c|}{ Fuel Designation } \\
\hline $1-(\mathrm{Top})$ & AFC2A-R1 & AFC2-A1 \\
\hline 2 & AFC2A-R2 & AFC2-A2 \\
\hline 3 & AFC2A-R3 & AFC2-A3 \\
\hline 4 & AFC2A-R4 & AFC2-A4 \\
\hline 5 & AFC2A-R5 & AFC2-A5 \\
\hline $6-($ Bottom) & AFC2A-R6 & AFC2-A6 \\
\hline
\end{tabular}

Capsule AFC-2B will be loaded with the appropriate rodlets as follows in Table 5.

Table 5. Capsule AFC-2B.

\begin{tabular}{|l|l|l|}
\hline \multicolumn{1}{|c|}{ Rodlet Position } & \multicolumn{1}{c|}{ Rodlet Designation } & \multicolumn{1}{c|}{ Fuel Designation } \\
\hline $1-($ Top) & AFC2B-R1 & AFC2-A1 \\
\hline 2 & AFC2B-R2 & AFC2-A2 \\
\hline 3 & AFC2-XX & AFC2-A3 \\
\hline 4 & AFC2B-R4 & AFC2-A4 \\
\hline 5 & AFC2B-R5 & AFC2-A5 \\
\hline 6 -(Bottom) & AFC2B-R6 & AFC2-A6 \\
\hline
\end{tabular}

Figures 28-33 show the capsule assembly process. 


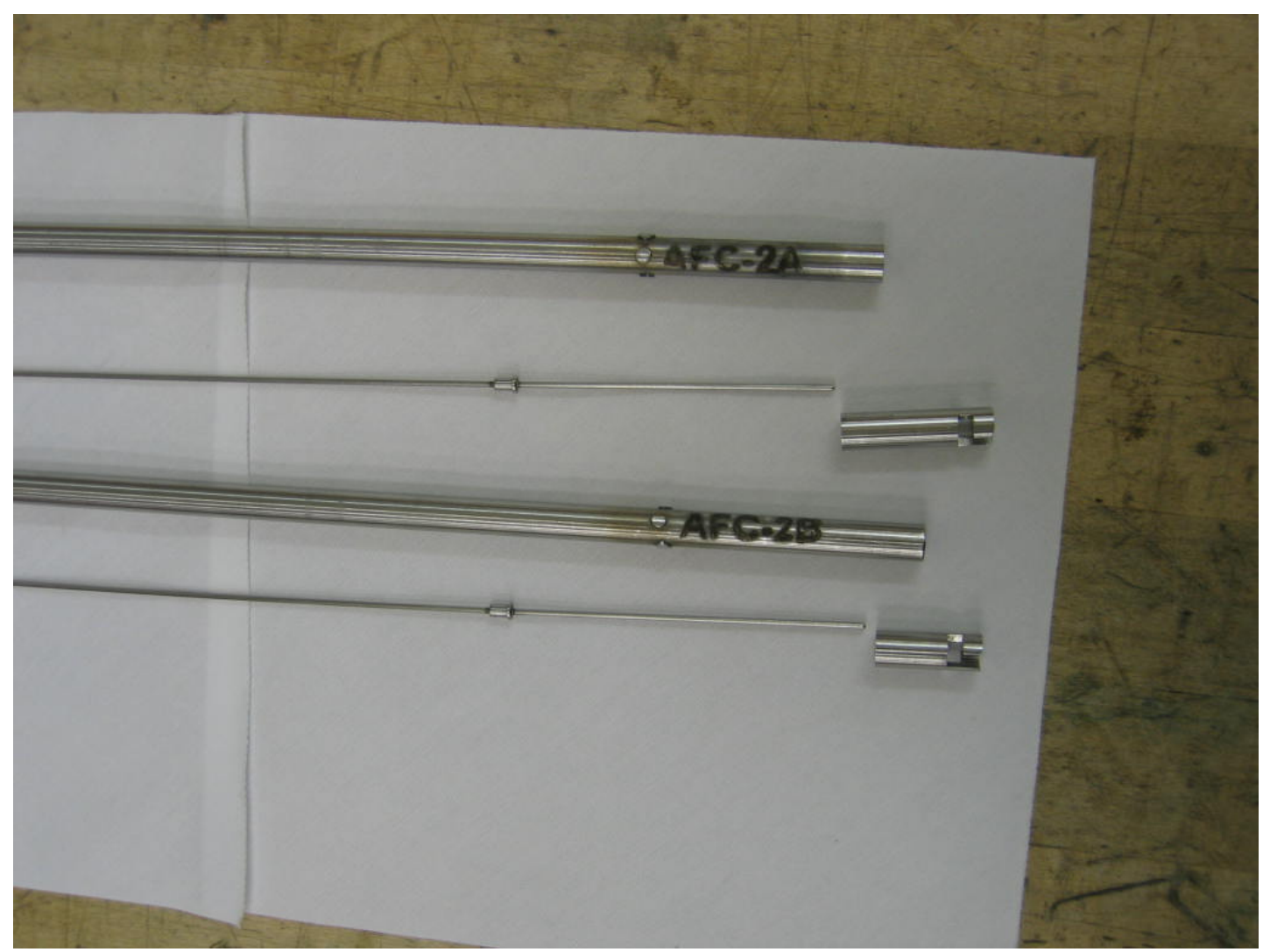

Figure 28. Etched capsules with spacer and end caps.

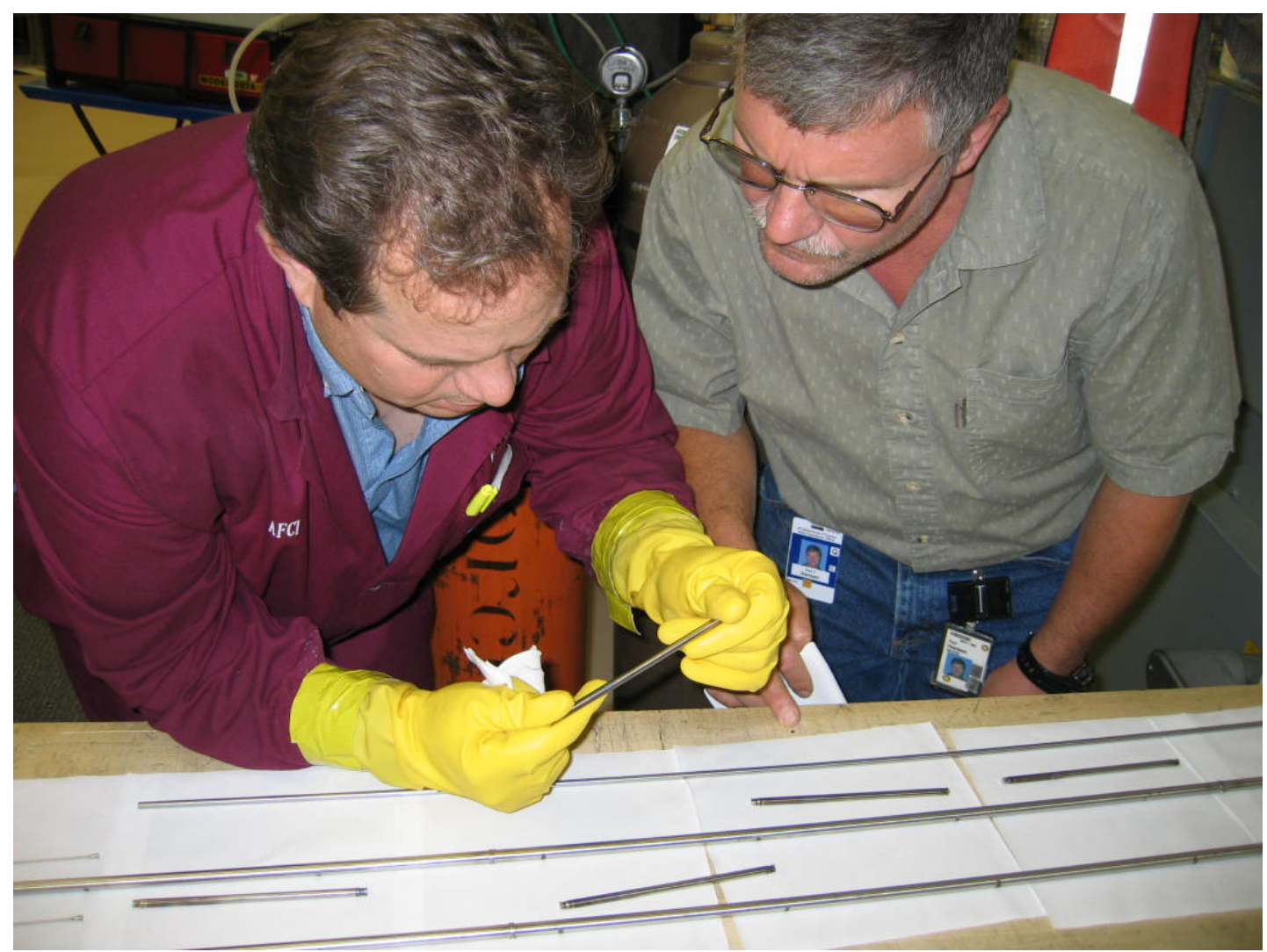

Figure 29. Verifying rodlet serial numbers and loading order. 


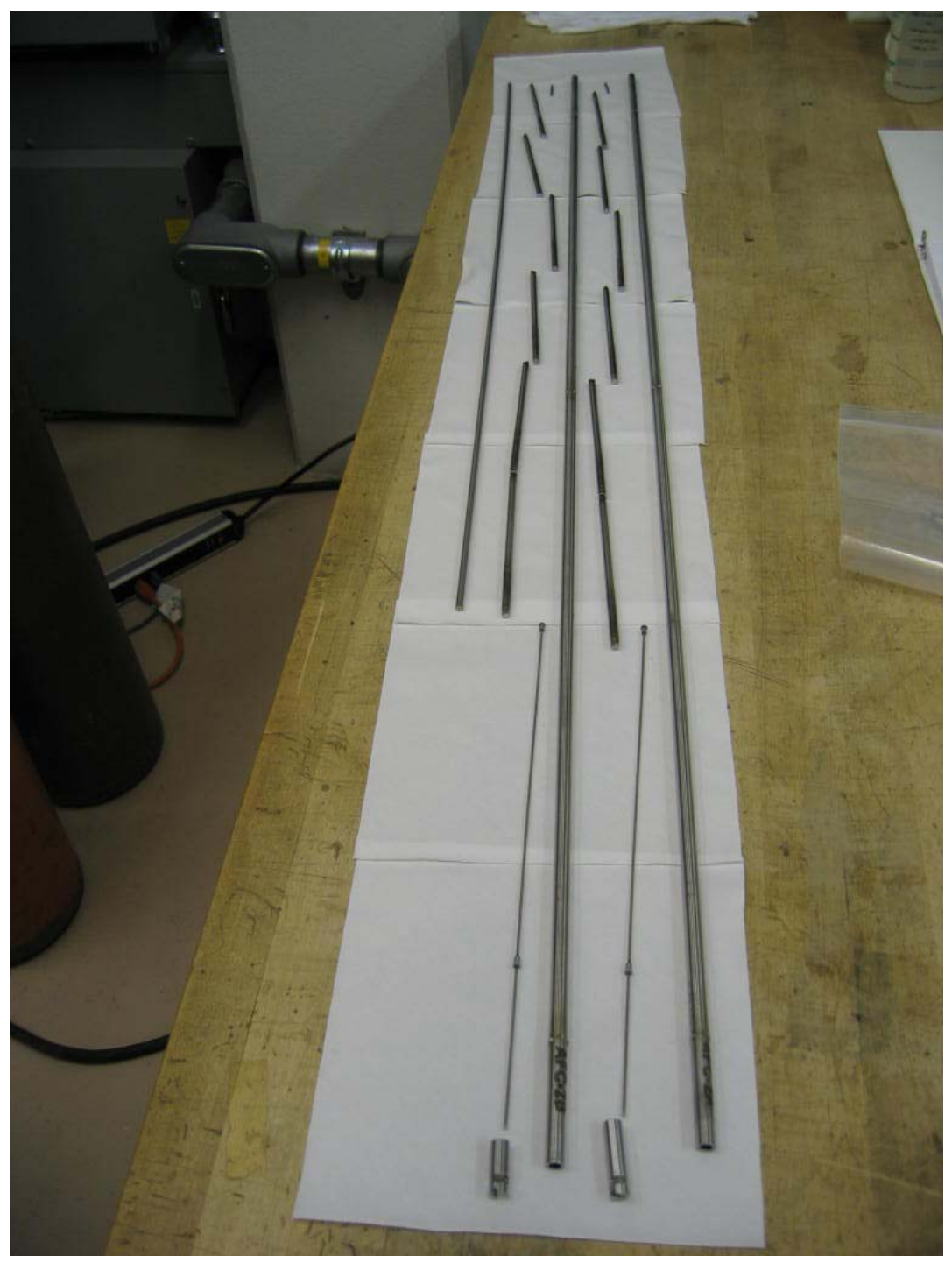

Figure 30. Rodlets and spacers laid out for loading into capsule. (The rod to the far left is a push rod for loading rodlets.) 


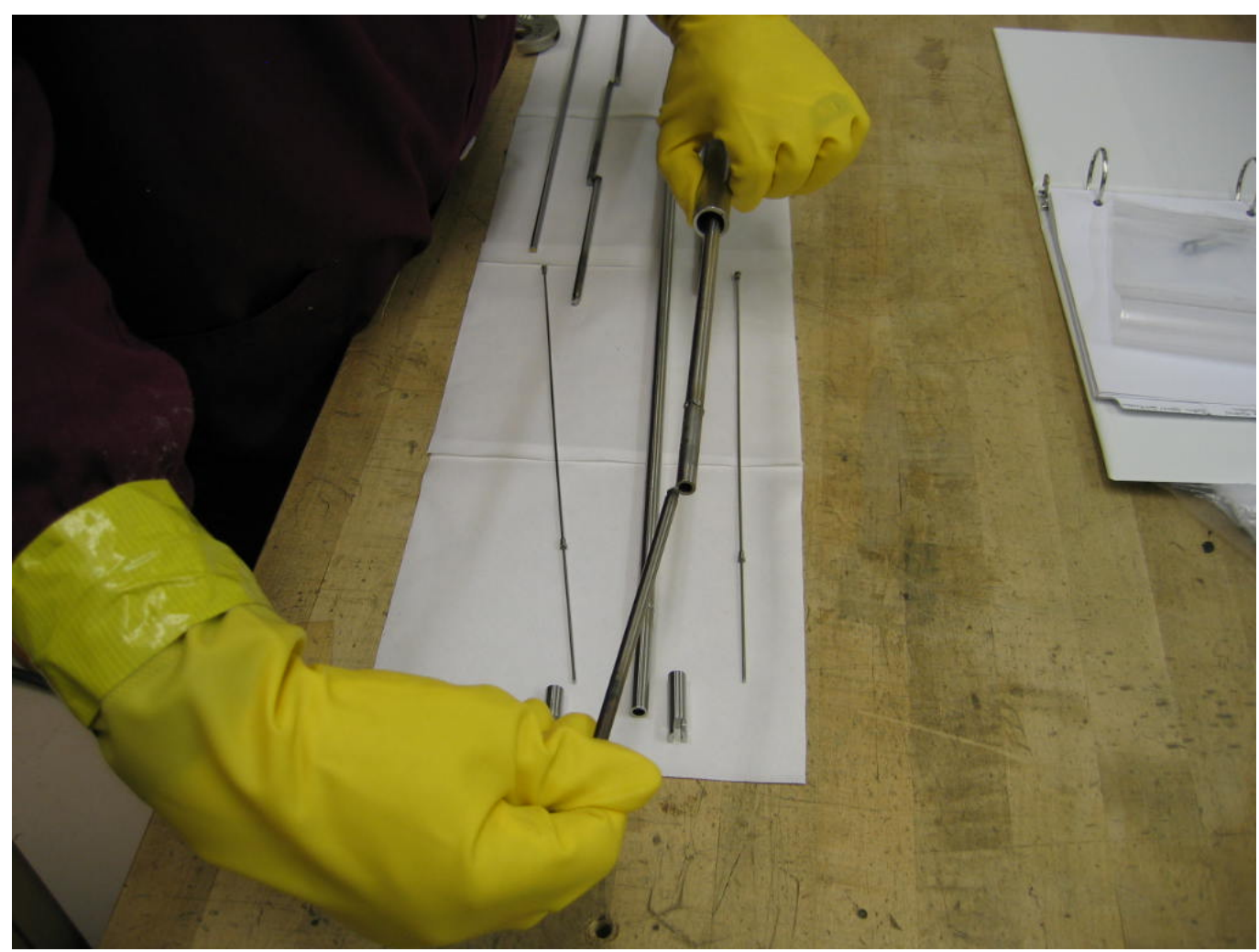

Figure 31. Inserting rodlet into capsule.

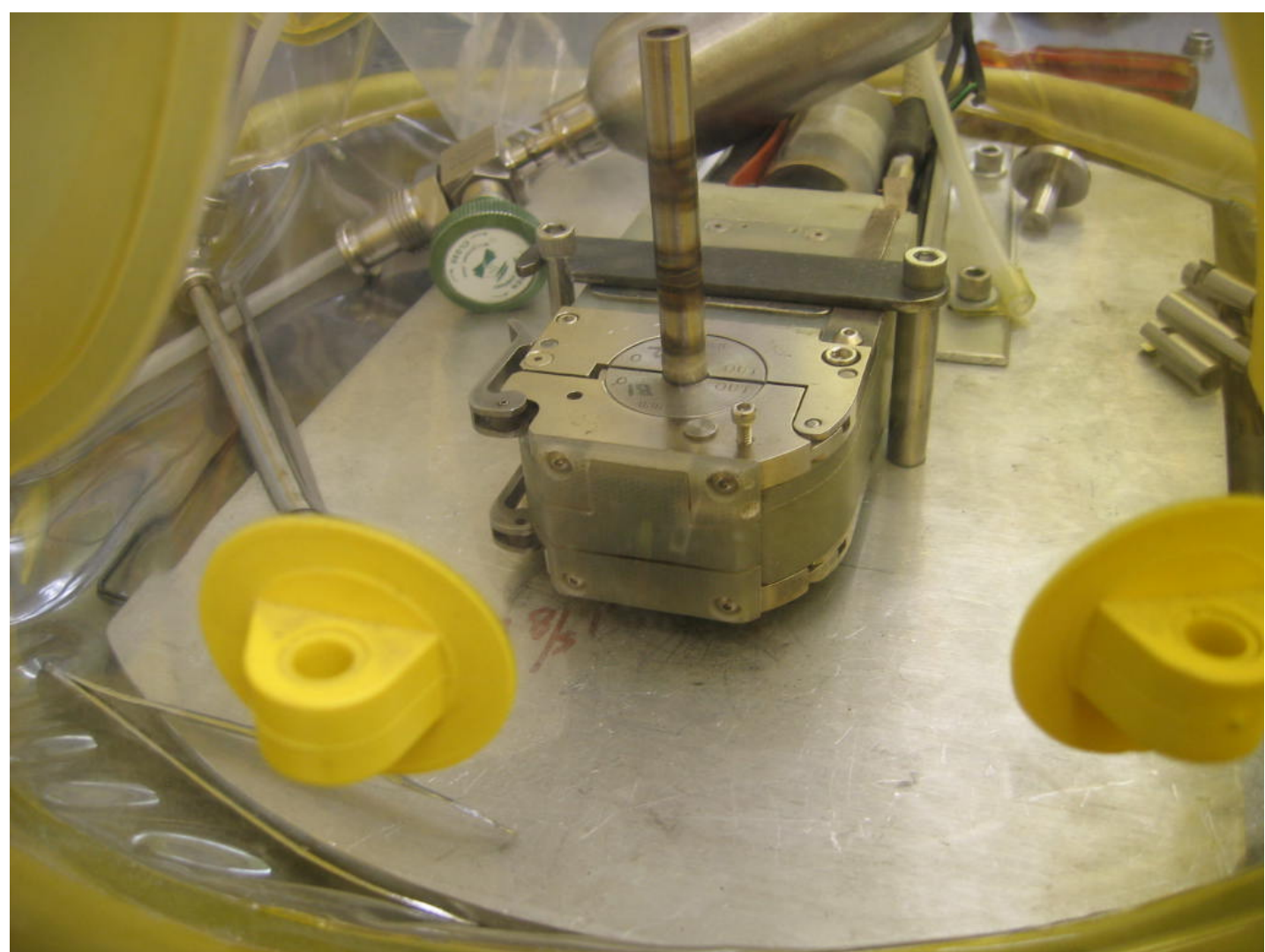

Figure 32. Orbital welding system for capsule closure inside a He glove bag with a test tube shown in place. 


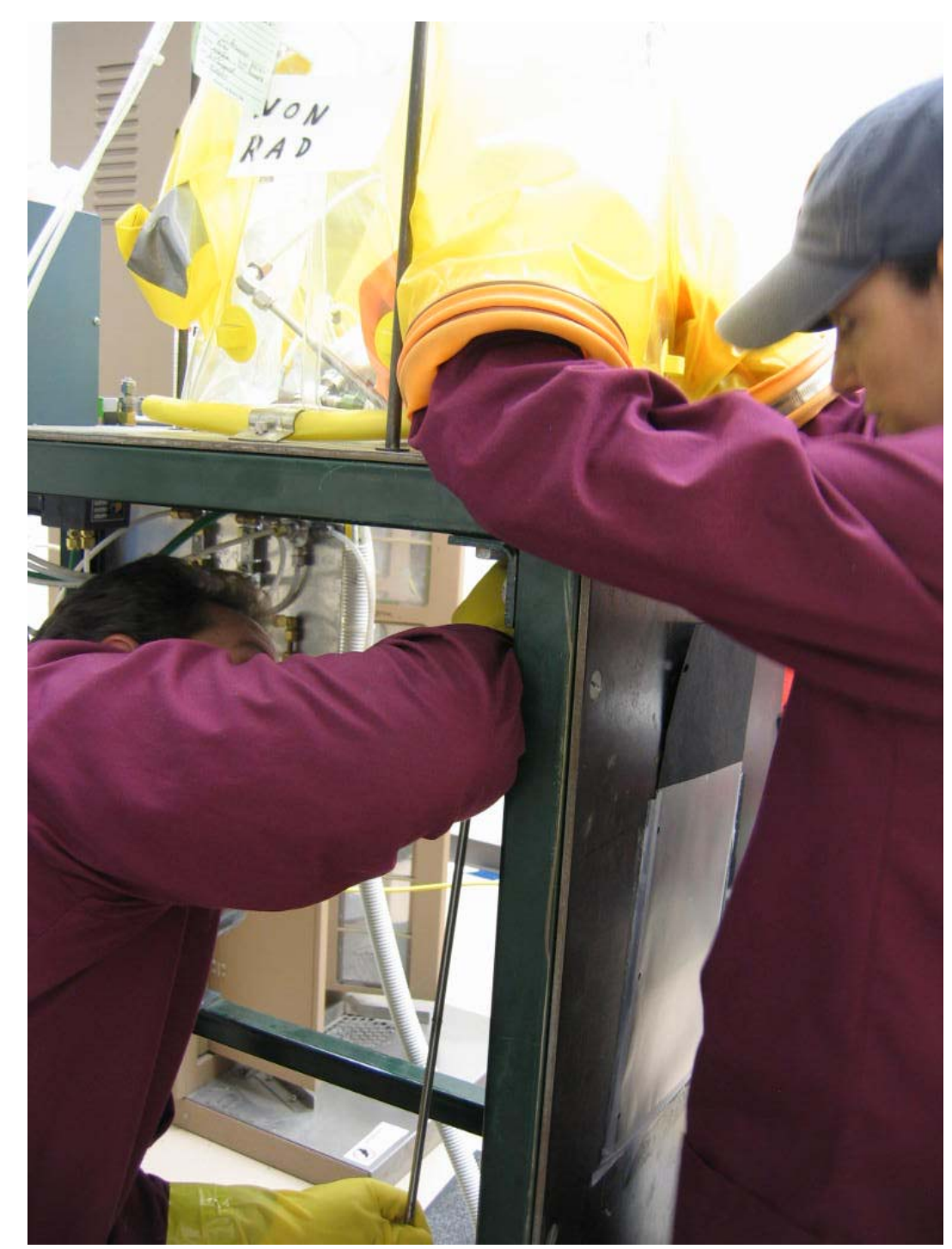

Figure 33. Inserting a loaded capsule into the orbital welding enclosure.

\subsubsection{Weld and Leak Inspection}

Finished fuel rodlets shall be subject to helium leak testing in accordance with PLN-2443.

The helium leak rate shall be less than $1 \times 10^{-8} \mathrm{~cm}^{3} / \mathrm{sec}$ standard at 1 atm differential pressure.

Radiographic inspection will be performed in accordance with PLN-2443. The radiograph in Figure 34 depicts a completed capsule showing a rodlet inside. 


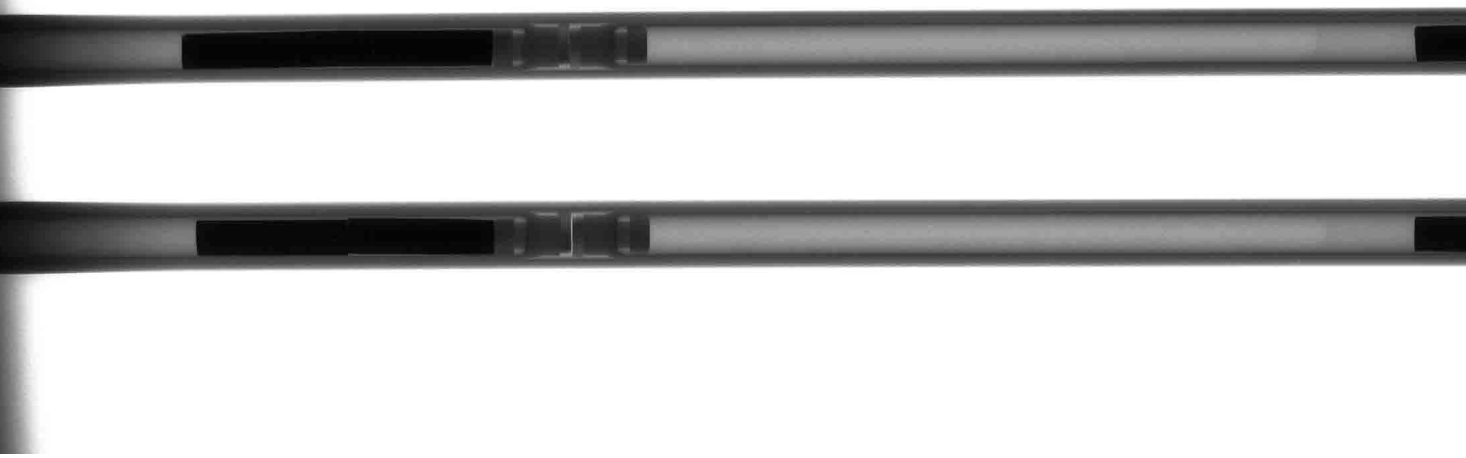

Figure 34. Capsule radiograph verifying rodlet position.

\subsubsection{As-Built Data Package}

A data package will travel with each fuel rodlet and capsule through the fabrication process. This traveler will be used to record completion of each fabrication activity and the data related to fabrication and quality assurance. Data extracted from the traveler are used in the As-Built Data Package.

As-Built Fuel Pin Summary Data Sheets and Fuel Pin Summary Final Inspection Sheets will be provided for each fuel rodlet to be inserted in the reactor (PLN-2443, Appendixes). Requirements for these data sheets are called out in TFR-452.

As-built data sheets will be provided for the assembled experiment capsules as detailed in PLN-2443, Appendix B.

A complete set of as-built drawings will be provided for all component parts of this experiment and for the final assembled test capsule.

\subsection{Basket Fabrication and Assembly}

This document does not cover the fabrication control for the basket assembly. The following documents are referenced here for a more complete picture of how the experiment is assembled for irradiation in the ATR.

ATR East Flux Trap ATW-1 Experiment Basket (BBWI DWG-520456).

Design Specification: “Advanced Accelerator Applications ATW-1 Fuel Test Specimen Drop-In Capsule," SPC-390.

\section{NONCONFORMANCE'S}

All fuel, cladding components, rodlets, capsule components, finished capsule assemblies, and irradiation hardware that do not meet the standards stated in the TFR fuel specification will be reported via the nonconformance reporting procedure LWP-13830, "Control of Non-Conforming Items," using Form 230.01, "Nonconformance Report." A total of five NCRs were issued for the AFC-2A and 2B experiments: 1) Fuel diameter and surface defects, 2) fuel chemical composition, 3) sodium height in some rodlets, 4) weld diameter on some rodlets, and 5) a process control weld for 
capsule closure failed inspection. All nonconformance reports are included in the as-built data package(s).

\section{REFERENCES}

Hayes, S. L., "Irradiation of Nitride and Metallic Fuels for Actinide Transmutation in the Advanced Test Reactor: Final Experiment Description and Design and Data Package for AFC-1A, AFC-1B, AFC-1C and AFC-1D," Argonne National Laboratory (West), Document No. W7520-0481-ES-02, February 2003.

Hilton, B. A., "Irradiation of Nitride and Metallic Fuels for Actinide Transmutation in the Advanced Test Reactor: Final Experiment Description and Design and Data Package for AFC-1Æ and AFC-1F," Argonne National Laboratory (West) Document No. W7520-0529-ES-03, November 2003.

Hilton, B. A., "Irradiation of Nitride and Metallic Fuels for Actinide Transmutation in the Advanced Test Reactor: Final Experiment Description and Design and Data Package for AFC-1G and AFC-1H," Argonne National Laboratory (West) Document No. W7520-0678-ES-00, August 2004. 


\section{Appendix A}

\section{Rodlet Leak Check Data Sheet}




\section{Appendix A \\ TEST NO. AFCR - BW07}

\begin{tabular}{|c|c|c|c|c|c|}
\hline DESCRIPTION & \multicolumn{5}{|c|}{ AFC RODLETS ( BOTTOM WELDS) } \\
\hline DWG \# (S) & \multicolumn{5}{|c|}{ W/R \# 81649} \\
\hline TEST DATE & $6 / 20 / 07$ & LOCATION & \multicolumn{3}{|c|}{ BLDG. 765 Rm. 26} \\
\hline MASS SPEC. (MSLD)MFG. & VARIAN & MODEL & 959 & S/N & LLL 0093 \\
\hline
\end{tabular}

LEAK RATE RESULTS

\begin{tabular}{|c|c|c|c|c|c|c|}
\hline COMPONENT/SYS. & TR & $\mathrm{BG}$ & ATLMR & $\begin{array}{l}\mathrm{AC} \\
\mathrm{C}\end{array}$ & REJ & $\begin{array}{c}\text { LEAK RATE } \\
\text { (ATM } \\
\text { CC/SEC-He) }\end{array}$ \\
\hline $\begin{array}{l}\text { AFC RODLETS } \\
\text { S/N AFC2 - xx }\end{array}$ & $<1.0 \times 10-9$ & $1.0 \times 10-9$ & $<1.0 \times 10-9$ & $\mathrm{X}$ & & $<1.0 \times 10-9$ \\
\hline AFC2 - yy & $<1.0 \times 10-9$ & $1.0 \times 10-9$ & $<1.0 \times 10-9$ & $\mathrm{X}$ & & $<1.0 \times 10-9$ \\
\hline $\mathrm{AFC} 2$ - PCS1 & $<1.0 \times 10-9$ & $1.0 \times 10-9$ & $<1.0 \times 10-9$ & $\mathrm{X}$ & & $<1.0 \times 10-9$ \\
\hline $\mathrm{AFC} 2$ - PCS2 & $<1.0 \times 10-9$ & $1.0 \times 10-9$ & $<1.0 \times 10-9$ & $\mathrm{X}$ & & $<1.0 \times 10-9$ \\
\hline $\mathrm{AFC} 2$ - PCS3 & $<1.0 \times 10-9$ & $1.0 \times 10-9$ & $<1.0 \times 10-9$ & $\mathrm{X}$ & & $<1.0 \times 10-9$ \\
\hline $\mathrm{AFC} 2$ - PCS4 & $<1.0 \times 10-9$ & $1.0 \times 10-9$ & $<1.0 \times 10-9$ & $\mathrm{X}$ & & $<1.0 \times 10-9$ \\
\hline AFC2 - PCS5 & $<1.0 \times 10-9$ & $1.0 \times 10-9$ & $<1.0 \times 10-9$ & $\mathrm{X}$ & & $<1.0 \times 10-9$ \\
\hline AFC2 - PCS6 & $<1.0 \times 10-9$ & $1.0 \times 10-9$ & $<1.0 \times 10-9$ & $\mathrm{X}$ & & $<1.0 \times 10-9$ \\
\hline $\mathrm{AFC} 2 \mathrm{~A}-\mathrm{R} 1$ & $<1.0 \times 10-9$ & $1.0 \times 10-9$ & $<1.0 \times 10-9$ & $\mathrm{X}$ & & $<1.0 \times 10-9$ \\
\hline $\mathrm{AFC} 2 \mathrm{~A}-\mathrm{R} 2$ & $<1.0 \times 10-9$ & $1.0 \times 10-9$ & $<1.0 \times 10-9$ & $\mathrm{X}$ & & $<1.0 \times 10-9$ \\
\hline $\mathrm{AFC} 2 \mathrm{~A}-\mathrm{R} 3$ & $<1.0 \times 10-9$ & $1.0 \times 10-9$ & $<1.0 \times 10-9$ & $\mathrm{X}$ & & $<1.0 \times 10-9$ \\
\hline $\mathrm{AFC} 2 \mathrm{~A}-\mathrm{R} 4$ & $<1.0 \times 10-9$ & $1.0 \times 10-9$ & $<1.0 \times 10-9$ & $\mathrm{X}$ & & $<1.0 \times 10-9$ \\
\hline $\mathrm{AFC} 2 \mathrm{~A}-\mathrm{R} 5$ & $<1.0 \times 10-9$ & $1.0 \times 10-9$ & $<1.0 \times 10-9$ & $\mathrm{X}$ & & $<1.0 \times 10-9$ \\
\hline $\mathrm{AFC} 2 \mathrm{~A}-\mathrm{R} 6$ & $<1.0 \times 10-9$ & $1.0 \times 10-9$ & $<1.0 \times 10-9$ & $\mathrm{X}$ & & $<1.0 \times 10-9$ \\
\hline $\mathrm{AFC} 2 \mathrm{~B}-\mathrm{R} 1$ & $<1.0 \times 10-9$ & $1.0 \times 10-9$ & $<1.0 \times 10-9$ & $\mathrm{X}$ & & $<1.0 \times 10-9$ \\
\hline $\mathrm{AFC} 2 \mathrm{~B}-\mathrm{R} 2$ & $<1.0 \times 10-9$ & $1.0 \times 10-9$ & $<1.0 \times 10-9$ & $\mathrm{X}$ & & $<1.0 \times 10-9$ \\
\hline $\mathrm{AFC} 2 \mathrm{~B}-\mathrm{R} 4$ & $<1.0 \times 10-9$ & $1.0 \times 10-9$ & $<1.0 \times 10-9$ & $\mathrm{X}$ & & $<1.0 \times 10-9$ \\
\hline $\mathrm{AFC} 2 \mathrm{~B}-\mathrm{R} 5$ & $<1.0 \times 10-9$ & $1.0 \times 10-9$ & $<1.0 \times 10-9$ & $\mathrm{X}$ & & $<1.0 \times 10-9$ \\
\hline $\mathrm{AFC} 2 \mathrm{~B}-\mathrm{R} 6$ & $<1.0 \times 10-9$ & $1.0 \times 10-9$ & $<1.0 \times 10-9$ & $\mathrm{X}$ & & $<1.0 \times 10-9$ \\
\hline $\begin{array}{l}\text { ACCEPTANCE } \\
\text { CRITERIA }\end{array}$ & \multicolumn{5}{|c|}{$<1.0 \times 10-8$} & $\begin{array}{l}\text { ATM } \\
\text { CC/SEC-He }\end{array}$ \\
\hline
\end{tabular}

ACTUAL TEST LEAK METER READING (ATLMR) = TOTAL READING (TR) - BACKGROUND (BG)

LEAK TEST TECHNIQUE

\begin{tabular}{|l|l|l|l|l|l|}
\hline BELL JAR & & HOOD & X & SOAK TIME (MIN.) & 2.00 \\
\hline DETECTOR PROBE ( & & HELIUM \% & 100 & TEST PRESSURE & $20 \mathrm{mtorr}$ \\
\hline
\end{tabular}


MSLD AND/OR SYSTEM SENSITIVITY

\begin{tabular}{|l|l|l|l|l|}
\hline & MANUF. & MODEL \# & SERIAL \# & RATING (ATM \\
\hline MSLD STD CALIB. & HLT, INC. & HLT - 9 & 2328 & 3.01 X $10-9$ \\
\hline SYS. STD CALIB. & N / A & N / A & N / A & N / A \\
\hline TEMPERATURE & NEWPORT & Q20007DFI & 76555 & $+/-.5 \%$ \\
\hline HELIUM SPECIFICATIONS & \multicolumn{4}{|l}{} \\
\hline UHP He Cylinder & S/N HS - 077729 & SYSTEM RESPONSE TIME (SEC.) & $<2.00$ \\
\hline
\end{tabular}

MSLD OR SYSTEM SENSITIVITY $=\frac{\text { STD CALIBRATING } \times X 2.0 \times 10-10 \text { ATM CC / SEC HE }}{\text { LEAK METER DIRECT READ OUT }}$

ACTUAL CALIBRATOR LEAK METER READING (ACLMR) BEFORE AND AFTER TEST

\begin{tabular}{|l|l|c|c|c|c|c|}
\hline \multirow{2}{*}{$\begin{array}{l}\text { PRE } \\
\text { TEST }\end{array}$} & MSLD ACLMR & $4.0 \times 10-9$ & $-\mathrm{BG}$ & $1.0 \times 10-9$ & $=$ TOTAL READING & $3.0 \times 10-9$ \\
\cline { 2 - 7 } & SYSTEM ACLMR & N/A & $-\mathrm{BG}$ & N/A & $=$ TOTAL READING & N/A \\
\hline \multirow{2}{*}{$\begin{array}{l}\text { POST } \\
\text { TEST }\end{array}$} & MSLD ACLMR & $4.0 \times 10-9$ & $-\mathrm{BG}$ & $1.0 \times 10-9$ & $=$ TOTAL READING & $3.0 \times 10-9$ \\
\cline { 2 - 7 } & SYSTEM ACLMR & N/A & $-\mathrm{BG}$ & N/A & $=$ TOTAL READING & N/A \\
\hline
\end{tabular}

\begin{tabular}{|l|l|c|c|}
\hline \multirow{2}{*}{$\begin{array}{l}\text { PRE } \\
\text { TEST }\end{array}$} & MACHINE SENSITIVITY & $2.0 \times 10-10$ & ATM. CC/SEC HELIUM \\
\cline { 2 - 4 } & SYSTEM SENSITIVITY & N/A & ATM. CC/SEC HELIUM \\
\hline \multirow{2}{*}{$\begin{array}{l}\text { POST } \\
\text { TEST }\end{array}$} & MACHINE SENSITIVITY & $2.0 \times 10-10$ & ATM. CC/SEC HELIUM \\
\cline { 2 - 4 } & SYSTEM SENSITIVITY & N/A & ATM. CC/SEC HELIUM \\
\hline
\end{tabular}

\begin{tabular}{|l|l|l|c|c|c|}
\hline \multicolumn{2}{|c|}{ LEAK TEST WAS PERFORMED IN ACCORDANCE WITH } & YES & REVISION & 1.0 \\
\hline TECHNICIAN & G. J. MITCHELL & $\begin{array}{l}\text { QUALIFICATION } \\
\text { LEVEL (SNT-TC-1A) }\end{array}$ & II & EXP-DATE & $8 / 31 / 09$ \\
\hline TECHNICIAN & N/A & $\begin{array}{l}\text { QUALIFICATION } \\
\text { LEVEL (SNT-TC-1A) }\end{array}$ & N/A & EXP-DATE & N/A \\
\hline RESPONSIBLE ENGINEER & R. FIELDING/T. HYDE & \multicolumn{1}{l|}{} \\
\hline
\end{tabular}


Fig. 1

AFC Rodlets

(Bottom Welds)

Test No. AFCR - BMNOT

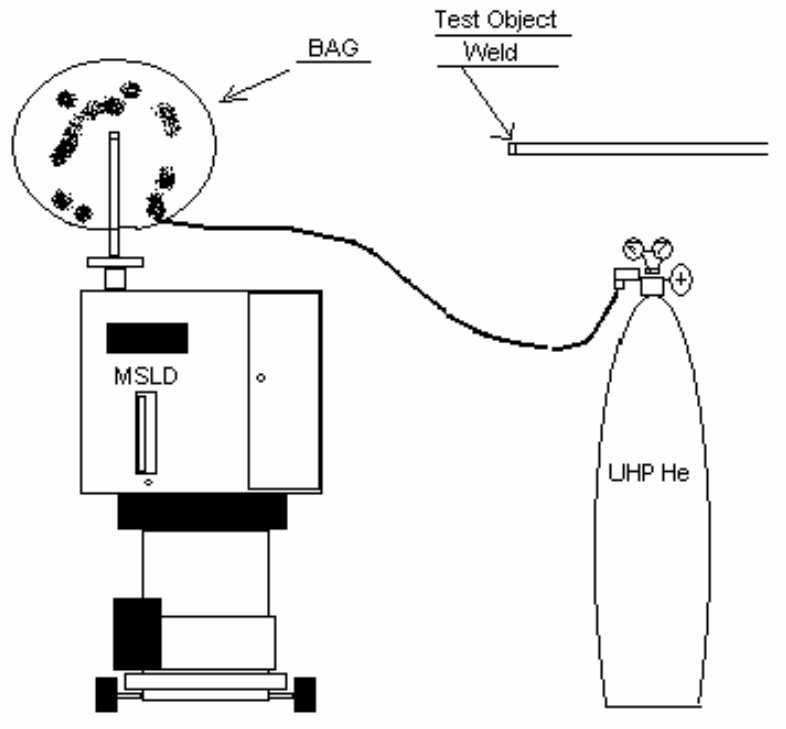


Appendix B

TEST NO. AFCR - L107 


\section{Appendix B \\ TEST NO. AFCR - L107}

\begin{tabular}{|c|c|c|c|c|c|}
\hline DESCRIPTION & \multicolumn{5}{|c|}{ AFC RODLETS ( LOADED) } \\
\hline DWG \# (S) & \multicolumn{5}{|l|}{$\mathrm{N} / \mathrm{A}$} \\
\hline TEST DATE & $6 / 27 / 07$ & LOCATION & \multicolumn{3}{|c|}{ BLDG. 704 (Fume hood) } \\
\hline MASS SPEC. (MSLD)MFG. & VARIAN & MODEL & 959D & $\mathrm{S} / \mathrm{N}$ & LLD 1149 \\
\hline
\end{tabular}

LEAK RATE RESULTS

\begin{tabular}{|c|c|c|c|c|c|c|}
\hline COMPONENT/SYS. & TR & BG & ATLMR & $\begin{array}{c}\mathrm{AC} \\
\mathrm{C}\end{array}$ & REJ & $\begin{array}{c}\text { LEAK RATE } \\
\text { (ATM } \\
\text { CC/SEC-He) }\end{array}$ \\
\hline $\begin{array}{l}\text { AFC RODLETS } \\
\text { S/N AFC } 2-x x\end{array}$ & $<1.0 \times 10-8$ & $1.0 \times 10-8$ & $<1.0 \times 10-8$ & $\mathrm{X}$ & & $<1.0 \times 10-8$ \\
\hline AFC2 - PCS1 & $<1.0 \times 10-8$ & $1.0 \times 10-8$ & $<1.0 \times 10-8$ & $\mathrm{X}$ & & $<1.0 \times 10-8$ \\
\hline $\mathrm{AFC} 2-\mathrm{PCS} 2$ & $<1.0 \times 10-8$ & $1.0 \times 10-8$ & $<1.0 \times 10-8$ & $\mathrm{X}$ & & $<1.0 \times 10-8$ \\
\hline $\mathrm{AFC} 2 \mathrm{~A}-\mathrm{R} 1$ & $<1.0 \times 10-8$ & $1.0 \times 10-8$ & $<1.0 \times 10-8$ & $\mathrm{X}$ & & $<1.0 \times 10-8$ \\
\hline $\mathrm{AFC} 2 \mathrm{~A}-\mathrm{R} 3$ & $<1.0 \times 10-8$ & $1.0 \times 10-8$ & $<1.0 \times 10-8$ & $\mathrm{X}$ & & $<1.0 \times 10-8$ \\
\hline $\mathrm{AFC} 2 \mathrm{~A}-\mathrm{R} 6$ & $<1.0 \times 10-8$ & $1.0 \times 10-8$ & $<1.0 \times 10-8$ & $\mathrm{X}$ & & $<1.0 \times 10-8$ \\
\hline $\mathrm{AFC} 2 \mathrm{~B}-\mathrm{R} 1$ & $<1.0 \times 10-8$ & $1.0 \times 10-8$ & $<1.0 \times 10-8$ & $\mathrm{X}$ & & $<1.0 \times 10-8$ \\
\hline $\mathrm{AFC} 2 \mathrm{~B}-\mathrm{R} 6$ & $<1.0 \times 10-8$ & $1.0 \times 10-8$ & $<1.0 \times 10-8$ & $\mathrm{X}$ & & $<1.0 \times 10-8$ \\
\hline \multicolumn{2}{|c|}{ ACCEPTANCE CRITERIA } & \multicolumn{3}{|c|}{$<1.0 \times 10-8$} & \multicolumn{2}{|r|}{ ATM CC/SEC-He } \\
\hline
\end{tabular}

ACTUAL TEST LEAK METER READING (ATLMR) = TOTAL READING (TR) - BACKGROUND (BG)

LEAK TEST TECHNIQUE

\begin{tabular}{|c|c|c|c|c|c|}
\hline BELL JAR & $\mathrm{X}$ & HOOD & & SOAK TIME (MIN.) & 2.00 \\
\hline DETECTOR PROBE (SPRAY) & & HELIUM \% & $* *$ & TEST PRESSURE & 20 mtorr \\
\hline
\end{tabular}

MSLD AND/OR SYSTEM SENSITIVITY

\begin{tabular}{|l|c|c|c|c|}
\hline & MANUF. & MODEL \# & SERIAL \# & $\begin{array}{c}\text { RATING (ATM } \\
\text { CCISEC.Hol }\end{array}$ \\
\hline MSLD STD CALIB. & HLT, INC. & SC - 4 & 11700 & $1.8 \times 10-8$ \\
\hline SYS. STD CALIB. & N / A & N / A & N / A & N / A \\
\hline TEMPERATURE STD. & NEWPORT & Q20007DFI & 76555 & $+/-.5 \%$ \\
\hline \multicolumn{2}{|l|}{ HELIUM SPECIFICATIONS } & SYSTEM RESPONSE TIME (SEC.) & $<2.00$ \\
\hline UHP He Cylinder & FMF He manifold &
\end{tabular}

MSLD OR SYSTEM SENSITIVITY $=\frac{\text { STD CALIBRATING } \times 20 \times 10-9 \text { ATM CC/SEC He }}{\text { LEAK METER DIRET READ OUT }}$ 
ACTUAL CALIBRATOR LEAK METER READING (ACLMR) BEFORE AND AFTER TEST

\begin{tabular}{|c|c|c|c|c|c|c|}
\hline \multirow{2}{*}{$\begin{array}{l}\text { PRE } \\
\text { TEST }\end{array}$} & MSLD ACLMR & $2.8 \times 10-8$ & $-B G$ & $1.0 \times 10-8$ & $=$ TOTAL READING & $1.8 \times 10-8$ \\
\hline & SYSTEM ACLMR & $\mathrm{N} / \mathrm{A}$ & $-\mathrm{BG}$ & N/A & $=$ TOTAL READING & N/A \\
\hline \multirow{2}{*}{$\begin{array}{l}\text { POST } \\
\text { TEST }\end{array}$} & MSLD ACLMR & $2.8 \times 10-8$ & $-\mathrm{BG}$ & $1.0 \times 10-8$ & $=$ TOTAL READING & $1.8 \times 10-8$ \\
\hline & SYSTEM ACLMR & N/A & $-\mathrm{BG}$ & $\mathrm{N} / \mathrm{A}$ & $=$ TOTAL READING & $\mathrm{N} / \mathrm{A}$ \\
\hline
\end{tabular}

\begin{tabular}{|l|l|c|l|}
\hline \multirow{2}{*}{$\begin{array}{l}\text { PRE } \\
\text { TEST }\end{array}$} & MACHINE SENSITIVITY & $2.0 \times 10-9$ & ATM. CC/SEC HELIUM \\
\cline { 2 - 4 } & SYSTEM SENSITIVITY & N/A & ATM. CC/SEC HELIUM \\
\hline \multirow{2}{*}{ POST } & MACHINE SENSITIVITY & $2.0 \times 10-9$ & ATM. CC/SEC HELIUM \\
\cline { 2 - 4 } & SYSTEM SENSITIVITY & N/A & ATM. CC/SEC HELIUM \\
\hline
\end{tabular}

\begin{tabular}{|l|l|l|l|l|c|}
\hline \multicolumn{2}{|c|}{ LEAK TEST WAS PERFORMED IN ACCORDANCE WITH } & YES & REVISION & 1.0 \\
\hline TECHNICIAN & G.J. MITCHELL & $\begin{array}{l}\text { QUALIFICATION LEVEL } \\
\text { (SNT-TC-1A) }\end{array}$ & II & EXP-DATE & $8 / 31 / 09$ \\
\hline TECHNICIAN & N/A & $\begin{array}{l}\text { QUALIFICATION LEVEL } \\
\text { (SNT-TC-1A) }\end{array}$ & N/A & EXP-DATE & N/A \\
\hline RESPONSIBLE ENGINEER & T. HYDE
\end{tabular}

**Rodlets were welded in a $30 \%$ helium atmosphere.

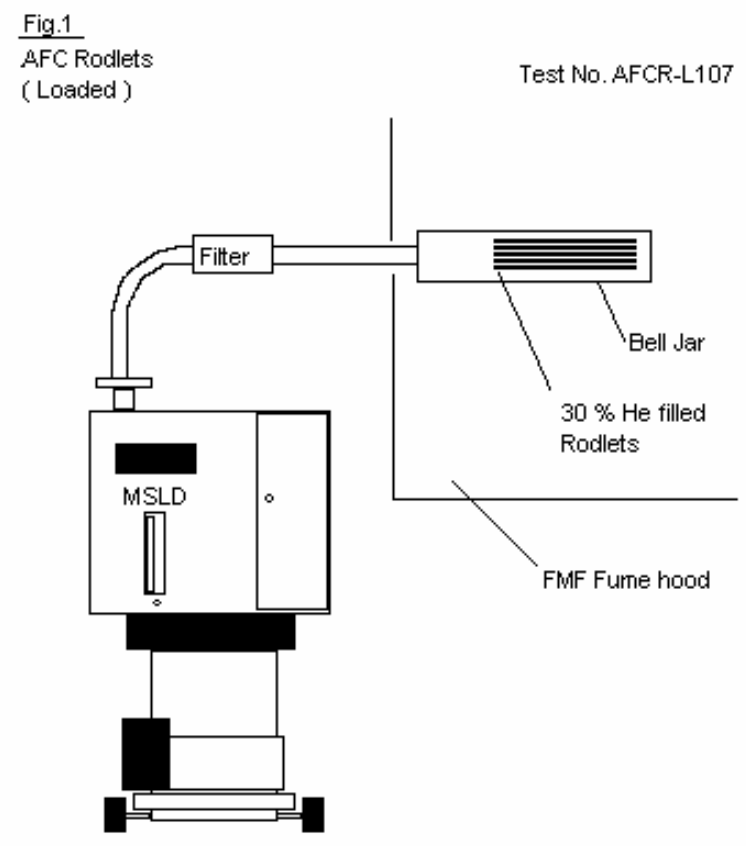




\section{Appendix C}

\section{Casting Improvements}




\section{Appendix C \\ Casting Improvements}

A centrifugal caster ordered for evaluation as a next-generation research casting process has been set up (see Figure $\mathrm{C}-1$ ) and tested with $\mathrm{Ti}, \mathrm{Zr}$ and a $\mathrm{Cu} / \mathrm{Zr}$ alloys (see Figures $\mathrm{C}-2$ and $\mathrm{C}-3$ ). In addition, it has been tested with single and multiple slug molds. The caster seems to be effective in all cases and can melt and cast an alloy in less than $2 \mathrm{~min}$. The conclusion is that this technology has good promise for future implementation, depending on the length of the fuel needed and other implementation requirements.

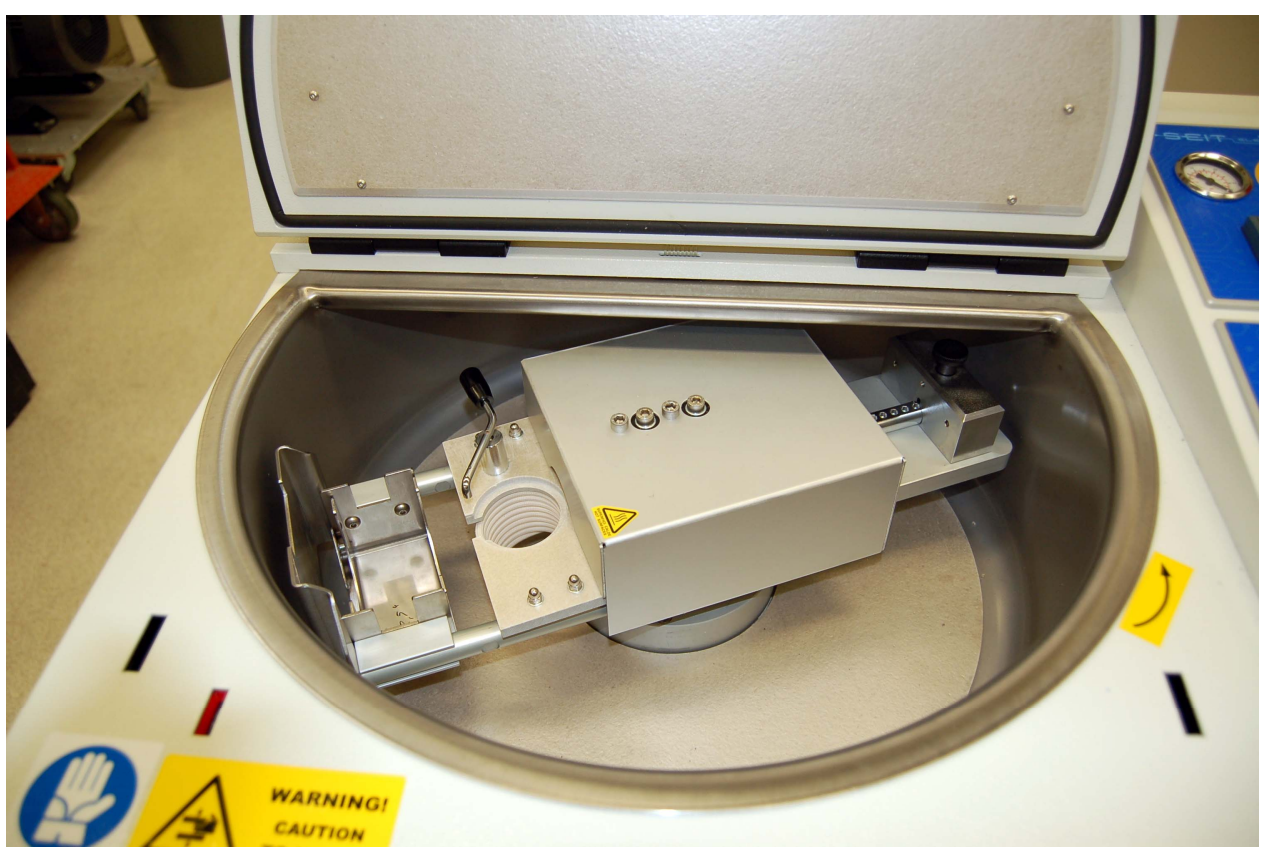

Figure C-1. Centrifugal Caster 


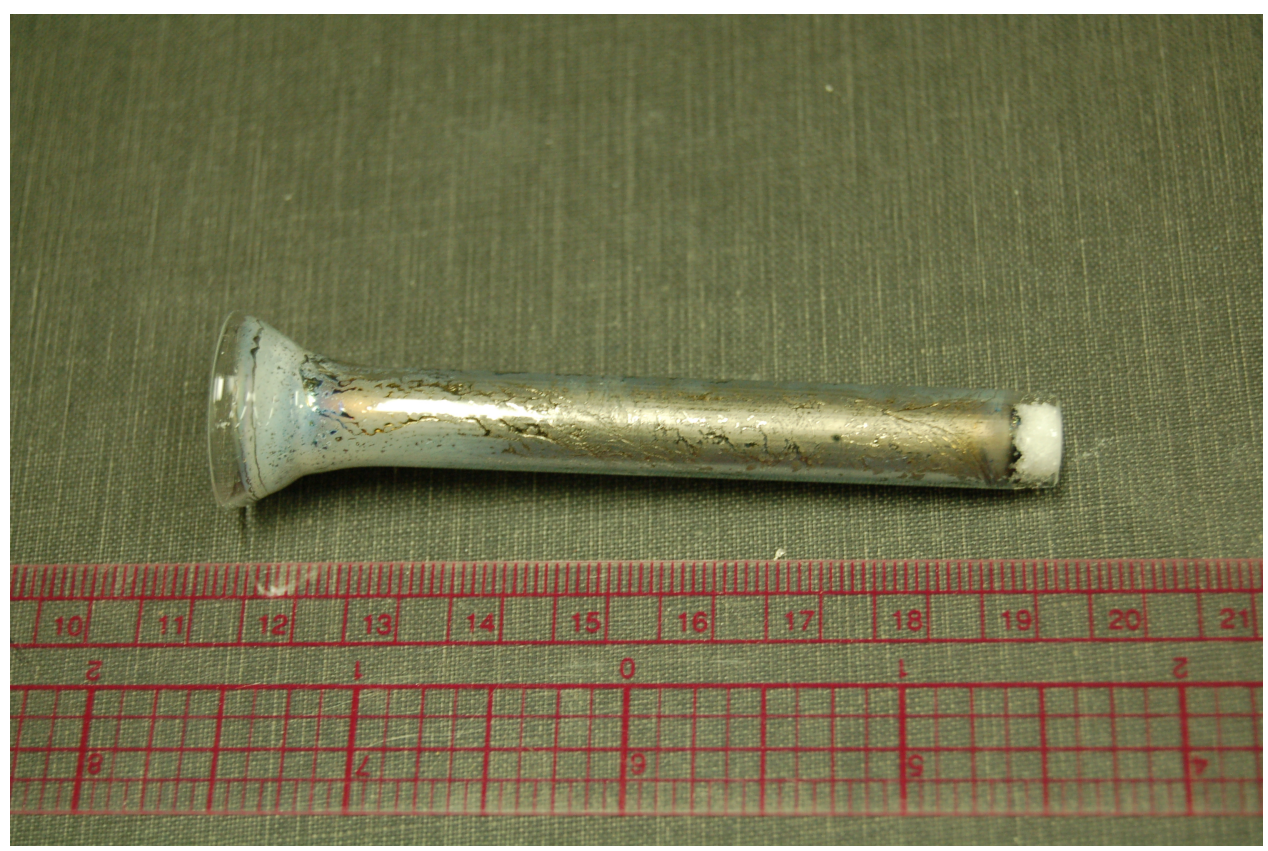

Figure C-2. Single Large Diameter Casting in Quartz Mold.

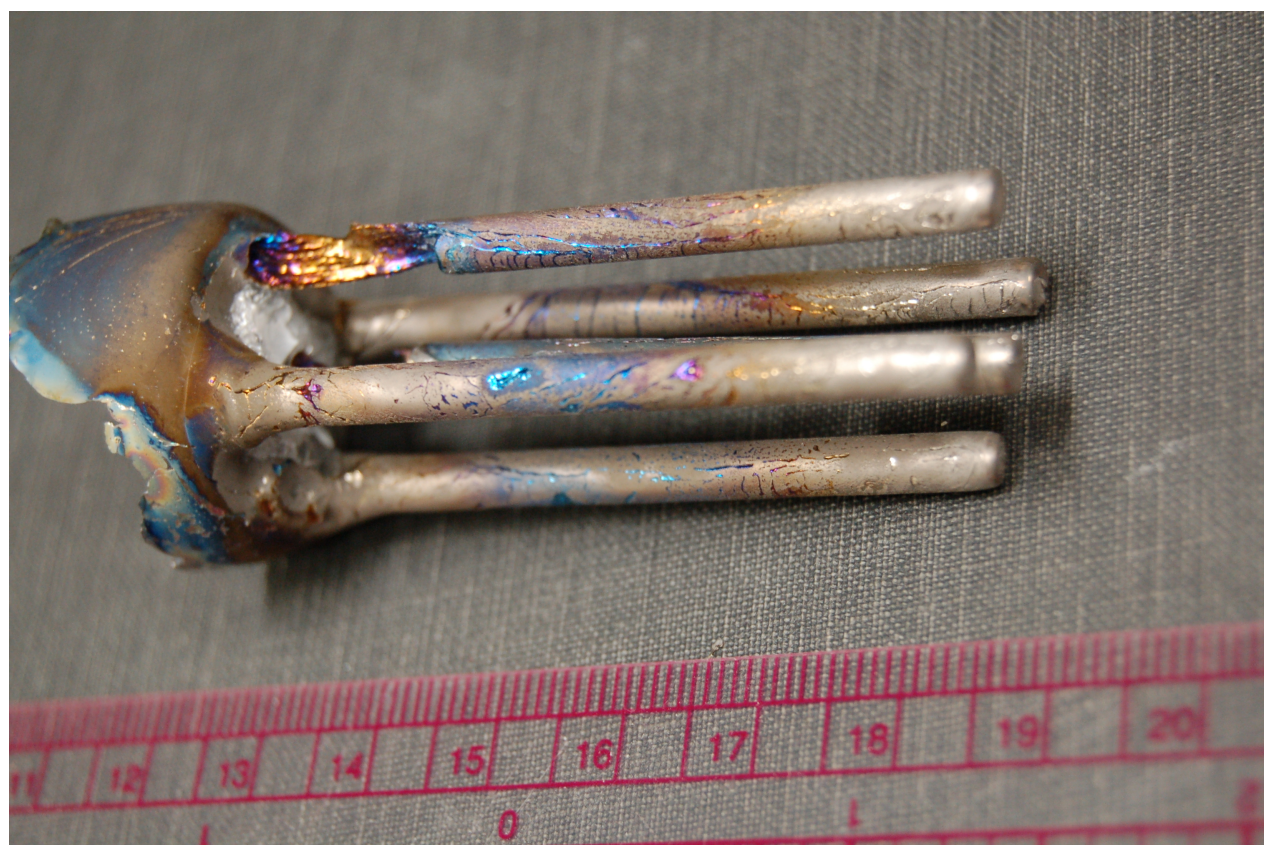

Figure C-3. Multiple AFC2 Representative Diameter Casting of Titanium.

The centrifugal casting system was used to produce a Sm sample for characterization. And was used to produce a $\mathrm{HfAl}_{2}$ sample for another nuclear technology program. 
Another research scale casting system was considered; the commercial system appears to have good production scalability. These systems where developed for the jewelry industry and have two separate chambers: one chamber for the crucible and melting, and one chamber for the mold. In general, the atmospheres of these two chambers are independent and can be used to push molten material from the crucible side into the mold side. Some of these off-the-shelf systems are capable of casting 15". Procurement of one of these systems was initiated. Figure C-4 illustrates a stand-alone vacuum casting system.

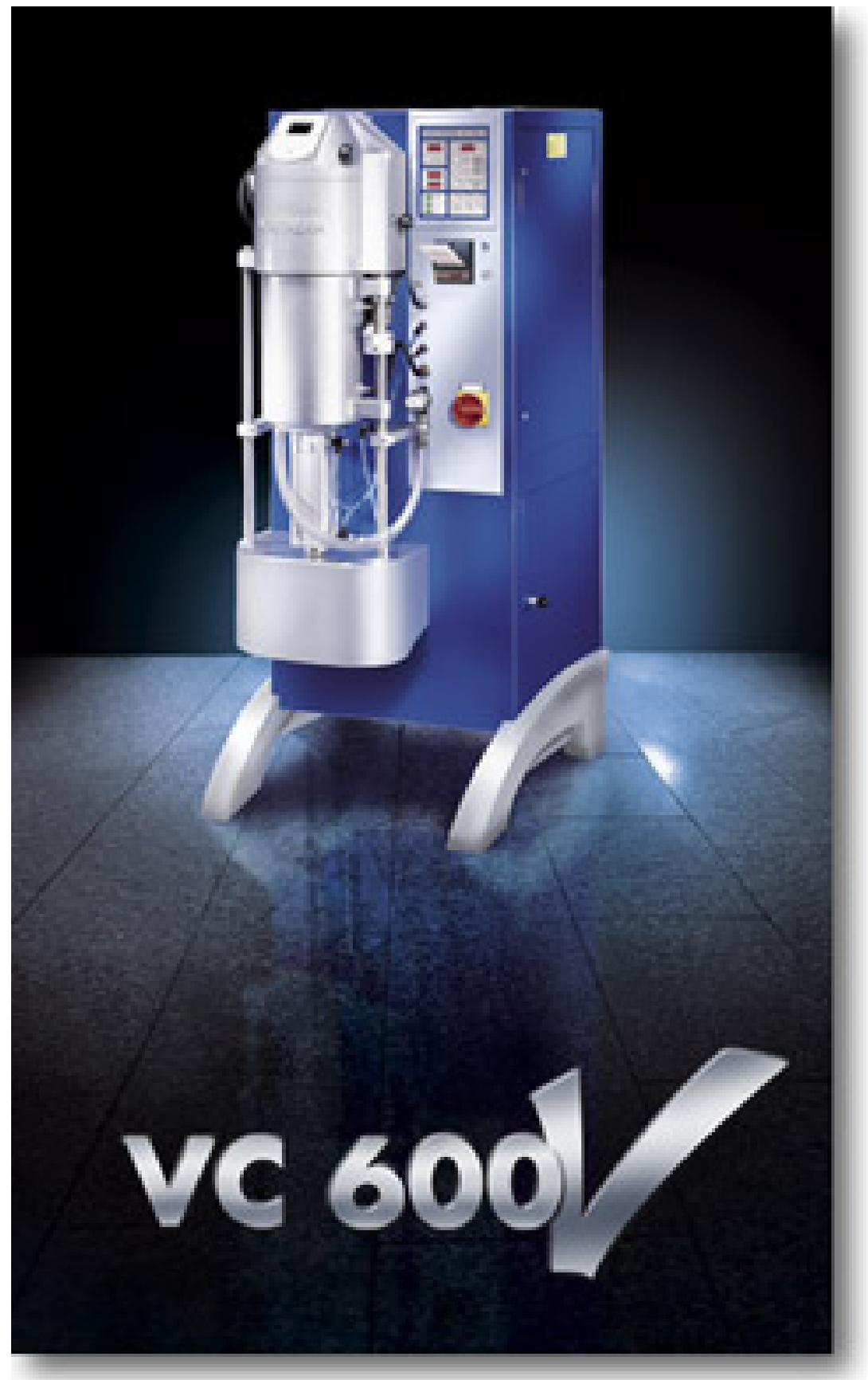

Figure C-4. Stand-Alone Vacuum Casting System. 
Figure C-5 shows the two-chamber concept of this system. This system will be fully evaluated when it arrives at the INL.

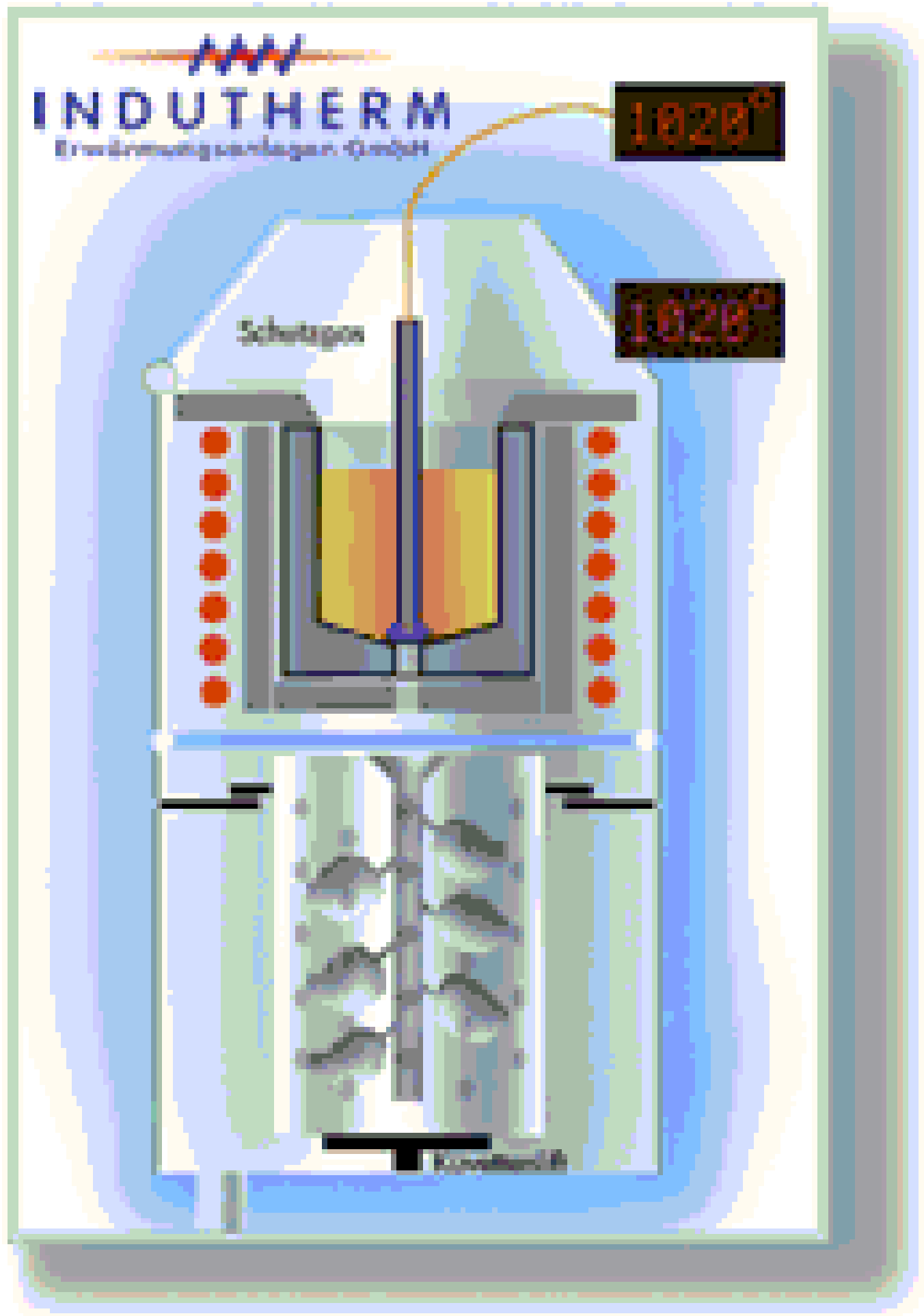

Figure C-5. Section view of the two-chamber casting concept. 